GreenMACC - Uma arquitetura para metaescalonamento verde com provisão de QoS em uma nuvem privada 



\title{
GreenMACC - Uma arquitetura para metaescalonamento verde com provisão de QoS em uma nuvem privada
}

\author{
Osvaldo Adilson de Carvalho Junior
}

Orientadora: Profa. Dra. Regina Helena Carlucci Santana

Tese apresentada ao Instituto de Ciências Matemáticas e de Computação - ICMC-USP, como parte dos requisitos para obtenção do título de Doutor em Ciências - Ciências de Computação e Matemática Computacional. VERSÃO REVISADA 
Ficha catalográfica elaborada pela Biblioteca Prof. Achille Bassi e Seção Técnica de Informática, ICMC/USP, com os dados fornecidos pelo(a) autor(a)

\begin{tabular}{|c|c|}
\hline \multirow[t]{3}{*}{ gg } & $\begin{array}{l}\text { de Carvalho Junior, Osvaldo Adilson } \\
\text { GreenMACC - Uma arquitetura para } \\
\text { metaescalonamento verde com provisão de QoS em uma } \\
\text { nuvem privada / Osvaldo Adilson de Carvalho Junior; } \\
\text { orientador Regina Helena Carlucci Santana. -- São } \\
\text { Carlos, } 2014 \text {. } \\
\quad 106 \text { p. }\end{array}$ \\
\hline & $\begin{array}{l}\text { Tese (Doutorado - Programa de Pós-Graduação em } \\
\text { Matemática) -- Instituto de Ciências Matemáticas e } \\
\text { de Computação, Universidade de São Paulo, } 2014 .\end{array}$ \\
\hline & $\begin{array}{l}\text { 1. Computação em Nuvem. 2. Computação Verde. } 3 \text {. } \\
\text { Computação Verde na Nuvem. 4. Escalonamento. 5. } \\
\text { Avaliação de Desempenho. I. Carlucci Santana, Regina } \\
\text { Helena, orient. II. Título. }\end{array}$ \\
\hline
\end{tabular}


Se desejas saber que causas foram feitas no passado, observe os resultados que se manifestam no presente. E se desejas saber que resultados serão manifestados no futuro, observe as causas que estão sendo feitas no presente.

Buda Nitiren Daishonin 

Dedico esta obra aos meus amados pais Maria José e Oswaldo 

Queria inicialmente agradecer à Deus, que é uma Energia Cósmica Universal que permeia nossas vidas e permite que nós consigamos manter a busca constante de nossa evolução pessoal.

Quero agradecer aos meus amados pais Maria José e Oswaldo, que são os responsáveis diretos pela minha existência, pela minha educação e pelo meu caráter. Pai e Mãe te amo.

Quero agradecer à minha amada esposa Karin, que desde nosso primeiro dia juntos sempre foi meu amor, meu apoio, minha paz e meu porto seguro. Karin, você é a minha alma gêmea e um dos motivos por eu ainda querer viver muito, mas muito tempo. Quero dançar com você a valsa das nossas bodas de ouro, platina, diamante, e o que tiver pela frente. Quero te agradecer também por me dar os 2 melhores presentes da minha vida, os nossos filhos.

Quero agradecer meus dois filhos, Daniela e o outro (ou outra) que está por nascer. Meus filhos, quero que vocês daqui alguns anos, quando lerem este texto, saibam que ambos foram desejados e amados desde o primeiro dia em que eu e sua mãe soubemos da maravilhosa notícia de que vocês estavam a caminho para iluminar nossas vidas. Papai os ama muito.

Quero agradecer toda a minha família pelo amor, pelo apoio, pelo carinho, pelas palavras, pelas festas, pelos abraços e beijos. Minha família também tem responsabilidade direta na pessoa que eu sou. Tio Rui e Tia Dirce obrigado mais uma vez por acreditarem em mim e me darem o apoio necessário para que eu seguisse com meu sonho.

Obrigado à minha Orientadora Professora Regina Santana por acreditar em mim e me ensinar o caminho das pedras. Também agradeço ao professor Marcos Santana pelas dicas e pelo apoio de sempre.

Quero agradecer muito à minha querida professora Sarita Mazzini Bruschi, que apesar de não ser oficialmente minha co-orientadora foi a responsável direta por eu conseguir finalizar esta tese de doutorado. Sarita, sem você eu não teria chegado até aqui. Muito Obrigado!

Agradeço à todos meus amigos e colegas, alunos e professores do LaSDPC. Foram 8 anos de convivência sadia, valiosa e de grande aprendizado. Sentirei saudades das nossas conversas no laboratório, nossos churrascos e amigos secretos. Obrigado por cada dica, informação e por cada segundo dedicado à me responder alguma dúvida que tinha em algum momento dessa caminhada.

Agradeço a todos os funcionários, técnicos e professores do ICMC-USP que de alguma forma me ajudaram a percorrer esse virtuoso caminho.

Agradeço a todos meus amigos e colegas da Universidade Federal de Alfenas que me apoiaram por todo o tempo de meu doutorado. E agradeço por terem aceito meu afastamento nos último meses do doutorado para que eu conseguisse finalizá-lo.

Agradeço à FAPESP, CNPq e Capes pelo apoio financeiro. 

Sta tese de Doutorado tem como objetivo apresentar uma arquitetura para metaescalonamento verde com provisão de qualidade de serviço em uma nuvem privada denominada GreenMACC. Essa nova arquitetura oferece a automatização na escolha de políticas em quatro estágios de escalonamento de uma nuvem privada, permitindo cumprir a negociação que foi estabelecida com o usuário. Devido a essa função, é possível garantir que o GreenMACC se comporte seguindo os princípios da computação verde sem deixar de se preocupar com a qualidade do serviço. Nesta tese o GreenMACC é apresentado, detalhado, discutido, validado e avaliado. Com os resultados apresentados pode-se concluir que a arquitetura proposta mostrou-se consistente, permitindo a execução dos serviços requisitados com diversas políticas de escalonamento em todos os seus estágios. Além disso, demonstrou flexibilidade em receber novas políticas, com focos verde e de qualidade de serviço, e eficiência na escolha das políticas de escalonamento de acordo com a negociação feita com o usuário. 

His $\mathrm{PhD}$ thesis aims to present an architecture for green metascheduling with provision of quality of service in a private cloud called GreenMACC. This new architecture offers the possibility of choosing automatically the four stage scheduling policies of a private cloud, allowing to reach the user's negotiation. As a result of this function, it is possible to ensure that GreenMACC's behavior follows the green computing principles and also is worried about the quality of the service. In this thesis GreenMACC is presented, particularized, discussed, validated and evaluated. The results show that the proposed architecture is consistent, allowing the execution of the requested services considering various scheduling policies in the stages. Moreover, GreenMACC proves to be flexible as allows new policies, focusing on green and quality of service, and to be efficient as chooses the scheduling policies following the user's negotiation. 

Resumo

$\begin{array}{ll}\text { Abstract } & \text { iii }\end{array}$

Lista de Siglas $\quad$ xi

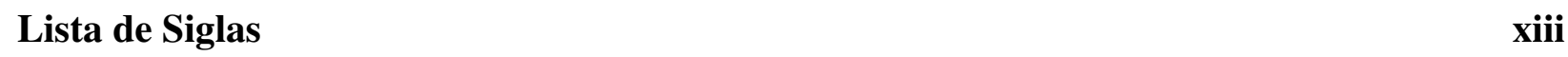

1 Introdução $\quad 1$

1.1 Contextualização e Motivação . . . . . . . . . . . . . . . . . . . . . . . . . . .

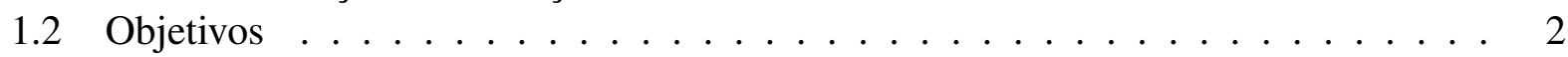

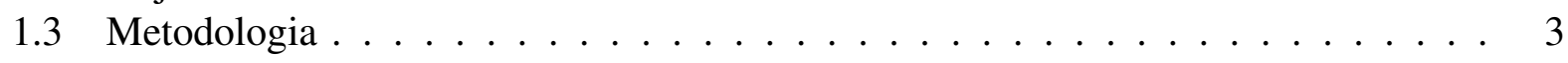

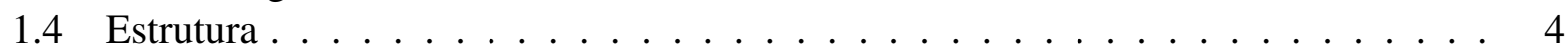

2 Computação Verde na Nuvem 5

2.1 Considerações Iniciais . . . . . . . . . . . . . . . . . . . . 5

2.2 Computação Verde . . . . . . . . . . . . . . . . . . . . . 7

2.2 .1 Histórico . . . . . . . . . . . . . . . . . . 7

2.2.2 Impactos Causados pela TI . . . . . . . . . . . . . . . . 8

2.2 .3 Gestão Verde . . . . . . . . . . . . . . . . . . . . . . . 9

2.2.4 Consumo de Energia e Emissão de $\mathrm{CO}_{2} \ldots \ldots \ldots$. . . . . . . . . . 10

2.3 Computação na Nuvem . . . . . . . . . . . . . . . . . . . . . . 11

2.3.1 Contextualização . . . . . . . . . . . . . . . . . . . 11

2.3.2 Tipos de Serviços . . . . . . . . . . . . . . . . . . . . . . 13

2.3.3 Modelos de Nuvem Computacional . . . . . . . . . . . . . . . 15

2.3 .4 Virtualização . . . . . . . . . . . . . . . . . . . 17

2.3.5 Data Center . . . . . . . . . . . . . . . . . . 19

2.4 Trabalhos Relacionados . . . . . . . . . . . . . . . . . . . . . . . . . . . . . . . . . .

2.5 Considerações Finais . . . . . . . . . . . . . . . . . . . 24

3 Metaescalonamento e Escalonamento na Nuvem $\quad 25$

3.1 Considerações Iniciais . . . . . . . . . . . . . . . . . . . . 25

3.2 Políticas de Escalonamento para Garantia da QoS . . . . . . . . . . . . . . 26

3.3 Políticas de Escalonamento Verde . . . . . . . . . . . . . . . . . . 30

3.3.1 PADEVE - Pontos de Análise para Decisão no Escalonamento Verde . . 30 
3.4 Metaescalonadores . . . . . . . . . . . . . . . . . . 36

3.4.1 Trabalhos Relacionados . . . . . . . . . . . . . . 37

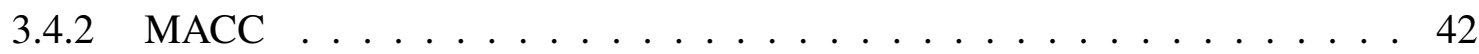

3.5 Consideraçõos Finais . . . . . . . . . . . . . . . . . . 47

4 GreenMACC 49

4.1 Considerações Iniciais . . . . . . . . . . . . . . . . . . . . . . 49

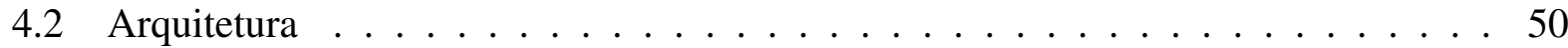

4.2.1 Camada de Interface Cliente/Servidor . . . . . . . . . . . . . . . 56

4.2.2 Camada do Núcleo do Metaescalonador . . . . . . . . . . . . . . . . 57

4.2 .3 Camada do Data Center . . . . . . . . . . . . . . . . . . . . . 59

4.2.4 Automatização do GreenMACC . . . . . . . . . . . . . . . . . . 59

4.3 Validação . . . . . . . . . . . . . . . . . . . . . 62

4.4 Flexibilidade do GreenMACC . . . . . . . . . . . . . . . . . . 67

4.5 Comparação Qualitativa . . . . . . . . . . . . . . . . . . . . . . 71

4.6 Considerações Finais . . . . . . . . . . . . . . . . . 73

5 Avaliação de Desempenho do GreenMACC $\quad \mathbf{7 5}$

5.1 Considerações Iniciais . . . . . . . . . . . . . . . . . . . . . 75

5.2 Metodologia . . . . . . . . . . . . . . . . 76

5.3 Eficiência na escolha das políticas dos 4 estágios de escalonamento . . . . . . . . 78

5.4 Influência entre as políticas dos 4 estágios de escalonamento . . . . . . . . . . . . 82

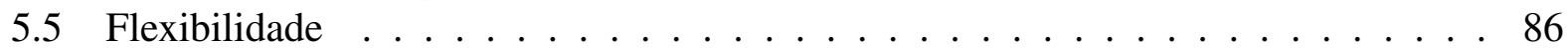

5.5.1 Avaliação dos resultados obtidos com a Nova Política Inserida . . . . . . . 89

5.6 Considerações Finais . . . . . . . . . . . . . . . . . . . . . 91

6 Conclusão $\quad 93$

6.1 Contribuições . . . . . . . . . . . . . . . . . . . 95

6.2 Trabalhos Futuros . . . . . . . . . . . . . . . . . . . . . 96

6.3 Artigos Produzidos . . . . . . . . . . . . . . . . . 96

6.3 .1 Artigos Publicados . . . . . . . . . . . . . . . 97

6.3 .2 Artigos Submetidos . . . . . . . . . . . . . . . . 97 


\section{Lista de Figuras}

2.1 Gestão Verde - Diagrama Adaptado de Santos e Jabbour (2013) . . . . . . . . . . . 9

2.2 Tipos de Serviços Oferecidos na Nuvem . . . . . . . . . . . . . . . . . . . . 13

2.3 Modelos de Nuvens Computacionais . . . . . . . . . . . . . . . . . . . 15

2.4 Virtualização - Figura Adaptada de Veras (2011) . . . . . . . . . . . . . . . 18

3.1 Visão Geral do MACC $($ Peixoto, 2012) . . . . . . . . . . . . . . . . . . . . 43

3.2 Diagrama de fluxo do MACC (Peixoto, 2012) . . . . . . . . . . . . . . 45

3.3 Modelo P2P adotado pelo MACC (Peixoto, 2012) . . . . . . . . . . . . . 47

4.1 Visão Geral do GreenMACC . . . . . . . . . . . . . . . . . . . . . . . . . . 51

4.2 Diagrama de Fluxo do GreenMACC . . . . . . . . . . . . . . . . . . . . . . 52

4.3 Diagrama de Sequência - Visão Geral . . . . . . . . . . . . . . . . . . 53

4.4 Diagrama de Sequência - Núcleo do Metaescalonador . . . . . . . . . . . . . . . . 55

4.5 Diagrama de Sequência - Erro de Autenticação . . . . . . . . . . . . . . . . 55

4.6 Diagrama de Sequência - Serviço Indisponível . . . . . . . . . . . . . . . . . 55

4.7 Valores Analisados pelo LRAM para Tomada de Decisão . . . . . . . . . . . . . . 60

4.8 Valores Analisados pelo LRAM para Tomada de Decisão . . . . . . . . . . . . . . 61

4.9 Diagrama de Classes do GreenMACC . . . . . . . . . . . . . . . . . . 63

4.10 Gráficos Comparativos das Arquiteturas MACC e GreenMACC . . . . . . . . . 66

4.11 Interface do GreenMACC com o Administrador do Sistema . . . . . . . . . . . . . 68

4.12 Benchmark utilizado pelo LRAM . . . . . . . . . . . . . . . . . . 69

5.1 Efeitos no Tempo Médio de Resposta com Carga de Trabalho Leve . . . . . . . . . 79

5.2 Efeitos no Tempo Médio de Resposta com Carga de Trabalho Pesada . . . . . . . . 79

5.3 Efeitos no Consumo de Energia com Carga de Trabalho Leve . . . . . . . . . . . . 80

5.4 Efeitos no Consumo de Energia com Carga de Trabalho Pesada . . . . . . . . . . . 81

5.5 Comparação entre o Melhor e o Pior Caso para Tempo Médio de Resposta e Consumo de Energia . . . . . . . . . . . . . . . . . . . . 82

5.6 Influência no Tempo Médio de Resposta com carga de trabalho Leve . . . . . . . 84

5.7 Influência no Consumo de Energia com carga de Trabalho Leve . . . . . . . . . . 84

5.8 Influência no Tempo Médio de Resposta com carga de trabalho Pesada . . . . . . . 85

5.9 Influência no Consumo de Energia com carga de Trabalho Pesada . . . . . . . . . 86

5.10 Valores Analisados pelo LRAM para Tomada de Decisão . . . . . . . . . . . . . 88

5.11 Valores Analisados pelo LRAM para Tomada de Decisão . . . . . . . . . . . . . 89

5.12 Comparação entre o Melhor e o Pior Caso para Tempo Médio de Resposta . . . . . 90

5.13 Comparação entre o Melhor e o Pior Caso para Emissão de $\mathrm{CO}_{2}$. . . . . . . . . . 90 
5.14 Comparação entre o Melhor e o Pior Caso para Consumo de Energia . . . . . . . . 91 


\section{Lista de Tabelas}

4.1 Fatores e Níveis Utilizados . . . . . . . . . . . . . . . . . . . . . 64

4.2 Cenários Utilizados . . . . . . . . . . . . . . . . . . . . 65

4.3 Formas de Escalonamento . . . . . . . . . . . . . . . . . . 65

4.4 Fatores e Níveis Utilizados no Benchmark . . . . . . . . . . . . . . . . . . . 70

4.5 Comparação de trabalhos relacionados . . . . . . . . . . . . 71

5.1 Cenários Escolhidos $\ldots \ldots \ldots \ldots \ldots \ldots$ 



\section{Lista de Siglas}

\begin{tabular}{|c|c|}
\hline AFCFS & - Adaptative first come first served \\
\hline BACEN & - Banco Central do Brasil \\
\hline BCR & - Baseada na Capacidade da Rede \\
\hline BPSO & - Binary Particle Swarm Optimization \\
\hline BRICS & - Brasil, Rússia, Índia, China e África do Sul \\
\hline CAGCA & - Carbon Aware Green Cloud Architecture \\
\hline CE & - Consumo de Energia \\
\hline CEB & - $\mathrm{CO}_{2}$ Emission Based \\
\hline $\mathrm{CO}_{2}$ & - Gás Carbônico \\
\hline Cobit & - Control Objectives related to Information Technology \\
\hline CORBA & - Common Object Request Broker Architecture \\
\hline CPU & - Central Process Unit \\
\hline CRV & - Capabitity Requirement Vector \\
\hline CSAAC & - Cooperative Scheduling Anti-load balancing Algorithm for Cloud \\
\hline CSV & - Capability Supply Vector \\
\hline DC & - Datacenters \\
\hline DCiE & - Datacenter Efficiency \\
\hline DSS & - Decision Support Systems \\
\hline DVFS & - Dynamic Voltage and Frequency Scaling \\
\hline DVM & - Dispatcher Virtual Machine \\
\hline ECTC & - Energy-conscious task consolidation \\
\hline EDC & - Enterprise Datacenter \\
\hline EDF & - Earliest Deadline First \\
\hline EIA & - Energy Information Administration \\
\hline ERES & - Energy-aware Real-time Elastic Scheduling \\
\hline FCFS & - first come first served \\
\hline GCA & - Green Cloud Architecture \\
\hline GCTA & - Green Cloud Task-scheduling \\
\hline GreenMACC & - Green Metascheduler Architecture to provide QoS in the Cloud Computing \\
\hline HICCAM & - Hybrid Cloud Construction and Management \\
\hline HPC & - High Performance Computing \\
\hline
\end{tabular}





\section{Lista de Siglas}

\begin{tabular}{|c|c|}
\hline IaaS & - Infrastructure as a Service \\
\hline IDC & - Internet Datacenter \\
\hline KVM & - Kernel-based Virtual Machine \\
\hline $\mathbf{K W} / \mathbf{h}$ & - kiloWatts por hora \\
\hline $\mathbf{k W} / \mathbf{s}$ & - kiloWatts por segundo \\
\hline LAN & - Local Area Network \\
\hline LJFS & - Largest Job First Served \\
\hline LRAM & - Local Resource Allocation Manager \\
\hline MACC & - Metascheduler Architecture to provide QoS in the Cloud Computing \\
\hline MDSM & - Monitoring and Discovery System Manager \\
\hline MIPS & - Million Instructions Per Second \\
\hline MV & - Máquina Virtual \\
\hline NIST & - Instituto Nacional Americano de Padrões e Tecnologia \\
\hline ONU & - Organização das Nações Unidas \\
\hline PaaS & - Plataform as a Service \\
\hline PADEVE & - Pontos de Análise para Decisão no Escalonamento Verde \\
\hline PIB & - Produto Interno Bruto \\
\hline PUE & - Power Usage Effectiveness \\
\hline QoS & - Quality of Service \\
\hline RAM & - Random Access Memory \\
\hline $\mathbf{R R}$ & - Round Robin \\
\hline SaaS & - Software as a Service \\
\hline SD2c & - $\quad$ Slotted Dynamic 2 vCores \\
\hline SD4c & - $\quad$ Slotted Dynamic 4 vCores \\
\hline SLA & - Service Level Agreement \\
\hline SQF & - Shortest Queue First \\
\hline TB-WSLA & - Template Base - Web Service Level Agreements \\
\hline TMR & - Tempo Médio de Resposta \\
\hline TI & - Tecnologia da Informação \\
\hline UDDI & - Universal Description, Discovery and Integration \\
\hline UMATGC2 & - Unified MetaScheduler Architecture for Telecom Grade Cloud Computing \\
\hline $\mathbf{U P}$ & - Unidades de Processamento \\
\hline UT & - Unidades de Tempo \\
\hline VMM & - Virtual Machine Manager \\
\hline
\end{tabular}




\subsection{Contextualização e Motivação}

O meio ambiente está no centro das discussões em diversas áreas do conhecimento. As preocupações ambientais estão cada vez mais no discurso de chefes de estado de todo o mundo. Atualmente tem-se observado um esforço para que ambos os temas possam ser trabalhados em conjunto. A ideia de uma economia sustentável, o uso adequado dos recursos naturais, a reutilização e reciclagem de materiais, o reflorestamento, a redução da emissão de gases tóxicos na atmosfera, a busca por soluções energeticamente eficientes, a busca por energia mais limpa são pontos de grande importância para a saúde do nosso planeta.

O crescimento acelerado do consumo de produtos eletrônicos com acesso a internet é visível e indiscutível. Esse crescimento tem sido um tema de preocupação dos ambientalistas, pois trás consigo uma série de problemas como o aumento do lixo eletrônico, o aumento do consumo de energia, o crescimento da emissão de $\mathrm{CO}_{2}$ (Gás Carbônico) na atmosfera. Além desses problemas outro fato que aparentemente não está ligado à sustentabilidade é o crescimento do uso de serviços na internet. Na verdade esse aumento da oferta e da procura de serviços na Internet está diretamente ligado aos problemas já citados anteriormente. Para se aumentar a oferta, necessita-se de aumentar a infraestrutura de Data Centers (Centros de Dados). Atualmente, o consumo de energia dessa infraestrutura é bastante considerável e consequentemente a energia consumida por eles, na maioria dos países, é gerada por usinas que emitem gás Carbônico na atmosfera. Devido a esse fato, os Data Centers nos dias de hoje são responsáveis pela mesma taxa de emissão de $\mathrm{CO}_{2}$ que toda frota de aviões das empresas de transporte aéreo no mundo (Arjona Aroca et al., 2014) (Cappiello et al., 2013). 
Devido aos fatos já citados, a necessidade de se criar soluções "verdes" que busquem a economia de energia e consequentemente a redução da emissão de gases poluentes na atmosfera se tornou tema relevante nos últimos anos. Assim surgiu uma nova área de pesquisa, a computação verde na nuvem ou em como conhecido na língua inglesa Green Cloud Computing.

Existem diversas maneiras de se buscar a economia de energia em Data Centers, algumas via aperfeiçoamento e criação de novas tecnologias de hardware e outras com soluções verdes através de software. Uma linha de pesquisa de computação verde na nuvem através de soluções de software é desenvolver técnicas de escalonamento que permitam essa economia.

Um dos pontos principais da computação em nuvem é a necessidade de prover ao cliente ou usuário Qualidade de Serviço (QoS - Quality of Service). Existem diversos trabalhos na literatura que buscam a qualidade de serviço, dentre eles uma boa solução é o MACC (Metascheduler Architecture to provide QoS in the Cloud Computing) (Peixoto, 2012). O MACC é uma arquitetura de um metaescalonador desenvolvida com o objetivo de prover qualidade de serviço ao usuário. Entretanto, não permite o uso de técnicas verdes de escalonamento.

Existem alguns trabalhos que permitem o metaescalonamento verde na nuvem, entretanto nenhum oferece um mecanismo que permita a escolha automática, dentre as várias políticas de escalonamento implementadas, da melhor configuração de políticas para se cumprir de forma otimizada o que foi negociado com o usuário.

A hipótese deste trabalho tem como base o questionamento da possibilidade e viabilidade de se oferecer uma solução de metaescalonamento na nuvem que escolha automaticamente, dentre as políticas de escalonamento implementadas no sistema, a melhor configuração de políticas de escalonamento de uma forma que as prioridades negociadas com o usuário sejam respeitadas.

Esta tese oferece uma solução chamada GreenMACC (Green Metascheduler Architecture to provide $Q o S$ in the Cloud Computing), que é uma extensão da arquitetura MACC. O GreenMACC é uma arquitetura que trás consigo a eficiência do MACC em prover qualidade de serviço ao usuário, porém agregado a esse importante fator, oferece uma arquitetura onde permite o uso de políticas de escalonamento verdes em conjunto das que primam pela QoS. Outro ponto importante a se ressaltar é a possibilidade do GreenMACC em negociar prioridades com o usuário e assim montar uma configuração de políticas de escalonamento específicas para o serviço requisitado.

A próxima seção apresenta os objetivos deste trabalho, na sequência a seção 5.2 está definida a metodologia adotada neste doutorado e finalmente na seção 1.4 apresenta-se a estrutura desta tese.

\subsection{Objetivos}

Tendo o que foi exposto na seção 1.1 como base, esta tese tem como objetivo principal apresentar um Metaescalonador que oferece estrutura para utilização de políticas de escalonamento verdes com provisão de Qualidade de Serviço para nuvens privadas. Para alcançar este objetivo propõe-se nesta tese o GreenMACC, que é uma extensão da arquitetura MACC proposta por Peixoto (2010) 
e que mantém sua eficiência na oferta de QoS, entretanto trás consigo diversas modificações que permitem o uso de computação verde na nuvem com igual eficiência.

Em relação ao MACC, o GreenMACC tem alguns módulos modificados, outros retirados e alguns módulos acrescentados de modo a conseguir oferecer uma arquitetura flexível, eficiente, automatizada e que permite o respeito ao contrato com o usuário, possibilitando ainda redução do consumo de energia do sistema como um todo (hosts, rede, refrigeração, etc.). Outro ponto a ser trabalhado é a redução da emissão de Gás Carbônico.

Para que esses fatos positivos ocorram, o GreenMACC oferece uma arquitetura de metaescalonamento em 4 estágios. São elas: escolha do Data Center, que irá receber a requisição do serviço e executá-lo; a criação de máquinas virtuais nos hosts do Data Center escolhido; a alocação das máquinas virtuais criadas; e finalmente a alocação de tarefas nas Máquinas Virtuais. O GreenMACC oferece uma arquitetura que permita a implementação de uma grande quantidade de políticas com objetivos dos mais variados para os quatro estágios de escalonamento citados. Além disso, dependendo das políticas implementadas, a arquitetura permite negociar com o usuário os fatores prioritários para a entrega do serviço requisitado, tais como: Tempo Médio de Resposta (TMR), Consumo de Energia, Emissão de $\mathrm{CO}_{2}$, dentre outros. Feita a negociação, o GreenMACC escolhe automaticamente quais das políticas implementadas deverão ser utilizadas em cada um dos 4 estágio de escalonamento.

\subsection{Metodologia}

Inicialmente foi realizado um levantamento dos trabalhos existentes na literatura com o objetivo de identificar o que já havia sido feito. A escolha dos trabalhos referenciados nesta tese teve como critério a busca por trabalhos publicados em congressos e revistas de conhecida relevância na área de Ciências de Computação em sua maioria indexaoas na Scopus, IEEE, ACM, Elsevier, dentre outras. Com o levantamento desses trabalhos finalizado, pôde-se analisar quais as lacunas existentes na literatura. Uma das lacunas existentes era um metaescalonador que além de garantir a Qualidade de Serviço (QoS) permitisse a implementação de políticas com objetivos "verdes" e, que além disso, oferecesse de forma automática uma configuração das políticas de escalonamento de acordo com as prioridades do usuário.

Dentre os trabalhos pesquisados, o que apresenta a arquitetura MACC chamou mais atenção devido a sua eficiência na negociação com o usuário e o mecanismo para garantia da QoS. Como esse trabalho foi desenvolvido no mesmo laboratório do grupo de pesquisa do autor desta tese, tomou-se a decisão de que o MACC poderia ser estendido para uma arquitetura que além de garantir o QoS, permitisse o uso de políticas verdes e que a escolha das políticas fosse feita de forma automatizada de acordo com a negociação com o usuário.

O MACC proposto e avaliado no trabalho de Peixoto (2012) foi implementado na ferramenta de simulação de nuvens computacionais CloudSim (Calheiros et al., 2009) na versão 2.1. E após 
a decisão de estender o MACC foi feita a migração dessa arquitetura, inicialmente implementada no CloudSim 2.1, para o 3.0. Isso foi necessário devido às limitações dos pacotes e modelos de computação verde na versão 2.1. A versão 3.0 possui pacotes e modelos mais atualizados e para execução de simulações de nuvens com objetivos de computação verde na nuvem.

Logo que o MACC foi migrado para a versão 3.0, iniciou-se a extensão da arquitetura onde optou-se pela retirada de alguns módulos do MACC que são desnecessários desnecessários para uma nuvem privada e que eram específicos para metaescalonamento em uma intercloud. Foram adaptados e modificados alguns módulos do MACC visando a automatização da escolha das políticas de escalonamento em quatro estágios. Também foram acrescentados novos módulos para que a nova arquitetura permita o uso de políticas verdes.

Terminada a implementação do GreenMACC no CloudSim 3.0, foi feita a validação da arquitetura, comparando seus resultados com os resultados obtidos pelo MACC. Após a validação, iniciou-se as avaliações de desempenho da arquitetura proposta nesta tese de doutorado. Foram avaliados alguns pontos importantes da arquitetura como capacidade de execução de políticas com objetivos distintos como, por exemplo, políticas que buscam a QoS e políticas verdes. Além disso, também foi avaliada a capacidade da arquitetura de fazer a melhor escolha das políticas de escalonamento de acordo com a negociação com o usuário. Outro ponto avaliado é a influência que cada política pode exercer nos resultados de outra política. A flexibilidade da arquitetura também foi avaliada e obteve resultados que comprovam essa característica.

\subsection{Estrutura}

O Capítulo 2 desta tese apresenta e discute dois temas fundamentais neste trabalho: a computação verde e a computação em nuvem. No Capítulo 3 é apresentado o estado da arte na área de escalonamento e metaescalonamento na nuvem. O Capítulo 4 apresenta, discute e valida o GreenMACC, arquitetura proposta nesta tese de doutorado. O Capítulo 5 é dedicado à avaliação de desempenho do GreenMACC em relação a sua automatização na escolha de políticas de escalonamento, flexibilidade de adaptação a novas políticas implementadas e a interação entre as políticas de estágios diferentes, onde é possível analisar a influência que políticas de um estágio específico tem nos resultados das políticas de outro estágio. E finalmente, o Capítulo 6 apresenta as conclusões obtidas no desenvolvimento deste trabalho. 
CAPÍTULO

2

Computação Verde na Nuvem

\subsection{Considerações Iniciais}

$\mathrm{D}$ Iscute-se, nas últimas décadas e, globalmente com muita ênfase, o meio ambiente. Vários temas, como emissão de gás carbônico, consumo sustentável de bens naturais, economia de energia e diversos outros pontos fundamentais, entram nos debates que defendem os interesses de um planeta que, se bem cuidado, servirá ainda por muitos anos como uma residência agradável da raça humana.

Todas as pessoas com uma visão humanística e que tenham uma consciência voltada ao bem estar de todos, já sabem e percebem a necessidade de contribuir com o meio ambiente. O consumo sustentável e racional permite que as indústrias foquem na produção de produtos ecologicamente viáveis. Forma-se então um ciclo virtuoso e sustentável. Desta forma, a própria ciência se vê como um dos alicerce da construção de um planeta mais limpo e que ofereça mais qualidade de vida ao ser humano. Com esta mesma visão ecológica é que surgiu a Computação Verde.

No final da primeira década do século XXI, assim que a Computação em Nuvem começou a ser uma importante área de pesquisa, uma ramificação desse novo paradigma de sistemas distribuídos nasceu. O novo conceito Green Cloud Computing (Computação Verde na Nuvem) nasceu da junção da Cloud Computing (Computação em Nuvem) com GreenIT (TI verde ou Computação Verde). Esse capítulo tem como objetivo abordar essas duas importantes áreas da computação, uma em cada seção. A separação dos temas se deve ao vasto conteúdo que cada um possui. Com a separação, espera-se facilitar a leitura e consequentemente o entendimento do conteúdo apresentado. No entanto, tem-se no decorrer do capítulo a conexão dos dois temas com o intuito de demonstrar como ambos trabalham juntos em harmonia. 
O tema Computação Verde na Nuvem, é a junção de duas áreas, Computação Verde e Computação em Nuvem. Como são dois temas relativamente novos se comparados com outros temas da computação, existem muitos gaps a serem pesquisados e trabalhados. Por outro lado, a quantidade de trabalhos na área aumentou consideravelmente nos últimos anos.

A Computação Verde é um tema abordado nos últimos anos que visa incentivar a utilização da TI (Tecnologia da Informação) com uma preocupação justa e legítima com o meio ambiente. No trabalho de (Murugesan, 2008) encontra-se a afirmação que "TI verde é o estudo e prática de projeto, fabricação, uso e descarte de computadores, servidores e subsistemas associados (como monitores, impressoras, dispositivos de armazenamento, redes e sistemas de comunicação) de forma eficiente e eficaz com impacto mínimo ou nulo sobre o ambiente".

A Computação Verde não deve estar restrita em apenas um estágio do desenvolvimento ou da prestação de serviços das tecnologias. Por ser um tema relativamente novo, ainda não foi inserido no contexto da população, sendo mais difundido em corporações privadas e instituições públicas. Entretanto, aos poucos esse novo conceito deve ser aceito e melhor entendido pelo consumidor final que compra novas tecnologias (GreenITBrasil, 2014). Existem mais preocupações na Computação Verde do que apenas economia de energia. Na seção 2.2 esse conceito é abordado com mais profundidade.

O uso crescente de um alto poder computacional gerando um crescimento considerável no consumo de energia e consequentemente na emissão de $\mathrm{CO}_{2}$ é um fato que exalta a real necessidade das práticas de Computação Verde visando um cenário sustentável. A Computação em Nuvem é um bom exemplo de um paradigma recente no mercado de TI e que demanda um alto poder computacional (Atrey et al., 2013). Esse fato justifica o crescente interesse de juntar os dois conceitos: Computação Verde e Computação em Nuvem.

A Computação em Nuvem foi definida pelo Instituto Nacional de Padrões e Tecnologia americano, NIST (National Institute of Standards and Technology) depois de 15 versões preliminares. Essa definição diz que "Computação em Nuvem é um modelo para acesso conveniente, sob demanda, e de qualquer localização, a uma rede compartilhada de recursos de computação (isto é, redes, servidores, armazenamento, aplicativos e serviços) que possam ser prontamente disponibilizados e liberados com um esforço mínimo de gestão ou de interação com o provedor de serviço" (Mell e Grance, 2011).

Nos últimos anos os serviços de Computação em Nuvem se tornaram a tecnologia mais utilizada por corporações como Microsoft ${ }^{\circledR}, \mathrm{Google}^{\circledR}$, Amazon $^{\circledR}, \mathrm{IBM}^{\circledast}$, etc. Esse novo paradigma da área de sistemas distribuídos exige cada vez mais grandes centros de dados distribuídos geograficamente. Esse crescimento se deve em parte à exigência da melhora da qualidade dos serviços prestados aos novos clientes que aumentam a cada dia. A demanda cada vez maior de recursos vem acompanhada do aumento do consumo de energia elétrica, e por consequência, faturas de energia elétrica mais elevadas. Existe atualmente um desejo das empresas de TI de oferecer ao cliente um serviço de qualidade e, ao mesmo tempo, reduzir a conta de energia elétrica (Kaur et al., 2014). 
Considerando-se a Computação Verde na Nuvem como tema principal deste capítulo, as duas áreas de estudo, Computação Verde (seção 2.2) e Computação em Nuvem (2.3), são melhor definidas e caracterizadas nas duas primeiras seções a seguir. Na terceira seção são expostos trabalhos relacionados ao tema desse capítulo.

\subsection{Computação Verde}

\subsubsection{Histórico}

Em 1992 ocorreu na cidade do Rio de Janeiro a primeira tentativa internacional de elaborar um plano de transição para um desenvolvimento sustentável. A cúpula formada por mais de 100 chefes de estado de todo mundo e também constituída por uma série de representantes de organizações da sociedade civil teve como meta discutir a solução para os problemas de degradação ambiental. $\mathrm{O}$ conceito de desenvolvimento sustentável foi popularizado em 1987 pela comissão de Brundtland ${ }^{1}$ no relatório chamado "Nosso Futuro Comum". Nesse relatório pode-se encontrar a definição que esclarece que desenvolvimento sustentável é o "desenvolvimento que satisfaz as necessidades do presente sem comprometer a capacidade das gerações futuras de satisfazerem as suas próprias necessidades" (Sustainable-DC, 2014).

A interpretação do conceito de desenvolvimento sustentável é variada, mas em essência é a busca do equilíbrio das limitações ambientais, sociais e econômicas (Sustainable-DC, 2014). Buscando-se esse equilíbrio pode-se obter diversos benefícios. Na área econômica, a sustentabilidade ambiental leva a redução de custos, diferenciação no mercado através de novos produtos e serviços, novos mercados, melhoria da imagem da empresa no mercado, dentre outros. Na área ambiental, alguns exemplos de benefícios são a redução no consumo de energia, redução de resíduos, redução de poluentes e mais saúde e consequente aumento da expectativa de vida. $\mathrm{Na}$ área social pode-se citar como alguns dos benefícios a equidade social e a melhora da qualidade de vida da população (Chou, 2013).

A ideia da Computação Verde, que é também conhecida por TI verde (Green IT), nasceu quando a agência americana de proteção ambiental (EPA) lançou um selo de qualidade que caracteriza o equipamento eletrônico como um produto que economiza, de forma eficiente, energia elétrica. Este selo é conhecido por Energy Star, e foi adotado pelas indústrias de TI de forma voluntária (Ruth, 2009).

Os sistemas e serviços desenvolvidos com foco na Computação Verde têm maior implicação para uma sociedade sustentável envolvendo de forma mais ativa os seus usuários. A pesquisa nessa área da computação deve ter um foco em produções mais compreensíveis e utilizáveis aos seus usuários ou clientes. A complexidade principal em uma pesquisa na área de Computação

\footnotetext{
${ }^{1}$ Comissão Mundial sobre o Meio Ambiente e Desenvolvimento criada pela ONU em 1983. O nome da comissão foi inspirado no nome da presidente da comissão e ex-primeira ministra da Noruega a médica Gro Harlem Brundtland (ONU, 2014)
} 
Verde está em como fazer uma avaliação qualitativa e quantitativa do grau de requisitos verdes (greenness) da inovação apresentada (Xu, 2012).

A TI causa diversos tipos de impactos ambientais. Mas existem outros tipos de impactos que a TI pode causar, como impactos sociais e econômicos. A TI verde não tem apenas uma preocupação ambiental, e sim socioambiental, devido a isso, que a TI verde estuda os meios de reduzir ou, em alguns casos, anular os efeitos desses impactos na sociedade. A próxima subseção discute com mais detalhes sobre esses diversos tipos de impactos.

\subsubsection{Impactos Causados pela TI}

No trabalho de Faucheux e Nicolaï (2011) pode-se observar os impactos causados pela TI na economia, no espectro social e também ambiental. Na economia, o setor de TI colabora com o aumento do PIB (Produto Interno Bruto) mundial incluindo os países emergentes como Brasil, Rússia, Índia, China e Africa do Sul (BRICS). Esse setor tem crescido a cada ano refletindo no aumento do número de empregos na área. O alto investimento na produção de hardware e software gera maior produtividade do que no setor industrial. A nova visão ambiental gera novos modelos de negócios reduzindo os custos de transação e tornando as empresas mais competitivas além de promover responsabilidade social nas corporações. A Computação Verde tem o potencial de ser a maior oportunidade de crescimento do século 21 (Faucheux e Nicolaï, 2011).

O impacto social da TI não é bem definido, pois na prática é mais difícil de se medir em comparação com o impacto econômico. O aumento de empregos no setor de TI é um fato importante pois as vagas existentes exigem alta qualificação e consequentemente maiores salários. Entretanto gera redução de postos de trabalho menos qualificados. O acesso à TI é um ponto social que deve ser abordado para evitar a exclusão de pessoas a esse novo mundo digital. Ações para acesso a Internet e dispositivos eletrônicos que permitem esse acesso devem ser executadas pelos governos para evitar a exclusão digital (Faucheux e Nicolaï, 2011).

A TI também gera impactos ambientais. O uso de recursos tóxicos e não renováveis (mercúrio, cádmio, chumbo, etc) na produção de dispositivos é um problema real. A Computação Verde entra nesse assunto gerando uma melhor aceitabilidade das empresas em mudar esse cenário. Mas o problema não está somente na produção. O descarte inadequado e a não reciclagem de equipamentos eletrônicos também é um caso onde a pesquisa na área de Computação Verde atua buscando soluções adequadas a esses problemas. $\mathrm{O}$ aumento no consumo de energia elétrica devido ao uso de TI deve ser lembrada principalmente por ser diretamente responsável pelo aumento da emissão de gases poluentes na atmosfera, principalmente o gás carbônico. O principal culpado na área de TI pelo aumento do consumo de energia são os Data Centers (Faucheux e Nicolaï, 2011). 


\subsubsection{Gestão Verde}

Para viabilizar o desenvolvimento sustentável nas empresas criou-se outro conceito: a gestão verde (Figura 2.1). A gestão verde viabiliza a sustentabilidade ambiental, a redução do desperdício obtendo vantagem competitiva através de estratégias e metas verdes integradas aos objetivos da empresa. Essa prática está associada ao princípio da eco-eficiência. Essa última busca oferecer preços e serviços competitivos ao mesmo tempo que reduz os impactos ambientais. As três dimensões da eco-eficiência são a redução do consumo de recursos, a redução do impacto sobre o meio ambiente e a melhoria do valor do produto (Santos e Jabbour, 2013).

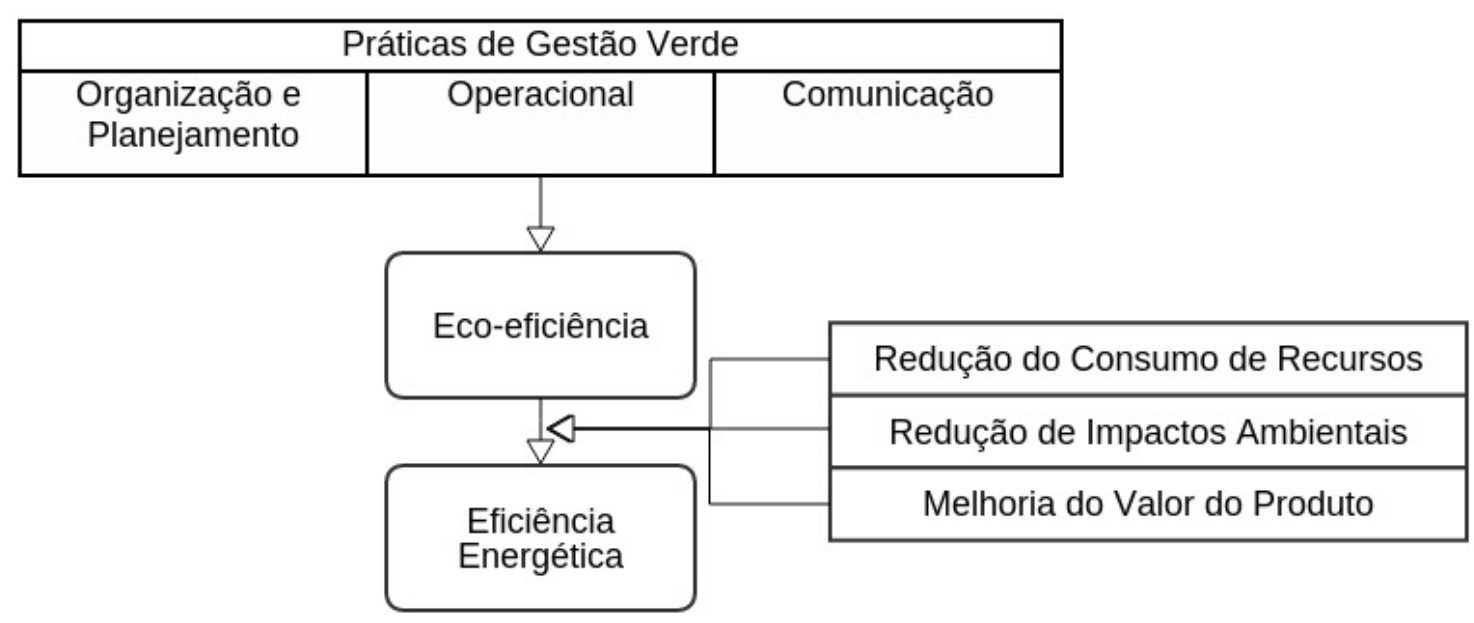

Figura 2.1: Gestão Verde - Diagrama Adaptado de Santos e Jabbour (2013)

Diante do exposto, pode-se afirmar que esta tese de doutorado está inserida no conceito de ecoeficiência e consequentemente entremeada na área de desenvolvimento sustentável. Uma vez que o objetivo deste trabalho é apresentar uma arquitetura de metaescalonamento verde que oferece as três dimensões da eco-eficiência e também faz uso do conceito de gestão verde, a contribuição a um desenvolvimento sustentável na área de computação fica evidente.

As atividades da Computação Verde devem estar na mesma sintonia do conceito de gestão verde, pois os objetivos convergem para pontos em comum. Os problemas da Computação Verde não se restringem exclusivamente ao desenvolvimento de sistemas. A produção de dispositivos de TI também deve ser uma preocupação da sociedade como um todo. A indústria de TI consome atualmente grande quantidade de recursos como água, energia e até compostos perigosos à saúde. Por essa razão os governos de todo o mundo têm criado leis que definem como a indústria deve fabricar e utilizar computadores, servidores, Data Centers, e demais dispositivos de forma eficiente buscando minimizar o efeito nocivo ao meio ambiente (Chou, 2013).

Murugesan (2008) em seu trabalho apresentou quatro caminhos para se alcançar os objetivos de uma Computação Verde: uso verde, descarte verde, projeto verde e produção verde. Cada caminho pode ser seguido tanto por consumidores (uso e descarte verdes) quanto por fabricantes 
de hardware e software (projeto e produção verdes). Além de se preocupar com os caminhos necessários para se alcançar a Computação Verde, Murugesan (2008) especificou em seu trabalho, quais são as atividades de Computação Verde. São elas:

- Computação com uso eficiente de energia;

- Gerenciamento de energia;

- Redução de riscos relacionados ao meio ambiente;

- Projeto para sustentabilidade ambiental;

- Projeto, layout e localização de Data Center;

- Virtualização de servidores;

- Descarte responsável e reciclagem;

- Adesões a regulamentos específicos;

- Métricas verdes, ferramentas de avaliação e metodologias;

- Uso de fontes de energia renováveis; e

- Eco-rotulagem de produtos de TI.

Analisando-se o contexto da Computação Verde apresentado, pode-se inserir esta tese de doutorado nas três primeiras atividades citadas. Ou seja, este trabalho pode ser relacionado à Computação Verde. Como o GreenMACC tem focos bem definidos dentro da área de Computação Verde, tais como o consumo de energia e a emissão de gás carbônico $\left(\mathrm{CO}_{2}\right)$, torna-se necessária uma discussão desses dois temas visando uma melhor compreensão de ambos. A próxima subseção apresenta esse essa discussão.

\subsubsection{Consumo de Energia e Emissão de $\mathrm{CO}_{2}$}

Em 2001, teve-se no Brasil uma crise energética conhecida popularmente como apagão energético de 2001. Graças a esse fato, foi criada a Lei $n^{\circ} 10.295$ visando delimitar o consumo e os requisitos mínimos para uma eficiência energética de máquinas e dispositivos no Brasil. O Plano Energético Nacional estima uma economia de energia de aproximadamente 53 Tera Watts até 2030 devido às ações para obtenção de eficiência energética (Santos e Jabbour, 2013). Este fato contribui para a percepção de quanto as ações conjuntas entre governo, pesquisadores e população são eficazes na busca de soluções para a redução do consumo de energia elétrica e consequentemente a redução da emissão de $\mathrm{CO}_{2}$ na atmosfera. 
A cada ano a infraestrutura de TI no mundo todo cresce, juntamente com esse crescimento vem a demanda por capacidade computacional. Com esse panorama, o consumo de energia elétrica é excessivamente grande. E a tendência é crescer cada vez mais conforme o poder computacional aumenta. O custo referente a energia pode ser até maior que o investimento na infraestrutura no decorrer do tempo (Beloglazov e Buyya, 2010a).

Os setores de TI e de telecomunicações respondiam em 2009 por três por cento do uso de energia global, e no mesmo percentual, a emissão de gás carbônico (Ruth, 2009). Atualmente somente os Data Centers são responsáveis por dois por cento da emissão de $\mathrm{CO}_{2}$ na atmosfera empatando com a emissão das companhias aéreas de todo o mundo (Arjona Aroca et al., 2014) (Cappiello et al., 2013). A expectativa é de que nos próximos 10 anos a emissão de gás carbônico causada pelos Data Centers chegue a $10 \%$ de todo $\mathrm{CO}_{2}$ lançado na atmosfera em todo planeta (Addis et al., 2014).

A importância significativa nas discussões sobre meio ambiente vão além da TI. Entretanto, grande parte de soluções apresentadas no mundo para reduzir a emissão de $\mathrm{CO}_{2}$, estão ligadas a economia de energia, e intrinsecamente, dependentes da TI. Atualmente a preocupação está mais focada na Computação em Nuvem devido ao grande crescimento de Data Centers pelo mundo. A Computação em Nuvem é atualmente um dos temas com maior expansão do número de trabalhos de pesquisa na área de sistemas distribuídos. Na próxima seção esse paradigma é abordado com mais detalhes.

\subsection{Computação na Nuvem}

\subsubsection{Contextualização}

O setor de serviços tem crescido de forma constante no Brasil (IBGE, 2014). A ideia de serviços para o cidadão comum normalmente é atrelada ao seu cotidiano. Na maioria das vezes, se perguntado, citará como exemplo de serviços aqueles que ele tem fora de casa no seu dia a dia como cabeleireira, mecânico, técnico especializado em concerto de eletrodomésticos, etc. Outros citarão serviços que têm em sua casa como aguá, luz e telefone. Nos primeiros serviços citados, normalmente o preço e o tempo são negociados antes da prestação do serviço. Já para os serviços citados em seguida, os preços variam de acordo com a demanda do cliente, ou seja, se usar pouco paga-se pouco, se usar muito o preço da conta eleva-se proporcionalmente. A Computação em Nuvem se enquadra nos serviços do segundo exemplo.

Esse paradigma da área de sistemas distribuídos vem crescendo a cada ano (Atrey et al., 2013) (Kaur et al., 2014) (Shon et al., 2014), sendo que às vezes as pessoas utilizam dos serviços na nuvem e nem percebem. Ou se sabem, não têm a menor ideia de como ele é oferecido e nem o local físico de onde vem esse serviço. Abrir um documento sem ter um editor instalado é um exemplo clássico. A beleza e o fascínio da Computação em Nuvem está exatamente nessa transparência. 
A Computação em Nuvem no início foi erroneamente definida como uma extensão das grades computacionais. Entretanto, em (Foster et al., 2008), foi melhor esclarecida e definida como um novo paradigma, com diversas características. Dentre as mais importantes, pode-se identificar: a satisfação do usuário pela qualidade do serviço prestado, virtualização, variedade de recursos, adaptação dinâmica, escalabilidade de recursos, pagamento conforme a utilização, e Qualidade de Serviço. Desta forma, pode-se concluir que a Computação em Nuvem tem suas próprias características e possui uma significativa complexidade (Gong et al., 2010).

$\mathrm{Na}$ literatura aparecem algumas definições de nuvem, desde que esse novo paradigma surgiu. Uma delas é apresentada no trabalho de (Buyya et al., 2011) onde se afirma que "Computação em Nuvem é um sistema computacional paralelo e distribuído que consiste em uma coleção de interconexões e virtualização de computadores, onde são dinamicamente ofertados um ou mais recursos computacionais baseados em contratos de serviço (SLA), estabelecidos entre uma negociação de clientes e provedores do serviço". No mesmo ano o NIST divulga seu relatório sobre Computação em Nuvem onde afirma que a Computação em Nuvem é "um modelo para acesso conveniente, sob demanda, e de qualquer localização, a uma rede compartilhada de recursos de computação (isto é, redes, servidores, armazenamento, aplicativos e serviços) que possam ser prontamente disponibilizados e liberados com um esforço mínimo de gestão ou de interação com o provedor de serviços"(Mell e Grance, 2011).

Outra forma de entender a Computação em Nuvem é imaginar um serviço que o usuário deseja utilizar. Não importa nesse momento exatamente qual o tipo de serviço. O acesso a esse serviço deve ser de fácil alcance e utilização para qualquer tipo de usuário. O usuário pagará somente o que ele usar, nada a mais e nada a menos, assim como a água ou a energia elétrica de casa, por exemplo. Esse usuário poderá acessar esse serviço de qualquer lugar e de qualquer dispositivo que tenha acesso a Internet. O serviço deve sempre estar disponível ao usuário da forma mais transparente possível. Essas características permitem que o usuário utilize o serviço que quiser na nuvem, com o mínimo esforço, em qualquer local com acesso a Internet e com o dispositivo que tiver disponível. Devido a isso, a Computação em Nuvem tem crescido nos últimos anos e tende a crescer cada vez mais.

Para que toda essa facilidade esteja disponível ao usuário, grandes empresas da área de TI investem pesado. Considerando-se que a grande maioria dessas empresas visam lucro, pode-se afirmar que esse é o principal objetivo das empresas no uso da Computação em Nuvem (Gong et al., 2010). O modelo de negócios na Computação em Nuvem é baseado em pay-per-use, ou seja, a conta depende da demanda do usuário. Entretanto, ao contrário da água e da energia elétrica, existem outras formas das empresas de Computação em Nuvem receber pelo serviço. Normalmente a cobrança por esses serviços são feitas de duas maneiras. Na primeira, o serviço é pago pelo próprio usuário. Entretanto um usuário leigo pode se perguntar: porque eu uso alguns serviços na nuvem e não recebo nenhuma conta para pagar? Como essas empresas conseguem se sustentar? Para responder essas perguntas é necessário apresentar a segunda forma de pagamento na Computação 
em Nuvem. Os anunciantes que pagam a conta. É por isso que, normalmente quando se usa um serviço gratuito na nuvem, existem anúncios de propaganda.

Vários assuntos são tratados dentro da área de Computação em Nuvem como: serviços, virtualização, Data Center, dentre outros. Nessa seção são abordados todos esses temas e discutidos mais detalhadamente com o objetivo de entender melhor como esse paradigma funciona.

\subsubsection{Tipos de Serviços}

Existem três tipos de serviços que pode ser ofertados na nuvem (Shon et al., 2014) (Buyya et al., 2009) (Furht e Escalante, 2010). O NIST, em seu relatório (Mell e Grance, 2011), caracteriza os 3 modelos de serviços: Infraestrutura como Serviço (IaaS), Plataforma como Serviço (PaaS) e Software como Serviço (SaaS) (Figura 2.2). O relatório do NIST além de citar os 3 modelos de serviços, também caracteriza cada um deles.

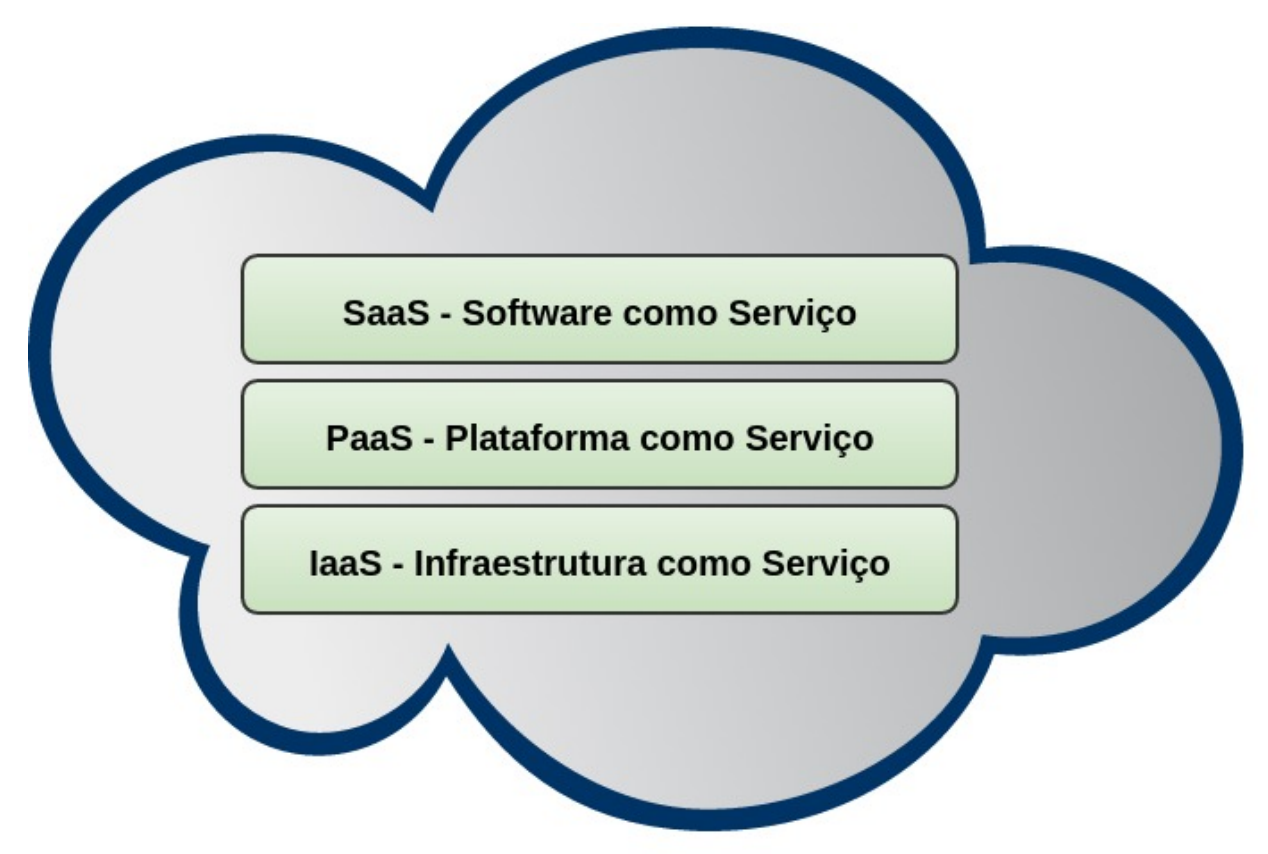

Figura 2.2: Tipos de Serviços Oferecidos na Nuvem

- SaaS (Software as a Service) : deve-se fornecer ao consumidor a capacidade de utilização de aplicativos não instalados no cliente e sim no provedor do serviço executando em uma infraestrutura de nuvem; as aplicações podem ser executadas de diversos tipos de dispositivos clientes, utilizando-se interfaces leves, de baixa exigência computacional como um browser ou interface de programa; o consumidor não tem controle sobre a infraestrutura da nuvem como rede, servidores, sistemas operacionais, armazenamento etc. As configurações devem ser limitadas as específicas ao usuário comum. Alguns exemplos de softwares oferecidos na nuvem são: Google Apps ${ }^{\circledast}$, Salesforce.com ${ }^{\circledast}$, Dropbox ${ }^{\circledR}$, etc. 
- PaaS (Platform as a Service) : a capacidade para uso do serviço fornecido deve ser destinada à infraestrutura criada ou comprada pelo consumidor; podem ser utilizadas linguagens de programação, bibliotecas, serviços e ferramentas suportadas pelo provedor; o consumidor não administra e nem controla a infraestrutura de nuvem como a rede, servidores, sistemas operacionais, mas tem controle sobre os aplicativos implementados e possivelmente sobre as configurações para o ambiente de hospedagem de aplicativos. Alguns exemplos de plataformas oferecidas como serviços são: Google App Engine ${ }^{\circledR}$, force.com ${ }^{\circledR}$, Microsoft Azure ${ }^{\circledR}$, IBM Cloud $^{\circledR}$ etc.

- IaaS (Infrastructure as a Service) : a t capacidade de execução dos serviços fornecida deve ser destinada ao provisionamento de processamento, armazenamento, redes e outros recursos de computação fundamentais onde o consumidor é capaz de implementar e executar softwares arbitrários, que permitem incluir sistemas operacionais e aplicativos; o consumidor não administra e nem tem controle sobre a infraestrutura de nuvem, mas tem controle sobre sistemas operacionais, armazenamento e aplicativos implementados, e possivelmente um controle limitado de componentes de rede selecionados (firewalls por exemplo). Exemplos que podem ser citados nesse modelo de serviço são: IBM Cloud ${ }^{\circledR}$, Amazon EC2 $^{\circledR}$, Locaweb $^{\circledR}$, GoGrid $^{\circledR}$, Microsoft Azure ${ }^{\circledR}$, etc.

O SaaS oferece diversos benefícios às empresas independentemente do tamanho ou ramo de atividade. Alguns dos benefícios são: melhor controle dos custos de aquisição de novos softwares; e focar os objetivos do setor de TI para o setor estratégico da empresa (Veras, 2012).

A aquisição de um novo software pode custar até centena de milhares de dólares. Quando se opta pelo SaaS, a necessidade de se adquirir uma grande infraestrutura é repensada. Um dos motivos é que aplicativos SaaS não exigem um grande aporte de infraestrutura no local do cliente. Caso o serviço de software não interesse mais a empresa, a desistência não terá um impacto tão relevante quanto se tivesse comprado uma infraestrutura cara para execução de um software instalado e gerenciado nativamente na empresa. Outro ponto relevante no custo é a possibilidade do provedor do serviço oferecer um período de testes para que a empresa teste o serviço e veja se realmente satisfaz suas necessidades. O segundo benefício está relacionado com foco do setor de TI da empresa. Com o uso do SaaS, a TI não fica preocupada com manutenção e gerenciamento do aplicativo, sendo isso de responsabilidade do provedor do SaaS. Devido a esse fato, a TI pode voltar-se para pontos estratégicos da empresa como prever o melhor uso da tecnologia para a empresa gerar lucros (Veras, 2012).

O PaaS pode ser considerado como uma plataforma de desenvolvimento que não executa nativamente, ou seja, a plataforma é executada nos Data Centers do provedor do serviço. A implantação de infraestrutura e o gerenciamento de servidores para uma plataforma distribuída é custosa para a empresa. Ao adotar PaaS, a empresa pode ter vários benefícios como: fornece um ambiente padrão; permite manter o foco da equipe nas aplicações; propicia um ambiente sob demanda; e pode ser implementado com previsão e resistência a faltas (Veras, 2012). 
O IaaS é o modelo que permite que empresas e/ou usuários não tenham altos gastos com aquisição de hardware, tanto no caso de necessitarem de infraestrutura para desenvolvimento e execução de aplicações de grande porte quanto no caso de aplicações que exijam alto poder computacional. O provedor de IaaS oferece uma infraestrutura virtual ao cliente que paga de acordo com o uso. O GreenMACC, metaescalonador apresentado nessa tese, foi projetado visando atender Infraestrutura como Serviço.

Todos os serviços apresentados estão virtualizados sobre uma camada de infraestrutura (Data Centers) que oferecem processamento, armazenamento de dados e conectividade (Furht e Escalante, 2010).

Caso uma empresa decida por aderir aos serviços da nuvem, um outro fator deve ser considerado para tomada de decisão: qual o modelo de implantação será adotado.

\subsubsection{Modelos de Nuvem Computacional}

Existem quatro modelos de nuvem computacional (Figura 2.3), os quais são descritos no relatório do NIST. São os seguintes: nuvem privada, nuvem pública, nuvem comunitária e nuvem híbrida (Mell e Grance, 2011).

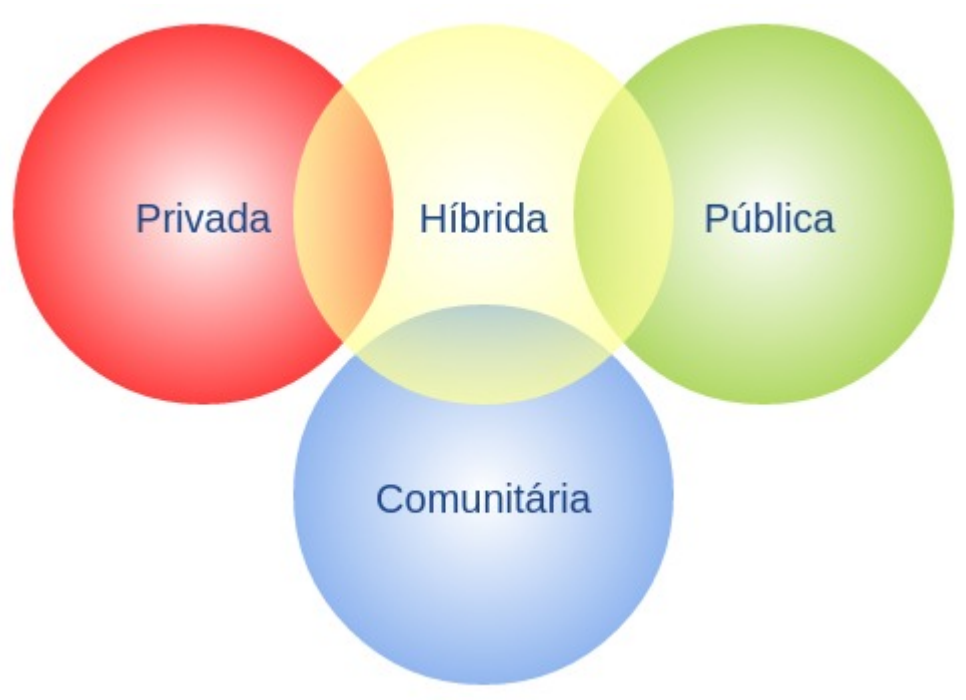

Figura 2.3: Modelos de Nuvens Computacionais

- Nuvem Privada: a infraestrutura da nuvem privada é provisionada para uso exclusivo de uma única organização, compreendendo múltiplos consumidores (por exemplo, unidades de negócio). Ela pode ser controlada, gerenciada e operada pela organização, um terceiro, ou alguma combinação deles, e pode existir com ou sem premissas para seu uso.

- Nuvem Pública: a infraestrutura de uma nuvem pública é provisionada para uso aberto ao público em geral. Ela pode ser controlada, gerenciada e operada por uma organização 
empresarial, acadêmica ou governamental, ou alguma combinação delas. Ela existe sob as premissas do fornecedor da nuvem.

- Nuvem Comunitária: a infraestrutura desse tipo de nuvem é provisionada para uso exclusivo por uma comunidade específica de consumidores de organizações que têm preocupações em comum (por exemplo, considerações referentes a missão, requisitos de segurança, política e compliance ${ }^{2}$ ). Ela pode ser controlada, gerenciada e operada por uma ou mais de uma das organizações da comunidade, por um terceiro, ou alguma combinação deles, e pode existir com ou sem premissas.

- Nuvem Híbrida: a infraestrutura característica desse tipo de nuvem é uma composição de duas ou mais infraestruturas de nuvem distintas (privada, comunitária ou pública) que permanecem como entidades únicas, mas são unidas por tecnologia padronizada ou proprietária que permita a portabilidade de dados e aplicativos (por exemplo, balanceamento de carga entre nuvens).

A nuvem pública segue o modelo de negócios pay-per-use, ou seja, o usuário utiliza um serviço disponível publicamente e esse paga conforme utiliza esse serviço. Os provedores desse modelo de nuvem são na grande maioria organizações públicas ou grandes corporações da área de TI. Isso porque necessita-se de uma grande infraestrutura para esse tipo de modelo. A nuvem privada é uma infraestrutura operada e quase sempre gerenciada pela empresa proprietária e cliente da nuvem. O gerenciamento pode ser feito por terceiros. Um exemplo de empresa que oferece o serviço de terceirização do gerenciamento de nuvem privada é a IBM ${ }^{\circledast}$. Caso uma empresa queira ter uma nuvem privada, porém não deseja gerenciá-la, esse serviço pode ser contratado. Diante desse fato, pode-se afirmar que existem dois tipos de nuvem privada: hospedada pela empresa cliente ou hospedada em provedor de serviço (Veras, 2012).

A Oracle ${ }^{\circledR}$ apresenta uma comparação entre esses dois primeiros modelos de nuvem. Os benefícios comuns entre os dois modelos são: alta eficiência; alta disponibilidade; elasticidade; rápida implementação. Os benefícios exclusivos da pública são: custos iniciais baixos; economia de escala; simplicidade para gerenciamento; e pagamento como despesas operacionais. Os benefícios da nuvem privada são citados como: a facilidade de integração; o controle da segurança, compliance e Qualidade de Serviço melhor controlados; custos totais mais baixos; despesas operacionais (Veras, 2012).

Outros dois modelos de nuvem são a comunitária e a híbrida . A primeira caracteriza-se principalmente pelo compartilhamento da infraestrutura entre organizações que possuem interesses de negócio em comum. Seu gerenciamento pode ser feito tanto por um membro ou grupo de membros da comunidade, quanto por uma empresa terceirizada. A nuvem híbrida é a miscigenação de duas

\footnotetext{
${ }^{2}$ Atividade que se apoia fortemente em processos cobertos pelo framework do Cobit (Control Objectives related to Information Technology)
} 
ou três dos modelos citados. Entretanto, cada modelo continua sendo uma entidade separada, o segredo da hibridez está na tecnologia que permite a conexão desses modelos (Veras, 2012).

$\mathrm{O}$ metaescalonador proposto nesse trabalho está inserido no modelo de nuvem privada. $\mathrm{O}$ objetivo é oferecer à empresa que utilizar o GreenMACC em sua nuvem uma Qualidade de Serviço necessária aos usuários (colaboradores da empresa) e possibilitar a utilização de técnicas verdes visando a economia de energia, a redução da emissão de gás carbônico, dentre outras.

O surgimento de um novo paradigma não acontece de um dia para o outro. A ideia, o conceito, o funcionamento, a infraestrutura não necessariamente devem ser recriadas. Isso remete a fala de Isaac Newton quando afirmou que "se vi mais longe, foi por estar de pé sobre ombros de gigantes". Esses gigantes citados são Galileu Galilei e Johannes Kepler de uma geração anterior. E esses dois se apoiaram nos ombros de outro gigante, Nicolau Copérnico. No caso da Computação em Nuvem não se fala em gerações, mas em anos. Os gigantes são todos os pesquisadores que no decorrer desses anos vêm aperfeiçoando a área de sistemas distribuídos. Todo o conceito de Computação em Nuvem não surgiu em um "big bang", veio sendo construído no decorrer desses anos. Mesmo antes desse paradigma ter sido "descoberto".

Por trás da nuvem existe uma grande infraestrutura de Data Centers espalhados por todo o globo. Esses Data Centers utilizam de virtualização para possibilitar ao usuário usufruir de serviços como infraestrutura, plataforma e software. Em alguns casos, para IaaS, pode-se encontrar casos sem virtualização como feito para alguns clientes da IBM $^{\circledR}$ e da Amazon $^{\circledR}$ por exemplo. Entretanto, a virtualização permite às empresas utilizar seus recursos de infraestrutura com mais eficiência. Os Data Centers utilizam da virtualização para serem mais eficientes e disponíveis aos usuários. Dessa forma, a virtualização possibilitou que a infraestrutura do Data Center fosse melhor aproveitada (Veras, 2012).

\subsubsection{Virtualização}

O Data Center é o elemento central de processamento e armazenamento na nuvem. A virtualização é a tecnologia central de um Data Center, podendo-se afirmar que a virtualização é uma das principais tecnologias na Computação em Nuvem. Graças a essa tecnologia é possível a abstração dos recursos físicos permitindo que vários hosts virtuais sejam criados em um host físico, ou o contrário (Peixoto, 2012).

Os hosts virtuais criados com essa técnica oferecem as características similares a um host físico. Isso permite a otimização dos recursos de um Data Center, possibilitando-se particionar os recursos de um host físico para ofertar serviços a mais de um cliente. A ideia principal é sair de um ambiente 1:1 (1 aplicação para 1 host) para N:1 (N aplicações para 1 host) ou 1:N (1 aplicação para $\mathrm{N}$ hosts) (Veras, 2011).

Pode-se conceituar a virtualização como uma camada abstrata entre hardware e software que protege e isola o acesso ao hardware. A virtualização, na grande maioria das vezes, é implementada através de um software específico. Além de tornar o gerenciamento mais simplificado, 
flexibiliza o poder de processamento e também possibilita melhorar a recuperação de desastres de ambientes computacionais tornando os custos desses procedimentos mais baixos (Veras, 2011).

Essa camada de virtualização (hypervisor), ou Monitor de Máquina Virtual (MMV), passa ao sistema operacional instruções de máquina iguais ao de um processador físico. Devido a esse fato, pode-se criar vários hosts virtualizados conhecidos como Máquinas Virtuais (MV) em um só host físico (Veras, 2012). Na Figura 2.4 é ilustrada a virtualização com o hardware.

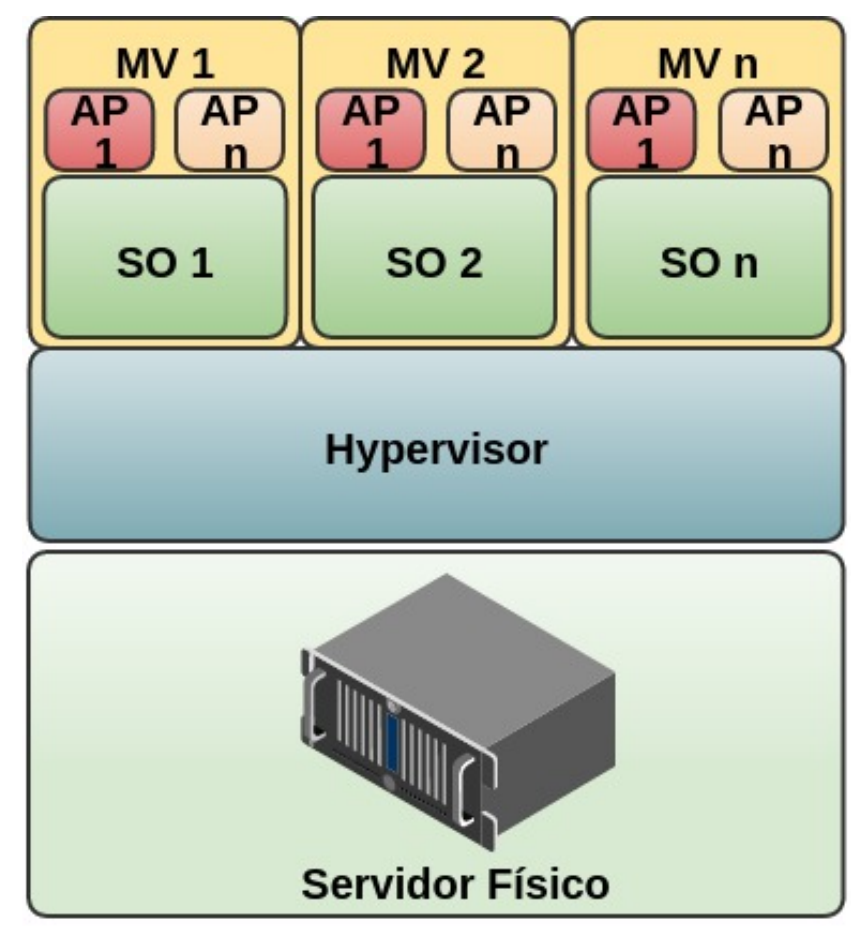

Figura 2.4: Virtualização - Figura Adaptada de Veras (2011)

A virtualização gerenciada pelo hypervisor pode ser implementada de forma completa ou paravirtualizada. A primeira cria uma abstração completa do sistema físico. O Sistema operacional e as aplicações são executados sem nenhum tipo de modificação. Porém, existe um inconveniente, o host possui um grande número de dispositivos. Esse fato torna difícil a implementação de uma máquina virtual que tenha comportamento idêntico ao do host físico. Já a paravirtualização é uma alternativa para minimizar os problema existentes no modelo anterior. A máquina virtual abstrai o hardware de forma diferente do host físico. Graças a esse fato, a MV não precisa testar cada instrução de software. Esse último em conjunto do uso de drivers específicos para o hypervisor formam um conjunto de vantagens que permitem um ganho considerável no desempenho e na eficiência no uso dos recursos (Peixoto, 2012).

Existem diversos hypervisors no mercado. No setor empresarial os principais fornecedores de software de virtualização são: VMWare ${ }^{\circledR}$ (ESX Server 3.x, VMWare ESXi e VMWare vSphere 4; Citrix $^{\circledast}$ (XenServer, Citrix Essential for XenServer e Citrix Essential for Hyper-V); Microsoft ${ }^{\circledR}$ (Hyper-V) (Veras, 2012). Podendo-se citar também o KVM (Kernel-based Virtual Machine, VirtualBox, etc. Apesar de todos terem a criação de máquinas virtuais como meta geral as características 
de implementação podem variar. Cada um desses citados também possuem objetivos específicos (Peixoto, 2012).

\subsubsection{Data Center}

Um Data Center (DC) ou centro de dados "é um conjunto integrado de componentes de alta tecnologia que permite fornecer serviços de infraestrutura de valor agregado, tipicamente processamento e armazenamento de dados, em larga escala, para qualquer tipo de organização"(Veras, 2009).

Os Data Centers na década de 60 eram centralizados e utilizavam grandes mainframes. Na década de 70, outras empresas além da IBM começaram a produzir esse tipo de equipamento. Na década de 80 , os microprocessadores surgiram colocando o poder de processamento ao alcance dos engenheiros e cientistas. O início da era cliente/servidor iniciou no momento que os microcomputadores e os mainframes começaram a comunicar entre si. Era o primeiro passo para o processamento distribuído. No inicio da década de 80 a descentralização foi crescendo e ao chegar a década de 90, a World Wide Web (Berners-lee et al., 1994) é adotada em conjunto da Internet como uma via de conexão com o mundo. No inicio desse milênio foram lançados os processadores multicore que em conjunto da ampliação da Internet possibilitou-se novamente a centralização e o termo Data Center veio novamente à tona (Veras, 2009).

Existem duas formas de categorizar um Data Center: tamanho e posse. Categorizar um Data Center pelo seu tamanho tem como objetivo oferecer uma classificação do porte do Data Center. Esses Data Centers podem ser empresarial, de médio porte, local, uma sala de servidores e por fim um armário de servidores. O fato dele ser privado ou não, independe desse tipo de categoria. Ao contrário da categoria caracterizada pela posse do Data Center. Essa última oferece duas modalidades: Enterprise Data Center (EDC) e Internet Data Center (IDC). A primeira modalidade caracteriza que o Data Center pertence e é operado por empresas privadas e instituições governamentais (Veras, 2009). A segunda remete a Data Centers que pertencem a empresas especializadas na oferta de serviços e tem como principal meio de comunicação a Internet (Shon et al., 2014).

A construção de um Data Center exige toda uma infraestrutura como: cabeamento; sistema de refrigeração e de controle de umidade; sistema de prevenção contra incêndio; segurança física; espaço físico para os Racks e piso elevado. Na década passada já era possível colocar os Racks em sistemas embutidos como contêineres. Todo esse equipamento deve ficar em uma sala-cofre que é um ambiente estanque, ou seja, isolado e protegido fisicamente de incêndio, umidade, acesso de pessoas não autorizadas, etc. Ou seja, o custo para sua construção é alto e a energia consumida é elevada (Veras, 2009). Todos essas ações na construção de um Data Center já são tomadas desde o nascimento da Computação em Nuvem e continuam atualmente. Para se tomar uma decisão da construção de um Data Center todos esses fatores devem ser avaliados, mas não somente esses. A posição geográfica e a infraestrutura ofertada fora do Data Center também são fatores importantes na tomada de decisão. 
Normalmente um Data Center segue um modelo proposto pela $\mathrm{Cisco}^{\circledast}$ com base em uma arquitetura tecnológica hierárquica. O modelo é o mesmo de projeto de redes. A mudança está na camada de distribuição que é substituída pela de agregação. Esta forma de construção da arquitetura também está de acordo com a norma ANSI/TIA-942 ${ }^{3}$. Essa arquitetura vem sendo testada e validada em Data Centers de todo mundo a muitos anos (Veras, 2012).

Os principais recursos físicos de um Data Center são: processamento, armazenamento e conectividade. A virtualização vem para otimizar o uso desses recursos agregando-os e podendo oferecer um conjunto de elementos virtuais e uniformes. Com a virtualização um Data Center virtual oferece os mesmos recursos citados pelo Data Center físico só que de uma forma mais eficiente (Veras, 2012).

Há poucos anos atrás a eficiência do Data Center era medida através de dois indicadores: disponibilidade e desempenho. Com o movimento criado pela Computação Verde outros aspectos começaram a ser observados e graças a esse fato o Green Grid ${ }^{4}$ criou duas métricas: PUE (Power Usage Effectiveness) e o DCiE (Data Center Efficiency). A PUE é o resultado do valor total de energia consumida pelo Data Center captada pelo medidor de alimentação de energia, dividido pela energia consumida de todos equipamentos de TI. E a segunda métrica é definida através da formula DCiE = 1/PUE. Graças a essas duas métricas permite-se comparar Data Centers para se ter uma noção real da eficiência e do consumo de energia de cada um desses Data Centers (Veras, 2012).

A busca por soluções verdes na área de Computação em Nuvem vem crescendo diariamente. Graças a esse fato, vem surgindo novos trabalhos nessa área que visam contribuir para a redução do consumo de energia e também para a redução da emissão de gás carbônico na atmosfera. A seção a seguir, apresenta alguns desses trabalhos.

\subsection{Trabalhos Relacionados}

As áreas de Computação Verde e Computação em Nuvem dispõem de um leque de opções de pesquisa bastante vasto, tais como: arquitetura do hardware, segurança, infraestrutura, dentre outras. Considerando-se esse fato, fica inviável apresentar todos os trabalhos de todos os setores de pesquisa em Computação Verde nessa seção. Dessa forma, os trabalhos apresentados foram selecionados buscando apresentar soluções que não fujam do tema desta tese, que é a redução do consumo de energia e emissão de gás carbônico.

Dispositivos móveis como smartphones, laptops e tablets também fazem parte do contexto da Computação Verde na nuvem, afinal atualmente é possível ter acesso a serviços oferecidos na nuvem através desses dispositivos. A busca por eficiência energética é fundamentada devido ao limite tecnológico atual da bateria desses dispositivos. Para se carregar um dispositivo desses

\footnotetext{
${ }^{3}$ Norma americana que se aplica na infraestrutura de um Data Center (Veras, 2009)

${ }^{4}$ Consórcio global formado em 2007 por empresas como Dell, Intel, VMWare, AMD e outras, visando definir práticas adequadas a eficiência energética em Data Centers.
} 
usa-se energia elétrica, ou seja, reduzindo-se o consumo da bateria essa poderá ser utilizada por mais tempo, aumentando-se o tempo entre os carregamentos. Diante disso, pode-se afirmar que diminuir o consumo da bateria reduz o número de carregamentos em um determinado período de tempo, ou seja, economiza-se energia elétrica.

No ano de 2013, o número de dispositivos móveis ultrapassou o número de habitantes no nosso planeta. Entre 2012 e 2017 o tráfego de dados nesses dispositivos aumentará 13 vezes. Os principais responsáveis por esse aumento são os vídeos com participação de quase $70 \%$ do tráfego total. Os vídeos considerados são os já existentes na Internet e os de video conferência. Em ambos os casos, o consumo de energia é relevante (Kennedy e Muntean, 2014).

O trabalho de Kennedy e Muntean (2014) propõe um algoritmo que aumenta a eficiência energética de aplicações de streaming. A economia é alcançada graças a ajustes dinâmicos da potência de transmissão e de qualidade do vídeo. Nesse trabalho foram obtidos resultados significativos onde a economia de energia chega a quase $20 \%$. Se existirem mais de 2 dispositivos na rede a economia pode alcançar a $58 \%$.

A rede também pode ser um setor de pesquisa para redução do consumo de energia. O uso de novas tecnologias nos equipamentos e de técnicas inovadoras para a transmissão de dados sem dúvida são pontos importantes de pesquisa. Sabe-se que para uma rede ser estável e protegida contra falhas a replicação de recursos é necessária. Entretanto, essa garantia contra um cenário de falha da rede demanda mais energia (Perelló et al., 2014).

O trabalho de Perello et al.(2014) enfatiza o uso de fibras óticas e de ajustes dinâmicos nas taxas dos transpônderes ${ }^{5}$ de acordo com o tráfego de dados. Em redes com altas capacidades qualquer falha pode ser um sério problema se não houver a replicação. Com esses ajustes automáticos propostos é possível não perder a robustez e ao mesmo tempo reduzir os gastos com energia. Utilizando-se dessa técnica pôde-se obter uma economia de energia de até $36 \%$.

Um fator importante na Computação em Nuvem é a possibilidade da oferta de serviços geograficamente distribuídos o que contribui com o equilíbrio da distribuição de carga de trabalho e do tráfego. Outra vantagem dessa distribuição é a possibilidade da otimização do consumo de energia (Addis et al., 2014).

No trabalho de Addis et al.(2014) é apresentada uma estrutura de otimização que coleta dados do sistema que permitem calcular o potencial de economia no consumo de energia além de mostrar os parâmetros relevantes para o desempenho geral do sistema. A programação da utilização de recursos e a alocação de carga é feita em um ponto central de decisões. A estrutura considera um cenário de Plataforma como Serviço e as máquinas virtuais são distribuídas em Data Centers distribuídos geograficamente, onde são executados os serviços. Os resultados demonstram que o formato do mapa de interligação dos Data Centers influenciam diretamente no consumo de energia.

\footnotetext{
${ }^{5}$ Dispositivo eletrônico utilizado na área de redes de computadores e de telecomunicação que recebe, amplia e transmite sinais para outros dispositivos da rede. Cada transpônder pode usar várias frequências e polarizações, com a finalidade de aumentar a largura de banda disponível. (J. Wetherall e Tanenbaum, 2011).
} 
As pesquisas na área da Computação Verde atualmente estão se preocupando cada vez mais com o consumo de energia dos Data Centers. O motivo desse interesse se faz graças ao considerável crescimento da Computação em Nuvem. Esse crescimento trás consigo o aumento do consumo de energia o que pode afetar a imagem pública e a viabilidade econômica desse novo paradigma (Arjona Aroca et al., 2014).

Sabe-se que uma parte do consumo de energia dos Data Centers pode ser reduzida, tornandose, desta forma, uma questão fundamental. Esta economia foi demonstrada em um trabalho que prevê o desligamento de hosts e servidores quando não estiverem em uso (Duy et al., 2010).

O trabalho de Aroca et al. (2014) apresenta um estudo visando compreender o comportamento do consumo de energia em diferentes servidores. O objetivo foi medir a energia consumida de vários pontos dos servidores como CPU, disco e rede. As duas principais contribuições apresentadas nesse trabalho são: a proposta de uma caracterização empírica do consumo de energia de um servidor e o fornecimento de novas informações do consumo de energia dos três componentes já citados do servidor. Algumas soluções para economia de energia são sugeridas como por exemplo desligar núcleos em tempo de execução. Outro ponto é que os discos ficam em segundo lugar no quesito de consumo de energia dos dispositivos testados, perdendo apenas para a CPU. A rede tem uma menor parte da responsabilidade do consumo, mas não deve ser desprezada. Devido à forma com que os pacotes são tratados pela pilha de protocolos a rede não é energeticamente eficiente, fazendo com que a construção de uma pilha de protocolos mais eficiente seja um ponto a ser melhor pesquisado buscando-se a economia de energia. Outra contribuição desse artigo é a afirmação que o gasto de energia nos servidores não é linear em relação ao crescimento do processamento. Esse trabalho apresentou um modelo para otimizar o consumo de energia e obteve resultados que mostram redução de $7 \%$ no consumo.

Como mencionado anteriormente a emissão de $\mathrm{CO}_{2}$ na atmosfera está diretamente ligada ao consumo de energia. Há trabalhos que demonstram que a implantação de um novo aplicativo para ofertar um novo serviço em um Data Center pode influenciar diretamente no consumo de energia. Pesquisar novos caminhos que visam apoiar o projeto de processos de otimização e configuração da implantação de um novo aplicativo em um Data Center torna-se uma necessidade. Medir e monitorar são ações que visam auxiliar o projetista de software na decisão de como modificar o processo de implantação desse aplicativo. Essa modificação se faz necessária diante de casos de ineficiência do sistema, ou se ainda há formas de melhoria (Cappiello et al., 2013).

Cappiello et al. (2013) afirma em seu trabalho que existe pouca atenção ao real impacto que o projeto e a implantação de um aplicativo têm em um sistema otimizado para obter eficiência energética. Esse trabalho apresenta uma proposta de otimizar o projeto e a implantação de um aplicativo em um Data Center. Isso é possível monitorando em tempo de implantação o consumo de energia, a emissão de $\mathrm{CO}_{2}$ e a satisfação de requisitos de desempenho medidos por indicadores adequados. Os resultados de monitoramento apresentados ao projetista visa auxiliá-lo na tomada de decisão para ações de adaptação. A ponderação entre o grau de requisitos verdes e desempenho tem como base os requisitos funcionais dos serviços prestados. Nesse trabalho afirma-se que 
através de monitoração obtêm-se resultados que auxiliam nas ações de adaptação da aplicação e que são de grande valia ao projetista de software para alcançar eficiência energética. E ainda que isso é possível em tempo de projeto dependendo diretamente da definição de variantes que compõem o processo de negócio. O conjunto de dados utilizados no trabalho para a tomada de decisão do projetista são: porcentagem de utilização dos recurso da máquina virtual (memória e CPU); número de operações realizadas dentro de um espaço de tempo determinado; consumo de energia em um determinado espaço de tempo; quantidade de $\mathrm{CO}_{2}$ emitido para execução da aplicação; relação entre o processamento da MV e a energia consumida; tempo de resposta de uma requisição.

Um foco constante da Computação Verde na nuvem é a redução do consumo de energia nos Data Centers. Entretanto, pouco se pesquisa a economia do lado do cliente. O consumo de energia do lado do servidor sem dúvida deve ser reduzido. E com esse mesmo pensamento, a economia do lado do cliente não deve ser desprezada, pois essa economia é relevante quando considerados os muitos clientes que uma nuvem possui (Chachar e Kulkarni, 2014).

Chachar e Kulkarni (2014) propõem em seu trabalho o uso de um algoritmo de balanceamento dinâmico que partilha os recursos entre servidor e cliente para obter economia de energia em ambos os lados, ou seja, obter eficiência energética tanto do lado do Data Center quanto do lado do cliente. A ideia é receber todas as solicitações do cliente de uma só vez e o algoritmo apresentado consegue encaminhar o pedido para o Data Center. No final desse processo, somando-se a redução de energia de ambos os lados, obtêm-se uma economia de $29 \%$ em comparação ao sistema sem o algoritmo apresentado.

Um Data Center na média consome de energia o equivalente à 25 mil residências. Recentemente foi criado um consórcio mundial com alguns dos maiores prestadores de serviços na nuvem. O objetivo é a busca por eficiência energética no funcionamento dos Data Centers sem perder a qualidade na prestação dos serviços (Al-Sulami et al., 2014).

A busca por uma nuvem mais verde tem incentivado trabalhos como o de Al-Sulami et al. (2014) que faz um estudo de alguns dos métodos utilizados nos Data Centers que conseguem obter resultados relevantes para a economia de energia e redução da emissão de gás carbônico na atmosfera. Cita-se nesse trabalho recomendações como o uso de energias renováveis como a eólica e a solar pelos Data Centers. Para obter economia de energia cita-se a redução do número de conversões entre as correntes contínua e alternada no Data Center. A ideia principal dessa última técnica é permitir uma única vez a conversão. A adoção de cautela antes da compra de hardware para os Data Centers também é citada nesse trabalho como uma atitude ecologicamente sustentável.

Quando fala-se de Computação em Nuvem a primeira imagem que vem a mente são Data Centers de grande porte de corporações internacionais. Entretanto, para oferta de serviços na nuvem pode-se ter os chamados mini Data Centers verdes distribuídos. A ideia fundamental desses Data Centers de pequeno porte é construí-los de uma forma que eles sejam baratos e eficientes e devem ser instalados ao lado das estações de geração de energia. Essa estratégia visa eliminar as 
grandes e caras infraestruturas de transmissão de energia. Além disso, para que esses Data Centers estejam ainda mais inseridos no contexto da Computação Verde em nuvem podem ser instalados próximos a geradoras de energia renovável como eólicas ou solares por exemplo. Este modelo de mini Data Centers verdes distribuídos melhora a eficiência e facilita a produção de energia renovável. Este modelo trás consigo o potencial de reduzir custos na infraestrutura de transmissão de energia (Bird et al., 2014).

São muito os trabalhos existentes na área de Computação Verde e de Computação em Nuvem. $\mathrm{Na}$ busca por literatura em ambos os temas pode-se encontrar diversos trabalhos que unem esses dois em um só, o que permite afirmar que os dois temas podem ser trabalhos em conjunto. Nessa seção pôde-se observar que a Computação Verde na nuvem é um tema de pesquisa em pleno desenvolvimento e tende a crescer cada vez mais.

\subsection{Considerações Finais}

Neste capítulo foi apresentado um tema de pesquisa que está em pleno crescimento. A Computação Verde na nuvem tem como base a Computação Verde e a Computação em Nuvem.

A Computação Verde surge com objetivos claros de oferecer formas de se obter desenvolvimento sustentável na utilização de recursos do setor de Tecnologia da Informação. A preocupação principal está na busca por eficiência energética, a redução de emissão de gases nocivos ao meio ambiente e por último, mas não menos importante, a fabricação, uso e descarte de equipamentos de TI de uma forma ambientalmente equilibrada.

Mesmo que as empresas não tenham como foco a preocupação com um planeta eco-sustentável, e uma visão ambiental correta, a redução de energia e, consequentemente, a redução de $\mathrm{CO}_{2}$ oferece uma outra vantagem: a redução nos custos operacionais. Inclusive algumas empresas tem dificuldades de achar locais com uma oferta suficiente de energia para atender sua demanda, e esse seria outro bom motivo para economizar energia (Grossman, 2011).

A Computação em Nuvem é um paradigma relativamente novo da área de sistemas distribuídos. Esse paradigma possui quatro modelos de implantação. Esses modelos caracterizam quem gerencia e quem é (são) o(s) proprietário(s) da nuvem. Uma nuvem pode oferecer um software como serviço, uma plataforma como serviço ou uma infraestrutura como serviço.

Através da busca por pesquisas nas áreas de Computação Verde e Computação em Nuvem, pode-se encontrar diversos trabalhos que unem os objetivos da Computação Verde na Computação em Nuvem. Essa área é chamada de Computação Verde na Nuvem.

O próximo capítulo visa apresentar conceitos e pesquisas na área de metaescalonamento e escalonamento em Computação em Nuvem que buscam eficiência e respeito à Qualidade de Serviço (QoS). Também são apresentadas políticas que utilizam de técnicas de Computação Verde. 


\section{Metaescalonamento e Escalonamento na Nuvem}

\subsection{Considerações Iniciais}

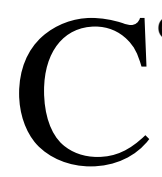

Om o decorrer do tempo, a Computação em Nuvem vem se tornando cada vez mais popular, e a demanda por processamento de alto desempenho cresce de forma diretamente proporcional (Baliga et al., 2011). Em conjunto da real necessidade da gestão eficiente do consumo de energia, é que se tem a Computação em Nuvem e a Computação Verde como duas áreas que podem andar juntas, tornando-se uma nova área, a Computação Verde na Nuvem. Essa nova área de pesquisa oferece serviços dos mais variados ao usuário. Esses serviços precisam ser ofertados de uma maneira eficaz e eficiente. Para que isso ocorra, o metaescalonador é uma peça fundamental no paradigma de Computação em Nuvem. O metaescalonador projetado para esse paradigma tem como função principal oferecer o serviço ao usuário de forma eficiente, transparente e com Qualidade de Serviço gerenciando as políticas de escalonamento em todos os níveis de uma nuvem.

$\mathrm{Na}$ literatura existem diversos trabalhos que tratam do metaescalonamento em Computação em Nuvem. Esse metaescalonamento trabalha em dois níveis da nuvem. No primeiro nível temse apenas um estágio, o estágio de escolha do Data Center. Esse estágio preocupa-se com a escolha de qual Data Center deve assumir o serviço requisitado pelo usuário (cliente). No segundo nível, ou no nível do Data Center, pode-se desenvolver políticas de escalonamento para 3 estágios distintos. O primeiro estágio desse nível preocupa-se com a criação das Máquinas Virtuais (MVs). Ou seja, as políticas desenvolvidas para esse estágio se preocupam com as características das 
máquinas virtuais a serem criadas nos hosts do Data Center. O segundo estágio é responsável pela distribuição e alocação das máquinas virtuais criadas no estágio anterior. As políticas de escalonamento desenvolvidas para o terceiro e último estágio no nível do Data Center têm como objetivo distribuir e alocar as tarefas (tasks) nas máquinas virtuais criadas no primeiro estágio e alocadas no segundo estágio.

Nesses dois níveis do metaescalonamento na nuvem pode-se encontrar, em diversos trabalhos, políticas de escalonamento com objetivos diversos. Algumas primam pela eficiência no tempo de entrega do serviço visando cumprir o contrato como o usuário. Esse contrato, definido na literatura como SLA (Service Level Agreement), tem em seus termos dados que especificam a forma como o serviço deve ser entregue ao usuário. Se esse serviço for entregue de acordo com o contrato firmado pode-se afirmar que tem-se Qualidade de Serviço (QoS - Quality of Service). Nesta tese, a QoS está relacionada diretamente ao tempo de retorno do serviço e consequente não quebra do deadline estipulado. Outra vertente de políticas para Computação em Nuvem são as que têm como objetivo oferecer o serviço ao usuário de forma ecologicamente correta e energeticamente eficiente. Essas políticas são denominadas como políticas de escalonamento verdes.

O objetivo principal desse capítulo é discutir e apresentar o estado da arte na área de escalonamento e metaescalonamento na nuvem. Os algoritmos de escalonamento, independentemente de qual estágio eles são projetados para atuar, desempenham um papel fundamental nos sistemas de Computação em Nuvem (Zhao et al., 2009). Dessa forma, o gerenciamento dessas políticas é importante para que o serviço oferecido na nuvem seja entregue ao usuário da forma mais próxima do ideal. Dentro desse contexto, o metaescalonador aparece como um dos responsáveis por garantir a satisfação do usuário em uma nuvem computacional.

Independente de para qual estágio do metaescalonador a política foi projetada, pode-se observar na literatura duas grandes vertentes. As políticas que têm a QoS como objetivo e as políticas verdes. Ambas têm suas importâncias e são relevantes para que o serviço seja entregue ao usuário. A primeira vertente possui trabalhos relevantes e que são apresentados na seção 3.2. As políticas verdes são discutidas na seção 3.3. Na seção 3.4 os trabalhos que apresentam metaescalonamento como foco são apresentados e discutidos.

\subsection{Políticas de Escalonamento para Garantia da QoS}

Desde o início da computação, os pesquisadores e a indústria vêm buscando aprimorar a eficiência no desempenho dos computadores. Quanto mais rápida a execução das tarefas e menor o tempo de resposta, melhor. Esse fato também é verdade na Computação em Nuvem, que é um paradigma em sistemas distribuídos, área em que eficiência e tempo médio de resposta são variáveis relevantes na avaliação desses sistemas. A importância se dá devido a necessidade da entrega do serviço dentro do contrato estipulado com o usuário com o objetivo de manter-se a QoS. 
Existem diversos trabalhos que buscam melhorar o desempenho na nuvem. A utilização de algoritmos genéticos para problemas de escalonamento em nuvem, utilizando técnicas como seleção natural e teoria da herança ${ }^{1}$, foi apresentado no trabalho de (Zhao et al., 2009). Esta técnica utiliza um modelo que possui uma unidade central que gerencia a alocação de todos os serviços nos outros hosts. Cada um desses hosts possui sua própria fila de recebimento. A unidade principal utiliza essas filas para se comunicar com as demais. Desta forma, a unidade central trabalha sincronizada com as outras unidades, possibilitando distribuir as novas tarefas e atualizar as filas de recebimento. A ordenação das tarefas nas filas é dependente do seu deadline.

Definido o modelo da nuvem, o artigo especifica o escalonador baseado em algoritmos genéticos. São definidos dois tipos de vetores: o CRV (Capabitity Requirement Vector) e o CSV (Capability Supply Vector). O primeiro refere-se às tarefas a serem executadas e o segundo às unidades de processamento (UP). A proposta é usar regras que têm a genética como essência. Ou seja, tem-se uma população inicial e um número de cromossomos referentes a cada indivíduo (tarefa). Inicia-se aleatoriamente a distribuição e caso alguma tarefa não cumpra o prazo estabelecido, recebe uma punição. Essa punição de forma prática pode ser uma variável que tem seu valor decrescido. Desta forma, o algoritmo vai exercendo um mecanismo competitivo entre os indivíduos. No final de um tempo pré-estabelecido compara-se os valores dessa variável de cada tarefa. Os menos punidos são considerados como melhores indivíduos e cruza-se seus cromossomos com os mais punidos. Com essa ação tem-se como objetivo melhorar os indivíduos mais punidos convergindo para um procedimento mais eficiente. Considera-se também o uso de um processo de mutação, técnica bastante usada em algoritmos genéticos.

Tendo-se os algoritmos evolutivos ainda como foco, em (Pandey et al., 2010) é apresentada uma heurística baseada em enxame de partículas para escalonamento em Computação em Nuvem. A ideia inicial baseia-se em uma teoria da área biológica, da qual se toma a inteligência coletiva como fundamento principal para a decisão no escalonamento de tarefas. Tem-se como exemplo as abelhas na defesa de sua colmeia e na produção de alimento, ou as zebras que andam em grupo para aumentar suas chances de sobreviver a um ataque de um predador. Analogamente nesse caso específico, as tarefas que devem ser escalonadas são as abelhas ou as zebras citadas anteriormente. O algoritmo baseado em enxames de partículas igualmente aos demais algoritmos evolutivos iniciase aleatoriamente e cada indivíduo (tarefa) tem um valor (variável) que será otimizado em cada geração.

Atualmente, busca-se cada vez mais otimizar o escalonamento visando reduzir o tempo de execução, mas isso não é exclusivo à área de Computação em Nuvem. Nas aplicações que exigem computação de alto desempenho (HPC - High Performance Computing) essa redução é fundamental. O uso de HPC na nuvem tem crescido nos últimos anos e os cuidados para buscar cada vez mais eficiência nesse contexto aumentou consideravelmente. O trabalho apresentado por (Khalid

\footnotetext{
${ }^{1}$ Teoria utilizada em algoritmos genéticos. Essa teoria se baseia na técnica de utilização de características para cada indivíduo e após o cruzamento de dois indivíduos é gerado um novo indivíduo que herda as características de seus "pais".
} 
et al., 2010), que está dentro do contexto de HPC, apresenta um escalonador que se preocupa com o prazo de término (deadline) de uma tarefa em execução nas máquinas virtuais. O objetivo é corrigir atrasos na execução das tarefas em tempo de execução.

Esse escalonador proposto por (Khalid et al., 2010) baseia-se em 3 métricas, onde a primeira mede o número total de tarefas completadas em um certo período de tempo, o segundo refere-se ao número de tarefas com seu deadline próximo a vencer e, a última métrica é a taxa de utilização da CPU e da memória. Essa última é necessária para medir-se quanto tempo cada recurso se manteve ativo. Baseando-se nestas métricas tem-se a tomada de decisão para um escalonamento em tempo de execução, que visa manter QoS e aumentar o desempenho de execução do serviço na nuvem.

O uso da Computação em Nuvem tem se fortificado no mercado a cada dia. Diversas empresas oferecem serviços na nuvem, assim como muitas outras usufruem desse aparato disponível visando à redução de custos com infraestrutura, suporte técnico e profissionais, dedicados à estrutura de TI. A segurança ainda é um ponto decisivo para a empresa decidir o uso da nuvem, entretanto a redução de custos torna-se um fator relevante na tomada de decisão. No trabalho de (Moschakis e Karatza, 2010) é apresentado o Gang Scheduling, uma política de escalonamento que é aplicada em um modelo de Computação em Nuvem já existente e presente no mercado, o Amazon Elastic Compute Cloud (Amazon EC2 ${ }^{\circledR}$ ).

O Gang Scheduling tem estratégias de alocação e de execução de tarefas bem definidos. A alocação das tarefas é feito pelo Dispatcher Virtual Machine (DVM). Caso o número de tarefas for menor ou igual à quantidade de máquinas virtuais, a tarefa é enviada no mesmo momento para uma MV sem fila. Entretanto, caso exista mais tarefas do que MV disponíveis, cada MV terá sua própria fila de tarefas. O DVM utiliza o algoritmo Shortest Queue First (SQF), isto é, aloca a tarefa sempre na máquina virtual com menor fila. Após alocada a tarefa, a MV precisa tomar a decisão de qual tarefa tem prioridade na execução. Para essa decisão os autores optaram por utilizar duas técnicas que são avaliadas no artigo, o AFCFS (Adaptative First Come First Served) e o LJFS (Largest Job First Served), muito utilizadas nas grades computacionais (Moschakis e Karatza, 2010).

O sistema ainda implementa um processo de ciclo de vida das máquinas virtuais de forma dinâmica, baseando-se em adequar a quantidade de MVs para servir a quantidade de trabalho existente. Ele ainda as cria e gerencia a sua eliminação quando ociosa, e verifica se a eliminação de uma MV não ocasionará nenhuma falta na execução do processo em andamento (Moschakis e Karatza, 2010).

A técnica de Backfilling é utilizada em sistemas distribuídos há anos e vem sendo utilizada em alguns trabalhos que visam a melhora da Qualidade de Serviço oferecida ao cliente. O trabalho de (Suresh e Vijayakarthick, 2011) apresenta uma análise e aprimoramento de políticas de escalonamento que utilizam Backfill, ou seja, priorizam as tarefas menores de forma conservadora. Isso quer dizer que a tarefa menor passa para a frente da fila caso não afete o tempo de nenhuma das tarefas que estão primeiro na fila. Para esse trabalho foi utilizado o simulador CloudSim (Ca- 
lheiros et al., 2009). Os resultados mostram que o uso desse tipo de técnica além de permitir escalonamento dinâmico também pode ajudar na garantia do respeito a QoS.

As políticas de escalonamento em sistemas distribuídos são um assunto vasto, com abordagens diversas e com número de propostas aumentando continuamente. Quando surgem paradigmas novos como a Computação em Nuvem, tende-se a buscar novas formas de escalonamento, entretanto algumas técnicas podem ser reutilizadas. O trabalho de (Assunção et al., 2010) avalia sete estratégias de escalonamento voltadas ao nível de infraestrutura para Computação em Nuvem.

As sete estratégias avaliadas são: natural ou ingênuo, ou seja o algoritmo verifica se o pedido pode iniciar de imediato na nuvem. Se puder, ele é enviado, caso contrário, entra em um fila. A estratégia de fila mais curta usa o escalonamento FCFS (first come first served) e calcula um índice que é proporcional ao número de máquinas virtuais exigidas pelos pedidos na fila, pelo número de processadores disponíveis no sistema. Caso o índice da nuvem seja menor que o do cluster (estrutura local), o algoritmo modifica a lista de requisições redirecionando-as para a nuvem, visando a equilibrar os dois índices. A Fila ponderada é uma extensão da anterior e mede a quantidade de requisições de MVs existentes no cluster e na nuvem. De posse dessa informação, o algoritmo equilibra a quantidade de requisições com o limite máximo da nuvem. Em tempo real envia as solicitações para nuvem até o seu limite máximo ser alcançado.

A quarta estratégia é a seletiva com a mesma abordagem de fila das anteriores, e que se diferencia pelo fato de que na verificação do fator que determina o tamanho da capacidade máxima da nuvem, e percebendo-se que está no limite, o algoritmo verifica o momento em que provavelmente a requisição será executada na nuvem e também verifica quando será executada no cluster local. De posse desses tempos, o algoritmo aloca onde provavelmente será executado primeiro. Já no modelo conservativo o algoritmo verifica se o cluster pode executar, e em caso negativo, verifica na nuvem. Caso ela possa executar, é feito o direcionamento. Caso a resposta também seja negativa, o algoritmo verifica qual será o que provavelmente atenderá primeiramente a requisição. Outra estratégia é a agressiva: no começo da chegada das requisições é criado um escalonador preliminar que se baseia na técnica de priorizar a execução dos que estão com o deadline acabando, ou seja, verifica se localmente é possível atender à requisição sem o risco de desrespeitar o deadline. Caso exista o risco, envia-se para a nuvem.

Finalmente, tem-se a estratégia conservativa com suporte de reserva, que verifica se a requisição exige o melhor esforço (besteffort) ou é uma requisição de reserva de recursos. No primeiro caso, a requisição é encaminhada para o site local (cluster), no segundo caso, verifica-se se há a possibilidade de ser resolvido localmente. Em caso negativo, verifica-se a disponibilidade da nuvem, se não existir, então, a requisição de reserva é rejeitada (Assunção et al., 2010).

Nesta seção foram apresentados alguns trabalhos de políticas de escalonamento que priorizam o desempenho e o respeito ao contrato visando prover QoS. Na próxima seção são apresentados estudos existentes na literatura que visam o escalonamento verde na Computação em Nuvem. 


\subsection{Políticas de Escalonamento Verde}

Essa seção tem como objetivo apresentar o estado da arte das políticas de escalonamento verde na nuvem. Em um ambiente de Computação em Nuvem, os recursos não utilizados respondem por uma quantidade significativa do consumo de energia. Enfatiza-se que na Computação em Nuvem, devido ao uso da virtualização, a estratégia na alocação de recursos melhora a eficiência energética, impreterivelmente (Lee e Zomaya, 2010).

A busca por otimização do Data Center e da satisfação do usuário é constante. O aumento da demanda na Computação em Nuvem vem tendo como consequência a criação de Data Centers cada vez maiores. Esse fato contribui diretamente com o aumento da atenção dos pesquisadores para a eficiência de energia, exigindo cada vez mais soluções verdes que consideram de forma conjunta os aspectos ambientais e econômicos (Bruneo et al., 2013).

Nos trabalhos existentes na literatura atual encontram-se pontos específicos que são estudados visando um escalonamento verde eficiente. Estes pontos, que neste trabalho serão chamados de Pontos de Análise para Decisão no Escalonamento Verde (PADEVE), são: Processador, Rede, Refrigeração e Emissão de $\mathrm{CO}_{2}$.

\subsubsection{PADEVE - Pontos de Análise para Decisão no Escalonamento Verde}

O escalonador precisa analisar pontos específicos para tomada de decisão. A análise desses pontos dependem do objetivo específico de cada uma das políticas de escalonamento em questão. Nos trabalhos que envolvem escalonamento onde a Computação Verde na Nuvem é a preocupação principal, tem-se basicamente 4 pontos de análise para decisão (PADEVE): processador, rede, refrigeração e emissão de gás carbônico. As quatro subseções a seguir dividem os trabalhos existentes na literatura tendo os 4 pontos de análise como referência. É relevante ressaltar que uma política de escalonamento não necessariamente deve usar apenas um PADEVE. Ou seja, a mesma técnica pode utilizar mais de um PADEVE para sua tomada de decisão.

\section{Processador}

O ponto de análise mais trabalhado na literatura para escalonamento verde é o processador. Uma das técnicas utilizadas para economia de energia é o DVFS (Dynamic Voltage and Frequency Scaling) (Laszewski et al., 2009) (Liu et al., 2009) (Lago et al., 2011) (Zhang e Chang, 2014) (Cao e Zhu, 2013) (Hosseinimotlagh e Khunjush, 2014). A velocidade ou frequência (GHz) do processador é um ponto muito observado para gerenciar o desempenho do sistema. Normalmente quanto maior a frequência melhor será a resposta do sistema como um todo. Entretanto o consumo de energia aumenta proporcionalmente. Os computadores modernos, em sua grande maioria, suportam uma carga de trabalho simples utilizando-se de DVFS. O sistema se adapta de acordo com 
a carga imposta. Se exige-se uma alta carga de trabalho a frequência da CPU aumenta. Com a carga de trabalho mais baixa o efeito é contrário, ou seja, o clock diminui para economizar energia (Zhang e Chang, 2014).

No trabalho de Laszewski et al.(2009) tem-se o DVFS como principal fator para o escalonamento. Duas regras básicas são levadas em consideração no escalonamento proposto: a redução de consumo de energia do EP (Elemento de Processamento) em uso e a escolha do EP que tem o menor consumo. Ainda no ano de 2009 uma nova arquitetura foi proposta, a Green Cloud (Liu et al., 2009). Nesta arquitetura é proposto um escalonamento que se baseia também na economia de energia utilizando o DVFS como item principal. Nesse trabalho propõe-se a distribuição da carga de trabalho primeiro e depois propõe o desligamento dos hosts inativos. Já o escalonamento proposto por Lago et al. (2011) propõe o desligamento de hosts subutilizados, migração de MVs e utilização de DVFS para redução de energia consumida.

O escalonador "Cool" (Zhang e Chang, 2014) tem como objetivo maximizar a economia de energia, de uma forma que não viole o contrato com o usuário (SLA), ajustando a frequência da CPU. Esse ajuste é feito analisando as fases de CPU-intensive e de Memory-intensive. Quando o sistema está em uma fase de memory-intensive o escalonador proposto reduz ao mínimo a frequência da CPU. Quando a fase de CPU-intensive inicia, a frequência volta a aumentar. Esse ajuste é feito em tempo de execução da aplicação e precisa ser utilizado em um ambiente multi-core, por depender de divisão das tarefas em threads. Essa ação permite com que ocorra economia de energia com o uso dessa técnica.

Existem outras formas de escalonamento analisando o processamento em conjunto com outros PADEVEs. Existem propostas que, para o escalonamento, podem verificar o consumo de energia do processador e também analisar o consumo de energia do ar condicionado, custo de energia e emissão de $\mathrm{CO}_{2}$ (Garg et al., 2010). Já outros trabalhos focalizam exclusivamente no processador se preocupando na distribuição das MVs de forma a sobrecarregar o processamento de alguns hosts para deixar outros sem carga e desligá-los, ou até calcular a média do tempo de processamento necessário da tarefa a ser executada em um host e com base nessa informação fazer o escalonamento desligando os hosts sem uso (Lee e Zomaya, 2010).

O algoritmo proposto por (Lee e Zomaya, 2010) pode gerir os recursos na nuvem, reduzindo o uso dos hosts, seja desligando-os quando ociosos ou até hibernando-os. Os algoritmos ECTC (Energy Conscious Task Consolidation) e MaxUtil possuem esse perfil. A ideia principal é encontrar qual o recurso mais energeticamente eficiente para executar a tarefa. A diferença entre ECTC e MaxUtil está em como fazer essa determinação, ou seja, possuem heurísticas distintas. A lógica por trás do ECTC é que um host com baixa utilização consome mais que sobrecarregar outro host e colocar o primeiro para desligar. Essa lógica consegue uma pequena economia. Já o MaxUtil tem seu cálculo baseado na utilização média do tempo de processamento da tarefa atual em um host. Ou seja, faz-se um balanceamento mas sem sobrecarga excessiva de outro host, causando economia de energia e também diminuindo a quantidade de recursos utilizados (Lee e Zomaya, 2010). 
Uma das principais preocupações existentes com o PADEVE processador para economia de energia é tentar reduzir a quantidade de processadores em uso ao máximo. Para isso existem diversas técnicas como o uso de redes neurais (Duy et al., 2010), o uso de algoritmos genéticos (Tao et al., 2014) ou uso de migração (Beloglazov e Buyya, 2010a) (Beloglazov e Buyya, 2010b) (Younge et al., 2010) (Beloglazov et al., 2011) (Zhu et al., 2013) (Akgun et al., 2014) (Alahmadi et al., 2014).

Em contrapartida existem políticas de alocação de máquinas virtuais que evitam a todo custo a migração. O objetivo principal é, através de uma métrica, calcular a utilização equilibrada de um host. Esse equilíbrio se faz alocando uma quantidade mínima de MVs e, quando necessário, aumenta-se a velocidade de processamento da máquina virtual em tempo de execução. Nesse caso trabalha-se em dois estágios de escalonamento na nuvem. O primeiro otimiza a alocação de MVs. O segundo gerencia a alocação de tarefas nas MVs criadas de uma forma que, caso seja necessário, a velocidade de execução da tarefa aumente (Hosseinimotlagh e Khunjush, 2014).

O algoritmo CSAAC (Cooperative Scheduling Anti-load balancing Algorithm for Cloud) é mais uma política de escalonamento que tem como ponto de análise o processador. Essa política permite em tempo de execução controlar o consumo global de energia das aplicações ligando ou desligando hosts. A diferença dos demais está na inclusão de técnicas de tolerância a falhas oferecendo alta disponibilidade. Além disso também utiliza de migração de máquinas virtuais para busca de eficiência energética e de respeito ao contrato (Thiam et al., 2013).

Seguindo-se na tentativa de identificação de hosts inoperantes ou sub-utilizados, o trabalho de (Thanavanich e Uthayopas, 2013) usa também dessa técnica para desligamento ou hibernação desses. O diferencial desse trabalho em relação aos já apresentados é que armazena-se essa informação do desligamento de hosts. Ou seja, a próxima vez que um serviço parecido for requisitado as tarefas serão alocadas tendo a informação que precisa-se de menos infraestrutura para o cumprimento do contrato. Diante dessa ação pode-se obter economia de energia. Mais dois algoritmos visando o desligamento de hosts inativos e a execução de MVs em um número mínimo possível de servidores são apresentados no trabalho de (Hongyou et al., 2013), entretanto o foco nesse trabalho é o escalonamento eficiente especificamente para cargas heterogêneas.

A previsão em um curto prazo de tempo da utilização ou não de um servidor físico pode ser uma informação importante para a tomada de decisão do desligamento de um host. Isso é possível observando-se uma base de dados do histórico de utilização dos recursos físicos de um Data Center. Utilizando-se dessa técnica pode-se prever os hosts que estarão superutilizados ou subutilizados em um certo espaço de tempo futuro (Farahnakian et al., 2013). Existem outros trabalhos que utilizam de previsão de carga. Em conjunto da previsão pode-se utilizar o algoritmo guloso para a alocação das máquinas virtuais nos hosts. Essa técnica visa alocar as máquinas virtuais de uma forma que o processador de cada host seja utilizado em 100\%. A previsão de carga é utilizada para migração de MVs caso esses hosts fiquem sobrecarregados (Wang et al., 2013a).

Algumas políticas têm como objetivo reduzir o consumo de energia de uma forma que a quantidade de violações do SLA seja a menor possível. Pode-se considerar para a tomada de decisão 
que o host esteja em três estados: Sobrecarga, Subcarga e Ocioso. Sobrecarga significa que o SLA pode ser violado a qualquer momento pelo host. Um host em Subcarga significa que está em uso mas não corre risco de ferir o contrato. E Ocioso é o estado onde o host está disponível e sem uso. Diante desse cenário pode-se ter algumas ações que visam obter economia de energia com um número de quebra de contrato reduzido. A primeira ação é escolher quais hosts estão com Sobrecarga e fazer a migração de máquinas virtuais até que ele fique com Subcarga. Outra ação é alocar as MVs em hosts com Subcarga de uma forma que não fique com Sobrecarga e, se for o caso, ligar hosts Ociosos. Mais uma ação é fazer a migração das máquinas virtuais restantes buscando sempre estarem com Subcarga (Cao e Dong, 2013).

A reutilização de máquinas virtuais é uma técnica utilizada em alguns trabalhos que visam a redução do consumo de energia sem deixar de ferir o SLA (Alahmadi et al., 2014) (Cao e Zhu, 2013). A ideia principal é reduzir a eliminação e criação de máquinas virtuais desnecessariamente. A técnica visa prever se a MV a ser eliminada poderá ser reutilizada por outra tarefa, caso afirmativo a MV é mantida e a nova tarefa alocada.

A utilização de diversas técnicas computacionais para a busca do escalonamento ideal vem sendo usado cada vez mais nos últimos anos. No trabalho de (Royaee e Mohammadi, 2013) as decisões de alocação das máquinas virtuais nos hosts têm como técnicas básicas o escalonamento dinâmico, a migração de MVs em tempo de execução, o limiar único de deadline, a hibernação de servidores e a utilização de algoritmos genéticos. Outro trabalho que utiliza várias técnicas é o do (Cao e Zhu, 2013), onde a estimativa de carga, o DVFS e a reutilização de máquinas virtuais já criadas são usadas para se obter redução do consumo de energia e da emissão de gás carbônico sem deixar de garantir a Qualidade de Serviço.

O uso de mais de uma técnica para fazer o escalonamento na nuvem vem aumentando, sendo que diversos trabalhos seguem essa linha (Royaee e Mohammadi, 2013) (Faragardi et al., 2013) (Cao e Zhu, 2013). Seguindo com esse tema, o trabalho de (Royaee e Mohammadi, 2013) utiliza duas técnicas para executar o escalonamento de máquinas virtuais: a migração de máquinas virtuais e a reutilização de máquinas virtuais já existentes, otimizando os processos de criação de MV.

A preocupação da comunidade científica com o escalonamento nos estágios de escolha de Data Center e de máquinas virtuais aparentemente é maior devido ao grande número de trabalhos nessa área. Entretanto, o estágio de alocação das tarefas nas máquinas virtuais não é menos importante que as citadas anteriormente. Pode-se citar como uma política que reduz o consumo de energia a ERES (Energy-aware Real-time Elastic Scheduling) (Chen et al., 2013). Essa política visa otimizar a distribuição das tarefas utilizando a política EDF (Earliest Deadline First). A EDF prioriza as tarefas cujos deadlines estão mais próximos de expirar. Mas o ERES não se resume a isso, utilizando em conjunto técnicas para eliminação de máquinas virtuais que estejam ociosas e de criação de mais MV quando o contrato corre riscos de ser quebrado.

Outro trabalho que visa o escalonamento de tarefas é o GCTA (Green Cloud Task-scheduling) (Ouyang et al., 2014). A política se baseia em uma técnica da computação evolutiva, a BPSO 
(Binary Particle Swarm Optimization). O uso da técnica de otimização baseada em enxame de partículas binárias tem como objetivo fazer a distribuição das tarefas nas máquinas virtuais de uma forma que se obtenha redução no consumo de energia. O uso de computação evolutiva no escalonamento de tarefas em Computação em Nuvem não é uma novidade. Existem outros trabalhos que já utilizaram dessa técnica (Pandey et al., 2010) (Zhao et al., 2009). Entretanto, esses trabalhos citados não tinham o mesmo objetivo que o GCTA que foi projetado para ser uma política verde. Outro trabalho que utiliza a otimização por enxame de partículas visando a economia de energia é no trabalho de (Wang et al., 2013b).

Conforme já afirmado anteriormente, a quantidade de trabalhos que utilizam o processador como PADEVE é relevante. Na próxima subseção serão apresentados trabalhos que utilizam a rede como ponto de análise na tomada de decisão.

\section{Rede}

A rede pode ser considerada como um dos PADEVEs mais utilizados no escalonamento verde na nuvem. No caso, perde em número de trabalhos apenas para o processador. Nessa subseção são apresentados alguns trabalhos que utilizam a rede como meio para o escalonamento verde na nuvem.

O trabalho de Baliga et al. (2011) comprova que transporte e comutação em uma rede computacional pode ter uma porcentagem significativa no consumo de energia na nuvem. A economia de energia existe em casos onde a computação é de baixa intensidade ou pouco frequentes. Foi comprovado que se o equipamento pessoal do usuário não economiza energia ou a energia no transporte é excessiva, o processamento em nuvem é menos eficiente em termos de consumo de energia compensando executar nativamente (Baliga et al., 2011).

Uma forma de analisar o ponto rede para o escalonamento na nuvem é também quando analisase a quantidade de migração de máquinas virtuais. Existem vários trabalhos que propõe a utilização de migração para redução do consumo de energia (Younge et al., 2010) (Lago et al., 2011). Outros trabalhos se preocupam com a migração mas evitando seu excesso, o que gera maior economia do que as demais (Beloglazov e Buyya, 2010a) (Beloglazov e Buyya, 2010b) (Beloglazov et al., 2011) (Alahmadi et al., 2014).

Para a tomada de decisão uma política pode observar a localização da informação. Essa ação visa reduzir o uso intensivo da rede. Para isso, envia-se as tarefas para o mesmo local de onde os dados necessários para a execução do respectivo serviço está localizado. Além desse ponto pode-se ter a capacidade de processamento como referência. Para a otimização dessa decisão pode-se utilizar algoritmos com operadores genéticos. Esses operadores podem ser o cruzamento e a mutação (Wang et al., 2014).

Existem alguns tipos de serviços que demandam uma alta taxa de uso da rede. As provedoras de serviços multimídia são uma dessas. Ter uma política que consegue buscar o serviço no Data Center mais próximo do usuário é uma opção inteligente para reduzir o tempo de entrega do 
serviço. Mas as condições da rede, como latência e congestionamento, também devem ser observados. Olhando-se esses fatores pode-se criar uma política que permite a escolha do Data Center que melhor poderá oferecer o serviço requerido (Gong et al., 2014).

O e-STAB é uma política de escalonamento que tem como base para suas tomadas de decisão a rede. O ponto principal dessa política é fazer o escalonamento de uma forma que evite a sobrecarga da rede interna do Data Center. Isso é possível devido sua técnica de balanceamento de carga o que, além de evitar o congestionamento da rede, consegue reduzir o consumo de energia (Heydarikiya et al., 2014).

Uma outra forma de economizar energia tendo a rede como ponto de análise no escalonamento é evitar o compartilhamento de um link. A ideia é fazer com que cada fluxo de dados tenha um caminho exclusivo sem dividi-lo com outro fluxo de dados. Para se controlar a garantia ao contrato pode-se utilizar de prioridades para garantir que um fluxo mais urgente utilize o caminho exclusivo primeiro. A ideia é enviar os fluxos um seguido do outro, sem sobreposição de tempo. Com isso tem-se a redução de perda de dados na transmissão e, por consequência, reduz-se o consumo de energia (Li et al., 2014).

No escalonamento verde na nuvem, além da rede e do processador, pode-se utilizar a refrigeração como um PADEVE. Na subseção seguinte são apresentados alguns trabalhos com esse objetivo.

\section{Refrigeração}

O uso da refrigeração no escalonamento verde na nuvem, apesar de poucos trabalhos que utilizam desse ponto de análise, é um fator importante e que deve ser melhor estudado.

Alguns trabalhos que tem a refrigeração como PADEVE se preocupam com o consumo do ar condicionado dos Data Centers. A escolha dos hosts para se alocar as máquinas virtuais é baseada na estimativa do consumo dos equipamentos de resfriamento do ar. A ideia é dividir as máquinas virtuais de uma forma que um ponto do Data Center não tenha mais processamento do que outro, equilibrando a temperatura e não exigindo que o ar condicionado de um ponto específico do Data Center precise trabalhar mais que os demais. Dessa forma, consegue-se uma redução no consumo de energia(Garg et al., 2010).

Outros trabalhos, visam a redução da rotação da ventoinha (cooler) do processador. O princípio básico dessa política é alocar as máquinas virtuais de uma forma que exista hosts ociosos. Observando-se a existência de hosts ociosos o escalonador fica responsável em enviar um comando para o hosts para que seu cooler reduza a rotação. Com essa técnica pode-se obter redução no consumo de energia (Lago et al., 2011).

Uma outra técnica é a redução da temperatura gerada pelo processador (Beloglazov e Buyya, 2010a). O objetivo é fazer a alocação das máquinas virtuais tendo a temperatura do processador do host como base. A ideia é manter a temperatura baixa dos processadores para que os dispositivos 
de refrigeração do ar no Data Center trabalhem o mínimo possível e, dessa forma, reduz-se o consumo de energia.

Outro trabalho que apresenta como ponto de análise a refrigeração, e que já foi citado anteriormente na subseção que se refere ao PADEVE processador, é o escalonador Cool (Zhang e Chang, 2014). Essa técnica usa da redução da frequência do clock para obter o resfriamento da CPU. O nome Cool foi dado ao escalonamento graças a essa característica.

$\mathrm{O}$ uso da refrigeração como um ponto de decisão para o escalonamento pode ser positivo. Em todos os trabalhos apresentados tem-se uma redução no consumo de energia.

\section{Emissão de $\mathrm{CO}_{2}$}

A emissão de Gás Carbônico $\left(\mathrm{CO}_{2}\right)$ é também utilizada em alguns trabalhos como um PADEVE. Esse ponto de análise, assim como a refrigeração, é pouco pesquisado. Entretanto, o benefício do seu uso para a Computação Verde na Nuvem torna necessária a intensificação dos estudos nessa área.

No trabalho de Garg et al. (2010) faz-se uma proposta de escalonamento onde analisa-se diversos pontos como consumo do processador, consumo de ar condicionado o custo de energia e a emissão de $\mathrm{CO}_{2}$. A ideia principal da análise desse PADEVE, é enviar ao metaescalonador um coeficiente de emissão de gás Carbônico dos Data Centers (dado pela agencia ambiental americana) e através desses dados tomar a decisão do escalonamento (Garg et al., 2010) (Garg et al., 2011).

A escolha do Data Center pode ter como parâmetro a sua eficiência energética. O Data Center que obtiver o maior coeficiente de eficiência deve ser escolhido. Essa técnica pode ser uma boa solução para a redução da emissão de gás carbônico na atmosfera (Cao e Zhu, 2013).

As políticas de escalonamento são fundamentais para que os serviços existentes em uma nuvem computacional sejam entregues com qualidade ao seu usuário (cliente). A diversidade de técnicas para que as políticas de escalonamento alcancem seu objetivo é notável. Independentemente se o objetivo é voltado à Qualidade de Serviço, redução do consumo de energia ou redução da emissão de gás carbônico os trabalhos de escalonamento na nuvem crescem de uma forma vertiginosa. As políticas de escalonamento na Computação em Nuvem podem utilizar de técnicas que visem a escolha do Data Center, a criação de máquinas virtuais, a alocação de máquinas virtuais nos hosts e a alocação de tarefas nas máquinas virtuais. Para se gerenciar tudo isso são necessários os metaescalonadores. A próxima seção é dedicada a essas arquiteturas.

\subsection{Metaescalonadores}

O Metaescalonador é um mecanismo de gerenciamento de vários ambientes de um sistema distribuído específico e não possui controle direto sobre os recursos desse sistema (Peixoto, 2012). Quem gerencia um único ambiente é o escalonador. Nesta seção é apresentado o estado da arte dos metaescalonadores para Computação em Nuvem. 
Na subseção Trabalhos Relacionados, são apresentados os metaescalonadores existentes na literatura que têm a Computação em Nuvem como base de seu funcionamento. O GreenMACC é uma arquitetura de um metaescalonador que tem o objetivo de permitir o uso de políticas verdes e ainda prover QoS em uma nuvem privada. Essa arquitetura foi baseada no MACC (Metascheduler Architecture to provide $Q o S$ in the Cloud Computing). Devido a esse fato, nessa seção dedica-se a subseção 3.4.2 ao MACC.

\subsubsection{Trabalhos Relacionados}

Nessa subseção são apresentadas diversas propostas existentes na literatura para metaescalonamento em uma nuvem computacional. O objetivo é apresentar o estado da arte da área de pesquisa relacionada a esta tese. No capítulo 4, onde o GreenMACC é apresentado, será feita uma comparação qualitativa entre a arquitetura proposta nesta tese com todos os trabalhos apresentados nessa subseção.

Foi apresentado em (Liu et al., 2009) uma nova arquitetura para Data Centers Verdes, ou seja que tenha a economia de energia como desafio. Esta arquitetura foi nomeada pelo autor de GreenCloud. Nesse trabalho afirma-se que uma boa forma de economia de energia é distribuir a carga de trabalho primeiro e depois desligar os dispositivos inativos (Liu et al., 2009).

Em conjunto com a preocupação da economia de energia, como os testes estão sendo feitos com jogos online, a satisfação do cliente deve ser também observada, ou seja, o tempo de retorno deve ser por volta de 600 milissegundos ou menos. Outro ponto fundamental é a migração online, que é uma técnica viável para esse tipo de aplicação (Liu et al., 2009).

A arquitetura proposta por (Liu et al., 2009) tem como objetivo melhorar a utilização de recursos e reduzir o consumo de energia em um ambiente de Computação em Nuvem.

A arquitetura tem alguns componentes principais como os serviços de monitoramento, o gerenciamento de migrações, o ambiente gerenciável e o simulador de carga de trabalho.

Os serviços de monitoramento (Monitoring Services), contém os coletores de informações, como utilização de recursos (Resource utilization), máquinas virtuais para executar a carga de trabalho necessária (VM Workload) e a situação do sistema, se está ligado ou não (On/Off Status). O serviço de monitoramento é construído baseado no framework Tivoli IBM, que é uma plataforma de gerenciamento de sistemas baseado no CORBA $^{\circledR}$ (Common Object Request Broker Architecture). O Xen é o monitor de máquinas virtuais. O servidor de monitoração é o centro geral de informações. Os dados gerados e armazenados nele são cruciais na tomada de ações do gerenciador de migração (Liu et al., 2009).

O Gerenciador de migrações (Migration Manager) verifica a situação da migração em tempo real e decide sobre a distribuição das máquinas virtuais nos hosts dos Data Centers. O mecanismo de escalonamento migratório (Migration Scheduling Engine) busca por uma distribuição otimizada graças a uma heurística descrita a seguir. O gerenciador de migrações ainda envia instruções para 
executar a migração de máquinas virtuais (VM Migration Control) e também ligar e desligar os servidores (On/Off Control) (Liu et al., 2009).

No GreenCloud existe um ambiente gerenciável (Managed Environment) que é onde se localizam as máquinas virtuais, máquinas físicas, dispositivos, aplicações e recursos. E existe também o E-Map que é um serviço web que disponibiliza uma interface para o usuário e apresenta uma série de dados incluindo consumo de energia (Liu et al., 2009).

Ainda na arquitetura apresentada por (Liu et al., 2009) existem o simulador de carga de trabalho (Workload Simulator) configurável pelo usuário, e um repositório (Asset Repository) que armazena informações estáticas do servidor como IP por exemplo.

A heurística presente no mecanismo de escalonamento baseia-se no custo de gerenciamento de energia, estado (status) da máquina virtual e o custo da migração da máquina virtual. A arquitetura GreenCloud demonstra, através de resultados, que realmente economiza energia e ainda sem quebrar o tempo estipulado por contrato (SLA - Service Level Agreement), essencial em sistemas que utilizam a nuvem.

O uso de Computação Verde em serviços disponibilizados na nuvem tem atualmente um grande desafio que é tornar possível seu uso comercialmente. Para que isso seja possível, é necessário economizar energia sem que um serviço tenha atrasos na resposta ou ainda que uma aplicação HPC (High Performance Computing) consiga manter um desempenho de execução na nuvem equivalente ou muito próximo do que se estivesse executando localmente em um cluster. Tendo esse objetivo como base é que foi proposto no trabalho de (Garg et al., 2011), um escalonador que consiga trabalhar com aplicações HPC em um ambiente de nuvem.

A ideia do trabalho presente em (Garg et al., 2011) é propor um metaescalonador que possibilite um usuário executar seus aplicativos de HPC na nuvem. Esse metaescalonador funciona como uma interface para infraestrutura da nuvem e aplicações de escalonamento. Visando a atender uma Qualidade de Serviço, ele analisa o pedido e decide se aceita ou não a requisição com base na disponibilidade dos hosts de um Data Center.

Os Data Centers na nuvem estão localizados em regiões distintas do planeta e emitem $\mathrm{CO}_{2}$ em taxas diferentes e possuem gastos diferenciados de energia. Cada Data Center tem que informar esses dados ao metaescalonador, visando uma distribuição eficiente em relação ao custo energético. Duas partes são fundamentais nesse processo: os usuários e os fornecedores. Os primeiros se preocupam em executar aplicações HPC da forma mais rápida e eficiente possível, demandando um parque de processamento paralelo robusto. A estimativa do tempo de execução de uma aplicação na nuvem é um problema bastante conhecido, graças aos diversos fatores variantes. Isso torna-se um problema, porque na nuvem paga-se conforme o uso e o usuário poderá pagar mais se sua aplicação demorar mais que o esperado (Garg et al., 2011).

No segundo nível dessa arquitetura estão os prestadores de serviço na nuvem. Esses possuem diversos Data Centers distribuídos por todo planeta. Cada Data Center por sua vez possui seu próprio escalonador. O metaescalonador interage com esses escalonadores que fornecem de forma 
periódica os períodos de tempo livre e o número de processadores para esses períodos. A economia de energia é conseguida através dos escalonadores locais que oferecem ao metaescalonador um coeficiente de emissão de gás carbônico, o desempenho de preço da eletricidade, potência da CPU, a quantidade de milhões de instruções por segundo (MIPS) dos processadores e a faixa de frequência de operação dos hosts (clock) do Data Center. A taxa de emissão de gás carbônico depende do tipo de combustível como publicado em agências americanas como a EIA (Energy Information Administration (Garg et al., 2011).

Alguns fatores são determinantes no consumo de energia dos Data Centers como os hosts, bancos de dados, roteadores, switches e ainda o ar condicionado. Nos hosts pode-se considerar a CPU, memória, discos e coolers como consumidores de energia, entretanto o fator principal a se considerar é o consumo dos processadores considerando-se aplicações cpu-bound. Outro ponto importante ao se modelar o consumo de energia, é não se apegar a muitos detalhes quando está se propondo trabalhar com um metaescalonador em nível global (Garg et al., 2011).

Para se obter resultados consistentes em relação ao consumo de energia deve-se observar alguns fatores como: consumo de energia dos processadores, energia total consumida pelo sistema de refrigeração, custo de energia e emissão de gás carbônico.

O metaescalonador proposto possui duas fases, a fase de mapeamento, em que o metaescalonador informa primeiro sobre a aplicação para o Data Center, e a segunda fase, que é a de escalonamento da aplicação para o Data Center.

Nos resultados apresentados, obteve-se na média uma redução de $33 \%$ no custo de energia, sem perder QoS, e ainda conseguindo redução na taxa de emissão de gás carbônico.

O metaescalonamento na Computação em Nuvem é bem diversificado, e envolve diversas áreas do conhecimento da área de computação. Uma proposta presente na literatura é encontrada no trabalho de (Jayarani et al., 2009) onde é apresentado um metaescalonador que visa oferecer Qualidade de Serviço (QoS) como foco principal, e ainda discute sobre a heurística de escalonamento das Máquinas Virtuais (MVs) em dois níveis, incluindo o nível dos Data Centers.

O metaescalonamento em dois níveis proposto por (Jayarani et al., 2009) utilizou a ferramenta CloudSim para simular o escalonamento em questão. Esse se preocupa na otimização do throughput do sistema, maximizando a utilização dos recursos, sem perder a QoS. Nesse mesmo trabalho, é apresentada uma proposta de como melhorar o desempenho no escalonamento de máquinas virtuais.

As propostas apresentadas são todas baseadas no simulador CloudSim. Inicialmente propõese que, no modelo atual do simulador em questão, o Broker Data Center escolha o Data Center que deve receber as MVs de uma forma igual e aleatória, sem critérios. A primeira proposta do trabalho de (Jayarani et al., 2009) é a criação de um metaescalonador que selecione os Data Centers baseando-se em um critério específico de QoS, como deadline do contrato vencendo.

Outra proposta é referente ao VM Provisioner, que tem a função de escolher o host que tem a menor carga de trabalho para que seja criada a nova máquina virtual. Isso permite um balancea- 
mento do sistema, mas existe de acordo com o autor possibilidade de falhas na criação de algumas MVs. Isso se deve a uma possível alocação onde mesmo o host tendo pouca carga não tem recursos suficientes para criação da nova máquina virtual. A melhoria proposta visa a seleção adequada das MVs, conforme sua exigência por recursos, ou seja, fazer com que as máquinas virtuais que exigem mais recursos sejam alocadas onde existem MVs com exigências de recursos menores (Jayarani et al., 2009).

Uma terceira proposta de modificação está no escalonador de máquinas virtuais, que nativamente no CloudSim o host de um Data Center é responsável pela criação e destruição de uma máquina virtual. Ou seja, ele cria as MVs e distribui os cloudlets (tarefas do serviço requisitado) nessas MVs. Nesse modelo atual a máquina virtual é destruída pelo host quando todas as MVs concluírem a execução de todos os cloudlets. Para otimizar esse processo, deve-se permitir a criação e destruição das MVs de forma independente visando a um balanceamento que deve ser adaptativo.

Os resultados apresentados se mostraram positivos na utilização de um metaescalonador que se preocupe tanto no nível mais alto quanto no nível mais baixo de escalonamento das máquinas virtuais.

A frequente utilização da ferramenta CloudSim em trabalhos de proposta e avaliação de escalonamento e arquiteturas para Computação em Nuvem é um sinal positivo de que a ferramenta de simulação em questão oferece segurança nos resultados. Outro trabalho que utiliza esta ferramenta de simulação para execução de testes e geração de dados é o trabalho de (Beloglazov et al., 2011). Nesse trabalho é proposta uma heurística de realocação dinâmica de máquinas virtuais entre os nós de um Data Center visando economia de energia.

A arquitetura utilizada apresenta um responsável pela distribuição das requisições feitas pelos clientes (Dispatcher). Este envia para os gerenciadores globais Global Manager as requisições. Os gerenciadores globais são responsáveis pela execução de uma heurística que faz com que continuamente seja realocadas as máquinas virtuais nos nós conforme dados enviados pelos gerenciadores locais (Local Manager). Em conexão com os gerenciadores locais existe um monitor de máquinas virtuais (VMM) que verifica a utilização dos recursos no nó e mapeia seu estado térmico. As decisões de migração das MVs dependem de fatores como o fato da utilização de um recurso estar saturada e poder afetar o contrato de serviço, ou se algum recurso está sub-utilizado e as máquinas virtuais alocadas nele devem migrar para outro nó e desligar o primeiro. Deve-se também analisar para migração se uma MV tem comunicação intensa com outra que está alocada em outro nó físico e finalmente a temperatura supera o desejável (Beloglazov et al., 2011).

Cada gerenciador global está conectado a um conjunto de nós e recebe dados a partir dos gerenciadores locais existentes em cada nó. Após obtenção dos dados ele emite ordens para migração em tempo de execução. Os gerenciadores globais estão interconectados e trocam informações entre si para decisões de migração. Os gerenciadores locais propagam aos gerenciadores globais informações de MVs e recursos que vêm dos monitores (VMM) (Beloglazov et al., 2011).

Alguns requisitos foram enfatizados no trabalho em questão para desenvolvimento do algoritmo de escalonamento, como eliminar um ponto único de falha do sistema utilizando a descen- 
tralização dos gerenciadores globais, e capacidade em se adaptar com eficiência às mudanças de carga de trabalho e garantir o QoS.

Observando os resultados, a economia de energia fica nítida e a utilização de migração pode melhorar o desempenho do escalonamento proposto. Entretanto, a utilização de migração deve ser usada com cautela pois essa técnica demanda muito recurso de comunicação sobrecarregando a rede se mal utilizada (Beloglazov et al., 2011).

A Computação em Nuvem, como já citado neste trabalho, possui três vertentes de serviços que podem ser oferecidos: Infraestrutura como Serviço (IaaS), Plataforma como Serviço (PaaS) e Software como Serviço (SaaS), e ainda possui 4 modelos que determinam as limitações de seu uso, como as nuvens privadas, públicas, comunitárias e as híbridas. O trabalho apresentado por (Bossche et al., 2010) foca em um metaescalonamento que busca otimizar nuvens híbridas que oferecem infraestrutura como serviço visando o deadline de contratos e cargas de trabalho preemptivas, sem utilizar migração e caracterizadas pela CPU, memória e transmissão de dados. Com base nessas características, foi apresentado o projeto HICCAM (Hybrid Cloud Construction and Management). O modelo possui componentes e algoritmos que facilitam a construção de uma nuvem híbrida que permite gerenciamento de seus recursos.

Os usuários desse modelo utilizam uma interface oferecida pelo DSS (Decision Support Systems), que lhe possibilita decidir qual será a ação prioritária entre desempenho da aplicação e custo. Esta decisão é enviada ao ponto de contratação da nuvem (CPE), que é o que gerencia a aquisição de recursos da nuvem pública. Dentro do CPE tem-se o escalonador (scheduler) que é responsável pela otimização da distribuição das cargas de trabalho visando minimizar os custos da execução (Bossche et al., 2010). Ainda dentro do CPE existem um alocador de recursos (Resource Allocator) e um coletor de dados (Data Collector), responsáveis por permitir o uso de sistemas diferentes em sistemas distintos.

Na proposta em questão existe um sistema contador (accounting) que mantém os gastos do cliente (Logging \& Tracking) e ainda um controle orçamental (Budget control), fundamental para execução da política de escalonamento. Finalmente o contador faz a gestão da contribuição (Contribution Management), a qual é responsável por calcular os custos referentes ao uso de recursos de terceiros (Bossche et al., 2010).

$\mathrm{O}$ escalonamento apresentado tem um funcionamento adequado em relação à minimização de custos e ao suporte de decisão dos usuários. Entretanto, não apresentou um bom desempenho quando utilizou o modelo híbrido. Nesse sentido, faz-se necessária a utilização de outras políticas de escalonamento ou aperfeiçoamento apresentada para obter melhores resultados.

O trabalho do (Zhang et al., 2013) apresenta uma arquitetura de um metaescalonador que visa trabalhar com diferentes cenários de serviços em nuvens computacionais voltados a área de Telecomunicações (UMATGC2). Operadoras tradicionais de telecomunicações tais como a NOKIA ${ }^{\circledR}$ e Motorola ${ }^{\circledR}$ por exemplo também oferecem serviços em nuvem para usuários finais. 
Nesse trabalho onde o UMATGC2 é apresentado as principais contribuições são: a análise da capacidade da arquitetura gerenciar diversos recursos de forma consistente; comportamento de serviços específicos de empresas de Telecom na arquitetura; e a garantia da Qualidade de Serviço.

Alguns módulos são importantes no funcionamento do UMATGC2: módulo de registro e autenticação do usuário; módulo de controle de admissão que, baseando-se na informação da carga de trabalho em execução, aceita ou rejeita a requisição do cliente; módulo de negociação com o usuário, onde o SLA é construído; módulo com informações de latência e a variação estatística do atraso na entrega de dados (Jitter); módulo dos escalonadores locais, onde as informações da rede podem ser utilizadas; o módulo de auditoria que tem como finalidade avaliar dentro de pequenos espaços de tempo o comportamento dos recursos com o objetivo de evitar um travamento dos mesmos; e módulo de gerenciamento das operações coordena todo processo do sistema.

A arquitetura UMATGC2 oferece como suas principais vantagens o gerenciamento de diferentes recursos, a garantia de QoS para serviços com finalidade específica de Telecomunicações, e manutenção de fatores essenciais em uma nuvem computacional como segurança e gerenciamento de SLA.

Nessa subseção foram apresentados trabalhos publicados de arquiteturas de metaescalonadores para Computação na Nuvem. Na próxima subseção é apresentada a arquitetura que o GreenMACC teve como base para sua criação, o MACC.

\subsubsection{MACC}

O MACC é uma arquitetura de um metaescalonador que foi desenvolvida com o objetivo de oferecer ao usuário serviços em nuvem priorizando a Qualidade do Serviço. Essa arquitetura permite que o cliente negocie o tempo de resposta (deadline) do serviço e com base nesse deadline o MACC calcula primeiro se pode oferecer esse serviço e depois negocia o valor com o usuário. O metaescalonador proposto por Peixoto (2012) foi projetado para executar em uma Intercloud, ou seja, caso o serviço requisitado não esteja disponível na nuvem de uma empresa o MACC procura se esse serviço está disponível em outras nuvens com proprietários diferentes. O MACC tem a Qualidade de Serviço como foco principal de seu funcionamento, a qual está diretamente relacionada com o tempo de resposta do serviço requisitado ao usuário. As políticas criadas e implementadas nessa arquitetura e as avaliações apresentadas no trabalho de Peixoto (2012) têm o tempo de resposta como dado fundamental para as avaliações de desempenho e para as políticas desenvolvidas tomarem suas decisões no escalonamento.

Nos trabalhos onde o MACC é apresentado (Peixoto, 2012) (Peixoto et al., 2010), tem-se uma visão geral da arquitetura, a qual pode ser observada na Figura 3.1. A camada mais acima é a de interação com o usuário, onde são feitas as requisições e onde são oferecidos os serviços. A camada logo abaixo é a que tem como finalidade controlar o fluxo de serviços através de 2 componentes: controle de admissão e controle de valores. A terceira camada é onde são gerenciadas as principais operações do metaescalonador. Na quarta camada encontra-se o hypervisor, como por exemplo 
Xen ou VMWare. E finalmente, a última é a camada de Infraestrutura Física. Os componentes intercamadas comunicam-se entre si trocando informações visando a oferta do serviço requisitado.

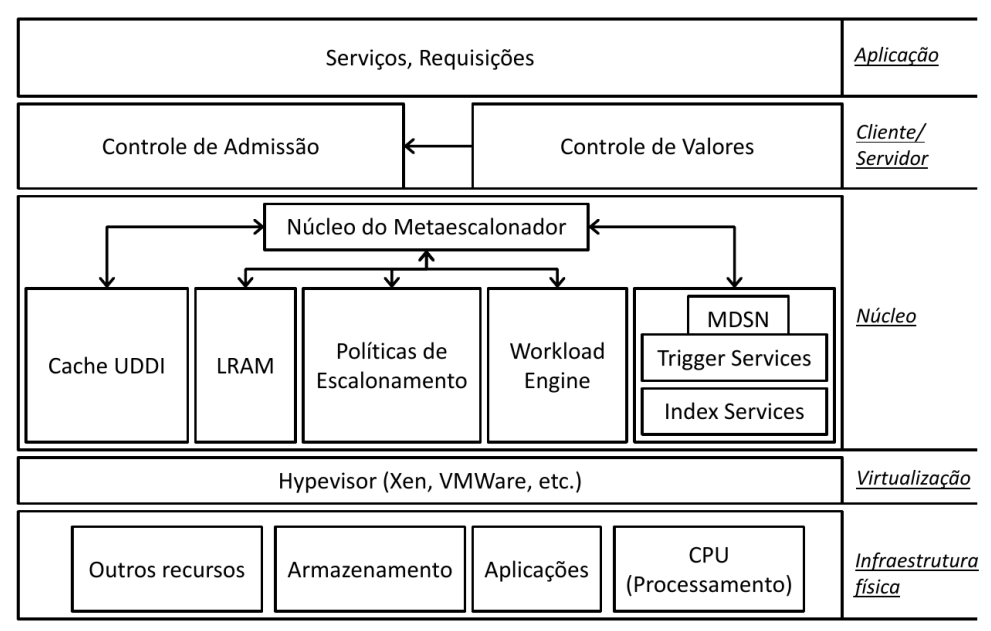

Figura 3.1: Visão Geral do MACC (Peixoto, 2012)

Cada módulo do MACC tem sua função específica. A seguir é feito um detalhamento de cada um desses módulos de acordo com o trabalho apresentado por Peixoto (2012).

Serviços e Requisições : os serviços utilizados pelo MACC são classificados como leves ou pesados. O primeiro tipo é caracterizado por serviços que utilizam baixo poder computacional e os serviços pesados são requisições que demandam um poder computacional alto.

Controle de Admissão : é responsável por aceitar ou descartar a requisição de um serviço de acordo com as métricas de utilização. Se por um lado esse módulo é um importante mecanismo para garantia da QoS, por outro lado o descarte excessivo de requisições pode afetar negativamente a satisfação do usuário.

Controle de Valores : esse módulo utiliza modelos econômicos para negociar o valor do serviço requisitado. No MACC para efetuar a negociação é utilizado um protocolo de comunicação chamado TB-WSLA (Template Base - Web Service Level Agreements) permitindo a conexão do usuário com o provedor do serviço. O cliente produz uma requisição que contém informações referentes a métrica da QoS negociada. No caso da negociação do MACC o preço se baseia no modelo de oferta e demanda. Depois de firmada a negociação, é feita a confirmação da QoS e a conexão é fechada.

Políticas de Escalonamento : módulo onde todas as políticas de escalonamento são implementadas. No MACC todas as políticas implementadas priorizam o respeito ao tempo de resposta do serviço contratado (deadline). Quando a resposta do serviço requisitado é igual ou inferior ao deadline estipulado pela negociação entre o usuário e o provedor tem-se a Qualidade de Serviço. 
Workload Engine : responsável por fazer a estimativa do tempo que um serviço será entregue. Este tempo é calculado utilizando-se a taxa de utilização dos recursos obtido por um valor médio em um determinado momento.

Trigger Service : o Trigger Service é um módulo que envia sinais de forma reativa a mudanças no ambiente do sistema. O metaescalonador, de acordo com o definido em tempo de projeto, toma ações que tem como objetivo alertar o sistema que uma MV está sobrecarregada ou não pode ser acessada.

Index Service : esse módulo tem como função armazenar dados que permitem analisar as variáveis do sistema e dos serviços que estão sendo executados. Esses dados são atualizados periodicamente com medições dos recursos da infraestrutura disponível no Data Center.

QoS : para que o MACC possa cumprir o SLA firmado com o usuário, todas os dados necessários para que a QoS seja monitorada e respeitada estão nesse módulo da arquitetura.

SLA : responsável por armazenar todos os contratos negociados com o usuário.

LRAM : no MACC, o LRAM tem a função de estabelecer a comunicação entre o metaescalonador e o escalonador local do Data Center. Esse módulo é importante para que a arquitetura tenha a capacidade de cumprir o contrato com o usuário.

Cache UDDI : módulo que contém informações dos serviços oferecidos localmente e de serviços que estão disponibilizados remotamente. O UDDI (Universal Description, Discovery and Integration) utiliza a interface padrão de acesso a serviços SIA (Standard Interface Access). Sua função é buscar um serviço requisitado em outro local remoto quando esse não está disponível localmente.

Hypervisor : responsável por garantir a criação das máquinas virtuais de forma que não ocorra interferência entre elas. Todos os recursos possíveis de virtualização são atividades de responsabilidade do Hypervisor.

Infraestrutura Física : a infraestrutura física de um Data Center é constituída por hosts conectados por uma rede de alta velocidade onde cada host tem a mesma configuração de software. As características físicas do Data Center podem ser diferentes (Heterogêneo) ou iguais (Homogêneo). Todas essas características são gerenciadas pelo metaescalonador.

No trabalho de Peixoto (2012) é apresentado um diagrama de fluxo do MACC (Figura 3.2) que permite uma melhor visualização do funcionamento dessa arquitetura.

A sequência de execução inicia-se com a requisição enviada pelo usuário (cliente) com os critérios de QoS definidos. O controle de admissão recebe a requisição e verifica a disponibilidade de recursos no MDSM (Monitoring and Discovery System Manager). Em caso afirmativo, a requisição é enviada ao controle de valores para negociação de preço referente ao serviço desejado. Caso 


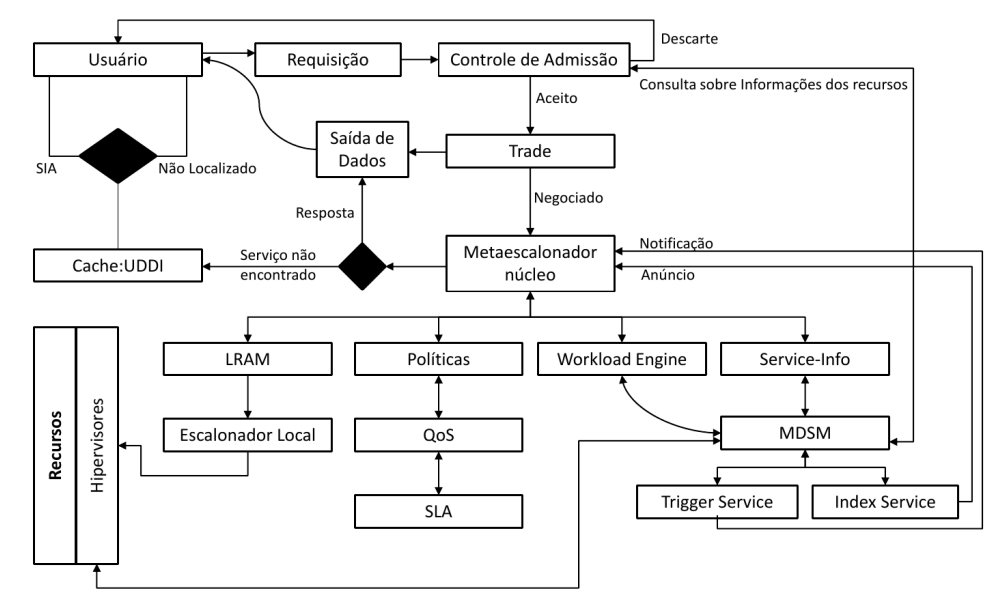

Figura 3.2: Diagrama de fluxo do MACC (Peixoto, 2012)

o acordo seja fechado, encaminha-se a requisição ao núcleo do metaescalonador que define as políticas de alocação e criação de Máquinas Virtuais (MVs) e a forma que o serviço será apresentado. Finalmente, com o término da execução do serviço, encaminha-se os resultados ao cliente.

O MACC foi projetado para utilizar Federações, ou seja, nuvens que possuem o mesmo serviço e, apesar de pertencerem à empresas distintas, se comunicam interagindo entre elas e quando uma percebe que não terá recursos suficientes envia a requisição de serviços do cliente para outra nuvem processá-la.

Outra característica do MACC é que essa arquitetura considera apenas dois estágios de escalonamento: Roteamento e Alocação. O Roteamento no MACC determina o Data Center que fará a execução do serviço requisitado. O estágio de Alocação do MACC tem três objetivos distintos: criação das MVs, alocação de MV nos hosts do Data Center escolhido, e finalmente, alocação de Tarefas nas máquinas virtuais criadas e alocadas.

As políticas de Roteamento do MACC são baseadas em duas métricas: o número total de saltos da origem ao destino e a latência da rede existente entre origem e destino. A primeira política de roteamento definida é a Round Robin (RR), onde a escolha é feita de forma que as requisições são distribuídas uma a uma seguindo uma lista circular simplesmente encadeada de Data Centers. Essa política tem como principal vantagem a não sobrecarga do metaescalonador, pois não há tomada de decisão que demande processamento intensivo. Entretanto a escolha do Data Center pode não ser a ideal, possibilitando que o serviço seja direcionado para um Data Center que já esteja sobrecarregado e com isso o tempo médio de resposta seja afetado negativamente.

As duas próximas políticas utilizam da mesma técnica que é baseada na capacidade da Rede (BCR), entretanto, diferem na métrica. A primeira utiliza a Latência da rede e a segunda o número de saltos necessários para se chegar no Data Center. A política BCR tem as informações da rede como ponto fundamental na tomada de decisões para escolher escolhe qual Data Center que irá receber a requisição do serviço enviado pelo cliente. Essa política sempre escolherá o menor valor, sendo o menor número de saltos ou a menor latência. A vantagem é que sempre será escolhida 
a melhor opção, no entanto, a sobrecarga no metaescalonador é alto, pois todos os Data Centers serão consultados.

As políticas que utiliza a técnica Chord (Stoica et al., 2001) baseiam-se em uma topologia de anel e é através dela que a escolha do Data Center é feita. A técnica considera a localização do cliente e analisa quais Data Centers melhor se encaixam na região desse cliente, ou seja, quais Data Centers estão mais próximos de onde partiu a requisição do serviço. Após a seleção dos Data Centers próximos é decidido através da métrica utilizada, por saltos ou por latência, qual Data Center será o responsável por executar o serviço requisitado. A principal vantagem da Chord é que não se consulta todos os Data Centers, reduzindo dessa forma a sobrecarga do Metaescalonador. Mas pode ocorrer da escolha do Data Center não ser a ideal, pois em determinados casos, o melhor Data Center pode não estar na região do cliente e por consequência não ser consultado e finalmente escolhido.

As duas últimas políticas implementadas tem como base de escolha do Data Center uma solução, assim como a Chord, baseada em P2P. A técnica Pastry (Rowstron e Druschel, 2001) diferentemente da anterior, não usa de uma topologia de anel para escolher o melhor Data Center. A topologia da abordagem Pastry é semelhante a de uma árvore binária. A busca inicia-se no nó raiz da árvore onde cada nó pode ser um Data Center ou um usuário, e a decisão de ir para direita ou para a esquerda depende da métrica utilizada. Suas vantagens são parecidas com a Chord em relação à redução de Data Centers consultados, reduzindo assim, a quantidade de iterações que o metaescalonador executa e diminuindo a sobrecarga sobre o mesmo. Entretanto, analisando-se essa mesma característica, pode-se observar a desvantagem dessa política. Essa desvantagem está na possibilidade de não consultar o Data Center que poderá oferecer o melhor resultado.

Após a escolha do Data Center pela política de Roteamento, segue-se para a segunda etapa de escalonamento, a de Alocação. As primeiras duas políticas são a SD2c (Slotted Dynamic 2 vCores) e a SD4c (Slotted Dynamic 4 vCores) onde a diferença está na quantidade de vCPUs (CPUs virtuais) criadas em cada Máquina Virtual (MV). Ambas as políticas possuem 3 fases, onde a primeira é a criação de MVs cujo número depende da demanda apresentada. Na segunda fase é onde as duas se diferem, pois é nessa fase que se define o número de vCPU para cada MV criada. Na política SD2c são definidos 2 vCPUs e na SD4c são 4. Em ambas a potência computacional das vCPUs é fixa. A terceira e última fase é definida a quantidade de núcleos físicos (cores) que cada vCPU terá. Esse número de núcleos podem ser 2, 4 ou 8 conforme a demanda. A política $\mathrm{SD} 2 \mathrm{c}$ foi escolhida para ser executada com as políticas de Roteamento por ser a política que cria de forma mais padronizada as máquinas virtuais com menor processamento. Busca-se com essa opção tornar os resultados das políticas de Roteamento mais evidentes. Uma máquina virtual com um alto poder de processamento pode ocultar os efeitos das políticas de Roteamento.

A próxima política é a Random Generator (RG), a qual não considera nenhuma informação para tomada de decisão. O número de MVs criadas é aleatória e a quantidade de vCPUs por MV é fixada em 4. Cada vCPU é definida com apenas um núcleo físico. No trabalho de Peixoto (2012), onde o MACC é apresentado, são feitas diversas avaliações de desempenho onde a arquitetura foi 
validada e várias políticas de escalonamento foram propostas e avaliadas. Com os resultados apresentados o MACC se provou capaz em prover QoS aos seus usuários em um ambiente Intercloud. Além disso, mostrou-se uma ferramenta importante para economia de recursos e dinheiro da empresa que o utilizar. O MACC, como já relatado anteriormente, foi projetado para trabalhar em um modelo de comunicação específico, o qual se baseia no ambiente Intercloud. Esse ambiente possui 3 camadas: aplicação, interconexão e federação. A primeira controla as solicitações do cliente e obtém informações do local geográfico do cliente. A camada de interconexão é responsável por conter e gerenciar as informações da rede onde os usuários e os Data Centers se conectam. É nessa camada que as políticas de roteamento atuam. A última é a federação, camada onde os serviços são executados, ou seja, os Data Centers. A arquitetura de metaescalonamento apresentada por Peixoto (2012) utiliza para sua conexão o modelo P2P hierárquico DHT (Distributed Hash Tables). Esse modelo divide o ambiente Intercloud em regiões e cada uma dessas possui seu próprio metaescalonador. Esse modelo pode ser observado na Figura 3.3 onde tem-se como exemplo um ambiente Intercloud dividido em três regiões.

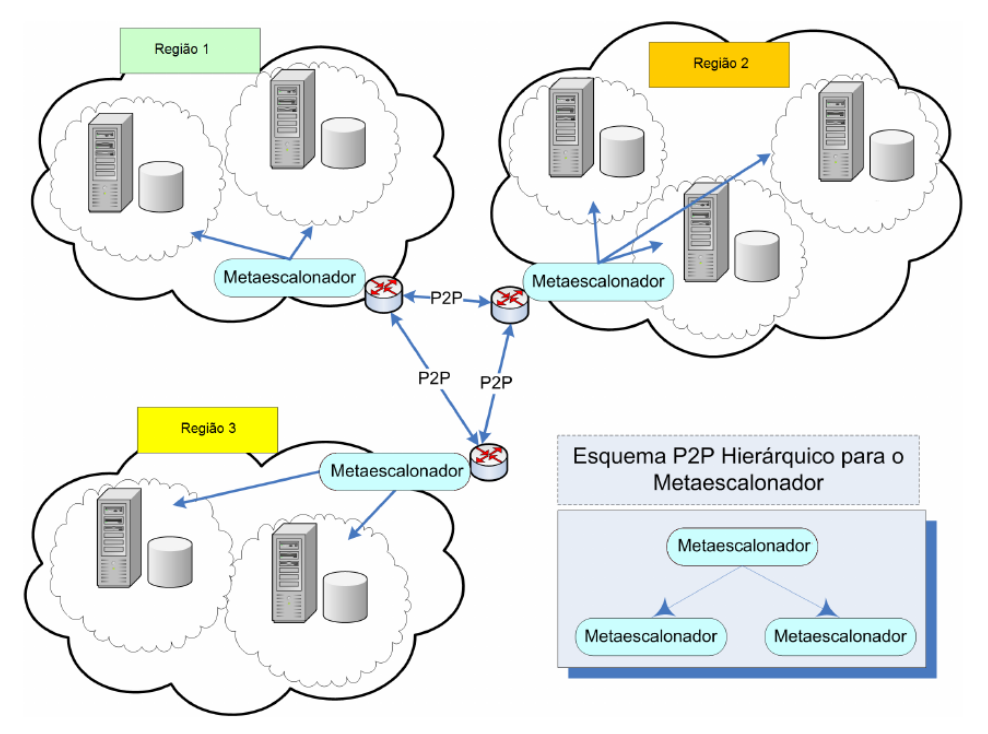

Figura 3.3: Modelo P2P adotado pelo MACC (Peixoto, 2012)

Como já mencionado, o MACC negocia e escalona com foco no custo do serviço prestado. No Capítulo 4 será apresentado o GreenMACC, que tem o MACC como base de sua arquitetura, entretanto com um foco diferente. Ao invés de ter uma Intercloud com escalonamento visando o custo e a QoS, a arquitetura proposta possibilita a implementação de políticas verdes provendo QoS em uma nuvem privada.

\subsection{Considerações Finais}

A Computação em Nuvem é um paradigma que está em pleno desenvolvimento. Na literatura pode-se encontrar muitas propostas de políticas inovadoras de escalonamento e de arquiteturas 
de metaescalonadores. Os trabalhos referentes a diversos tipos de escalonamento são abundantes, como por exemplo, algoritmos que primam pela eficiência energética, pela redução do gás carbônico ou pela garantia de prover QoS.

Os escalonadores apresentados trabalham em apenas um dos 4 estágios de escalonamento, salvo raras exceções. Ou seja, a grande maioria objetiva atuar em um único estágio de escalonamento. As exceções são as que na mesma política cria-se e aloca-se as máquinas virtuais.

Todos os trabalhos de escalonamento verde apresentados neste capítulo se enquadram em 4 diferentes pontos de análise para decisão no escalonamento verde (PADEVE). Esse pontos são o processamento, a rede, a refrigeração e a emissão de $\mathrm{CO}_{2}$.

Esse capítulo teve como principal objetivo apresentar o estado da arte nas áreas de escalonamento e metaescalonamento em uma nuvem computacional. Um levantamento bibliográfico cuidadoso foi feito com o intuito de apresentar a diversidade de trabalhos na área específica desta tese na atualidade.

Os trabalhos que tratam de metaescalonamento na nuvem não são tão abundantes quantos os que tratam do escalonamento. Talvez pela sua complexidade e notável dificuldade de consolidação da arquitetura. Um Metaescalonador possui vários módulos responsáveis desde a requisição do serviço, passando pela negociação do SLA e gerencia do escalonamento até finalmente a entrega do serviço ao usuário. A maioria dos metaescalonadores presentes na literatura apresentados neste capítulo têm limitações por possuir objetivos muito específicos. Esses dois últimos fatos tornaramse em motivações para a construção do GreenMACC.

No próximo capítulo o GreenMACC é apresentado em detalhes, discutido e comparado qualitativamente com outras arquiteturas de metaescalonamento apresentadas neste capítulo. 


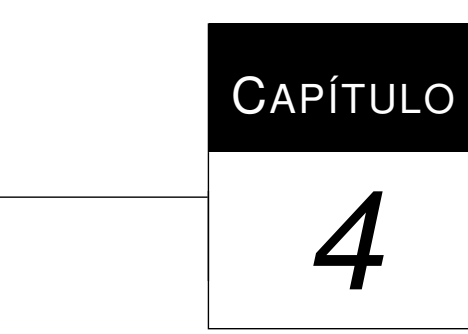

GreenMACC

\subsection{Considerações Iniciais}

$\mathrm{N}$

Os capítulos 2 e 3 foram apresentados temas que estão diretamente ligados a arquitetura proposta nesta tese: Computação Verde, Computação em nuvem, metaescalonamento e escalonamento. O objetivo principal deste capítulo é apresentar uma arquitetura de um metaescalonador verde para nuvens privadas. Essa arquitetura foi denominada GreenMACC (Green Metascheduler Architecture to provide QoS in the Cloud Computing), objeto principal deste projeto de doutorado e que neste capítulo é apresentada, discutida, validada e comparada qualitativamente com outros trabalhos que apresentam soluções de metaescalonamento na nuvem.

É público e notório o crescente interesse no mais novo paradigma dos sistemas distribuídos computacionais. A computação em nuvem está em pleno crescimento e as pesquisas nas mais diversas sub áreas de pesquisa desse sistema distribuído estão em constante ascensão. É fato que já existem soluções prontas e eficientes para esse paradigma, entretanto, várias pesquisa ainda podem ser desenvolvidas para que o ideal possa ser alcançado, se é que ele pode ser alcançado algum dia.

Outra área em foco entre os pesquisadores de quase todas as áreas de pesquisa é a sustentabilidade. Diversas ramificações de soluções nesse tema são publicados constantemente. Tanto na área de biológicas, humanas quanto de exatas, a sustentabilidade é tema atual e relevante nos diversos trabalhos científicos da atualidade. A computação não foge a esse fato e ainda é de forma incontestável uma das áreas que mais preocupam os ambientalistas devido a vários motivos como descarte de lixo eletrônico, consumo de energia e emissão de gás carbônico. A computação em nuvem está inserida nesse contexto e também tem sua parcela de responsabilidade nos problemas citados anteriormente. O número de Data Centers cresce vertiginosamente e o consumo de energia aumenta 
de forma proporcional. Com esse aumento do consumo de energia a emissão de gás carbônico também cresce junto, formando um grande efeito dominó. Na verdade um fator está ligado ao outro e, se um cresce, os outros tendem a seguir o mesmo caminho. Tendo todo esse contexto discutido, dentro da computação em nuvem naturalmente nasceu uma sub área de pesquisa voltada para a busca de soluções verdes, a qual foi denominada Computação Verde na Nuvem ou, em inglês, conhecido como Green Cloud Computing.

A proposta deste doutorado é apresentar uma solução verde para o gerenciamento de uma nuvem privada, onde de forma transparente o usuário tem acesso aos serviços da nuvem e pode negociar alternativas de como esse serviço deve ser entregue. Essas alternativas podem variar de acordo com os fatores que o usuário ache relevante, tais como tempo de resposta, consumo de energia, emissão de gás carbônico, dentre outros. Essa solução gerencia todos os quatro estágios de escalonamento em uma nuvem, escolhendo dinamicamente o melhor conjunto de políticas para se obter a melhor solução para o que foi negociado com o usuário anteriormente.

Diante do exposto pode-se afirmar que o GreenMACC é uma extensão do MACC (Peixoto, 2012) que, além de prover QoS, permite o uso de serviços disponibilizados na nuvem por usuários e, de forma transparente, utiliza políticas de escalonamento verde, ou seja, com a preocupação no consumo de energia e redução de $\mathrm{CO}_{2}$. Seu fluxo de dados é diferenciado pois foi projetado visando uma nuvem privada onde o interesse da empresa pela economia de energia fica mais evidente devido à redução de custos nas contas de energia elétrica.

As três seções seguintes apresentam com mais detalhes o GreenMACC. Na seção 4.2 a arquitetura e a implementação do GreenMACC são discutidos, na seção 4.3 é feita a validação da arquitetura e na seção 4.5 faz-se uma comparação qualitativa com outras arquiteturas propostas na literatura.

\subsection{Arquitetura}

Entre o MACC e o GreenMACC podem ser observadas algumas diferenças. A arquitetura modificada pode ser observada na Figura 4.1. A arquitetura proposta possui três camadas: Interface Cliente/Servidor, Núcleo do Metaescalonador e a Camada do Data Center.

A primeira camada é a interface cliente/servidor. Nessa camada encontram-se os módulos responsáveis por permitir a interação do usuário com os serviços disponíveis na nuvem. Além disso, é nessa camada que é feita a negociação com o usuário, permitindo determinar as prioridades para a entrega do serviço requisitado. Em relação ao MACC, nessa camada o controle de valores é retirado, uma vez que a arquitetura proposta será para uma nuvem privada, onde não existe nenhuma aplicação de regras de negócios para cobrança de valores dos usuários. Entram o controle de autenticação e o controle de negociação. O primeiro é responsável pela autenticação do usuário que pode ser feita por login ou outros métodos já conhecidos de autenticação automática. O segundo é responsável por determinar quais as prioridades do usuário para entrega do serviço requisitado, 
ou seja, o que é mais importante para o usuário que está fazendo a requisição? Como exemplo de resposta para essa pergunta tem-se: Tempo de resposta, Economia de energia e Emissão de $\mathrm{CO}_{2}$. Essa decisão pode ser automática, conforme a classe de usuário (gerente, analista, programador, etc), ou permitindo ao usuário escolher as prioridades possíveis.

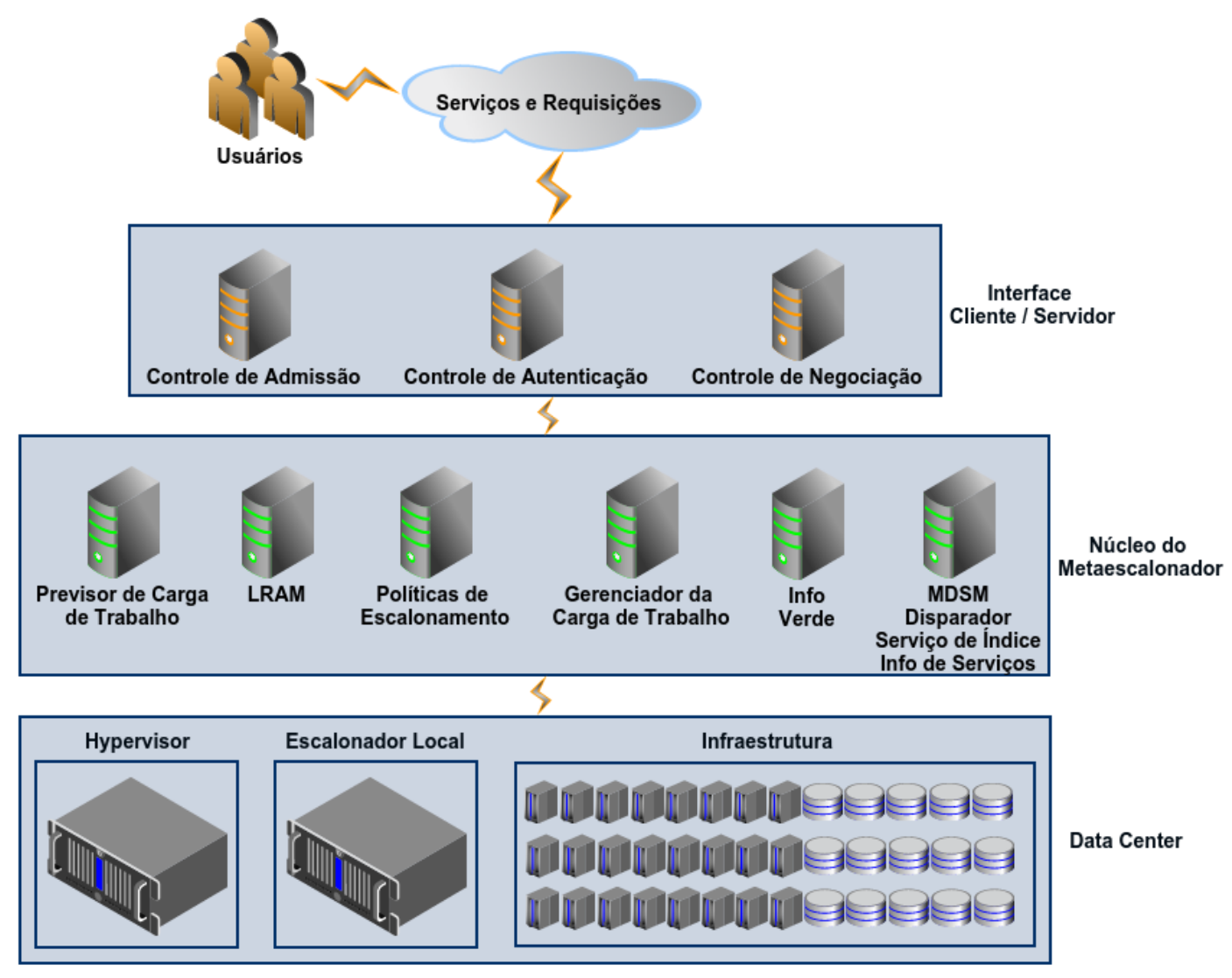

Figura 4.1: Visão Geral do GreenMACC

Na camada do núcleo do metaescalonador foi feita uma adequação do módulo de políticas de escalonamento, possibilitando a implementação de políticas verdes além das que se preocupam somente com a QoS. Para tanto, foram incluídos dois novos componentes: um responsável por conter e atualizar todas as informações necessárias à utilização de técnicas de metaescalonamento verde (Info Verde), tais como: consumo específico de cada processador existente no Data Center, uso de DVFS, o estado de todos os hosts (ligado, desligado, standby), temperatura de um processador, coeficiente de emissão de $\mathrm{CO}_{2}$ de um Data Center, etc; e outro, o Previsor de Carga, responsável pelos dados necessários à previsão de carga de trabalho de cada host ou núcleo de processador, necessários para tomada de decisão de algumas políticas de migração de máquinas virtuais e desligamento dos hosts. Ainda no núcleo do GreenMACC, apresenta-se uma alteração no LRAM (Local Resource Allocation Manager), que diferente do MACC onde ele somente fornecia as informações necessárias para o escalonador, no GreenMACC ele ajuda na tomada de decisão, escolhendo qual política de escalonamento será utilizada em cada uma dos 4 estágios: escolha do 
Data Center, criação da máquina virtual, alocação da máquina virtual e alocação do serviço na máquina virtual. Essa tomada de decisão pode ser feita observando diversos fatores como perfil e histórico do usuário ou analisando a carga atual imposta à nuvem. Para este trabalho a segunda opção foi utilizada.

Para melhor entendimento de como a requisição do serviço é processada e atendida, na Figura 4.2 pode-se observar um diagrama de fluxo de toda arquitetura.

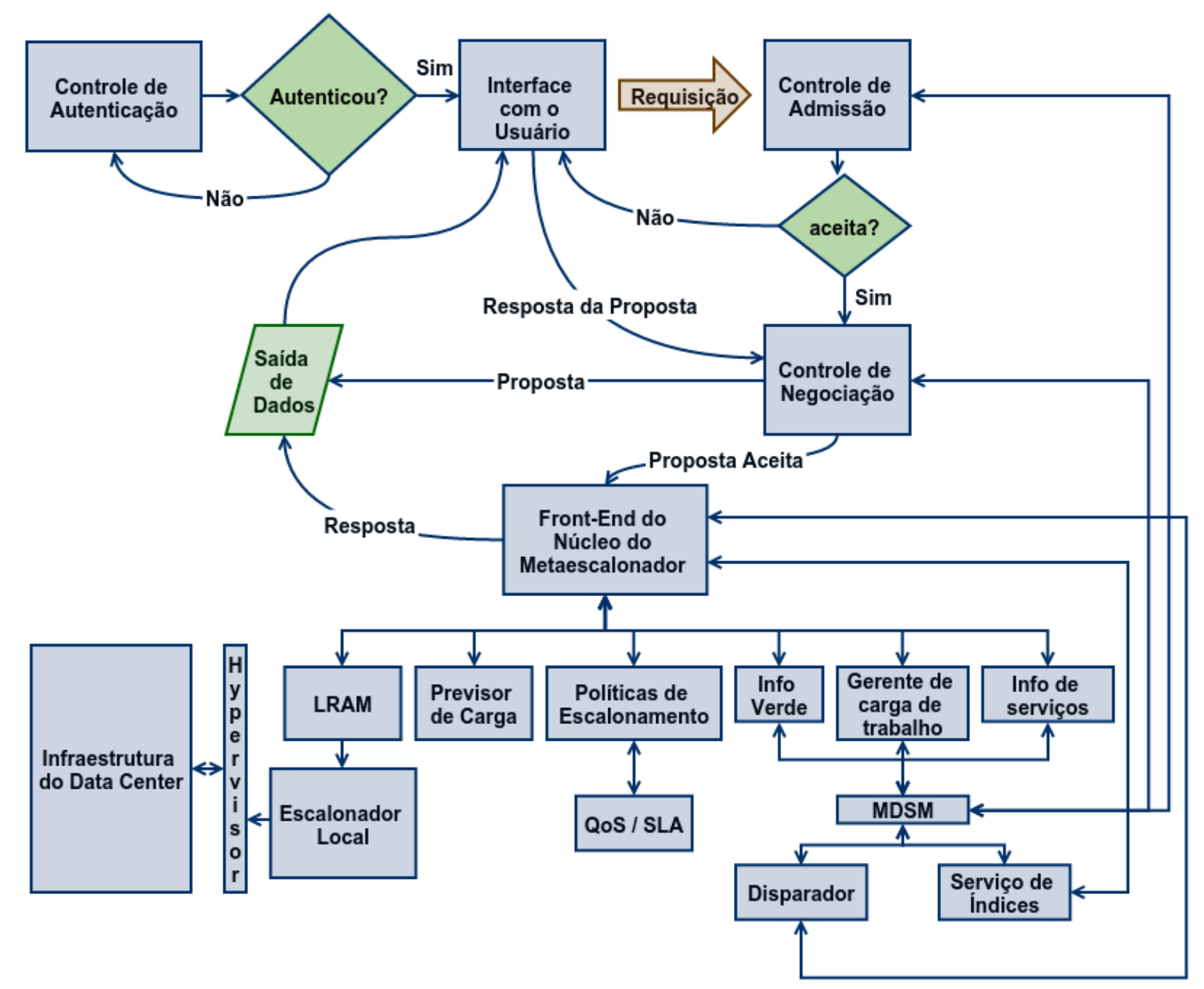

Figura 4.2: Diagrama de Fluxo do GreenMACC

O processo é iniciado com a autenticação do usuário. Em seguida, através da interface com o usuário, cria-se a requisição de serviço pelo usuário. A requisição é enviada para o Controle de Admissão o qual consulta o MDSM (Monitoring and Discovery System Manager) sobre a disponibilidade de recursos e serviços. O MDSM consulta informações de recursos no Serviço de Índice, sobre os serviços disponíveis no módulo de Informações dos Serviços (Info de Serviços) e ainda sobre o tempo necessário para execução do serviço requisitado no Gerenciador de Carga de Trabalho (Gerente de Carga de Trabalho). Nesse momento, o MDSM retorna as informações para o Controle de Admissão e esse decide pela admissão ou descarte da requisição. No caso de existirem recursos suficientes e o serviço requisitado estiver disponível, a requisição é passada 
para o Controle de Negociação. O módulo Controle de Negociação tem como objetivo negociar com o usuário uma forma para que o serviço seja atendido de acordo com o que o usuário deseje, por exemplo, com menor tempo de resposta, menor emissão de $\mathrm{CO}_{2}$, menor consumo de energia, entre outros. Esse processo é chamado de Negociação Verde. Para isso o Controle de Negociação consulta o MDSM que em seguida consulta o módulo de Informações Verdes (Info Verde) sobre as características verdes existentes na arquitetura. Esse último retorna os dados ao MDSM que em seguida são enviados ao Controle de Negociação. Feita a negociação com o usuário, que pode ser feita automaticamente ou não, as informações do contrato (SLA) e de QoS são passadas ao Front-End do núcleo do metaescalonador que as guarda em local específico para serem utilizadas pelas políticas de escalonamento (QoS/SLA). Nesse ponto a requisição é passada ao núcleo do metaescalonador que gerencia todas as informações contidas nos seus componentes. O núcleo envia todas as informações necessárias ao LRAM, onde esses dados são analisados e é tomada a decisão de quais políticas implementadas no metaescalonador serão utilizadas em cada um dos 4 estágios de escalonamento. Feita a escolha, essa informação é passada ao escalonador local onde os estágios de escalonamento são gerenciados. Quando o processamento do serviço é finalizado, a resposta é enviada ao usuário.

Para melhor compreensão de como é o processo como um todo, desde o usuário requisitar o serviço até a resposta desse serviço, são apresentados dois diagramas de sequência. O primeiro pode ser observado na Figura 4.3 onde pode-se observar o processo como um todo. Nesse diagrama assume-se que todas as consultas de disponibilidade de recursos e serviços foram respondidas positivamente e considerou-se também que a negociação verde com o cliente foi bem sucedida. Nesse diagrama o processo interno do núcleo do metaescalonador é omitido com o objetivo de oferecer uma visão geral do tempo de resposta da requisição do serviço. O detalhamento do processo interno do metaescalonador é apresentado no diagrama da Figura 4.4.

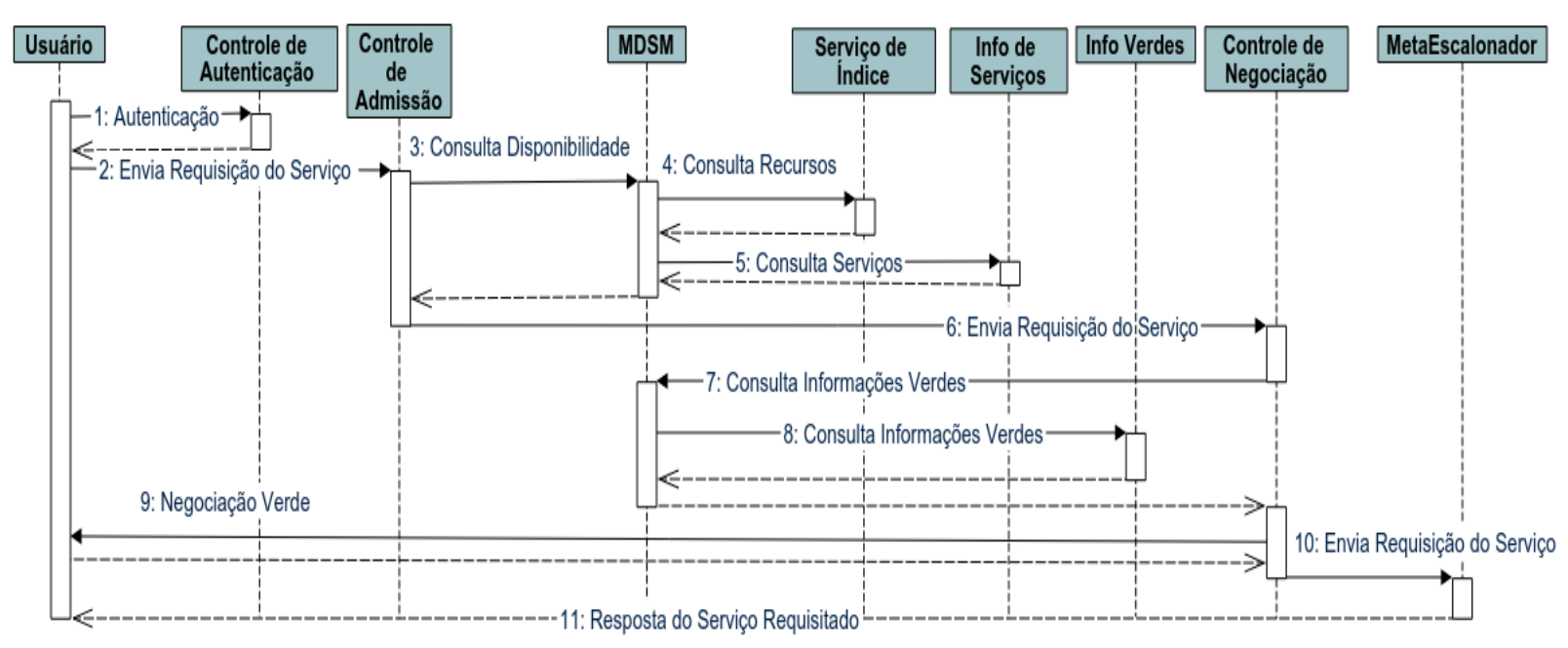

Figura 4.3: Diagrama de Sequência - Visão Geral 
O diagrama da Figura 4.3 permite observar o quão transparente é todo o processo para o usuário. Após a autenticação, o usuário envia a requisição do serviço onde todas as verificações necessárias são feitas sem que esse tome conhecimento do processo. Em seguida, o usuário recebe as propostas de possíveis ofertas do serviço. Após a escolha da proposta que melhor se adéqua as suas necessidades basta aguardar a resposta do serviço. Esse processo pode ser ainda mais transparente se a implementação da negociação for automatizada de acordo com as características ou histórico do usuário. Dessa forma, o usuário após a autenticação envia a requisição e não se preocupa com a negociação que envolve a economia de energia e o SLA.

Na Figura 4.4 pode-se observar a sequência detalhada de ações que ocorrem no núcleo do metaescalonador. Todo esse processo também é transparente ao usuário. Quando a requisição chega ao núcleo do metaescalonador o primeiro passo é enviar as características da carga e, se for o caso também do usuário, para o LRAM, o qual irá escolher a melhor política para cada estágio de escalonamento para esse específico caso. Após a escolha das políticas, o LRAM envia o nome das políticas escolhidas e em seguida essas são acionadas. As políticas escolhidas buscam todas as informações necessárias para sua execução nos módulos QoS/SLA, Informações Verdes e Previsor de Carga de Trabalho. A primeira política a ser executada é a de escolha do Data Center. Em seguida são enviadas as informações e a requisição dos serviços ao escalonador local que cria as Máquinas Virtuais. Logo após criadas, as Máquinas Virtuais são alocadas nos hosts do Data Center escolhido e finalmente os serviços requisitados são distribuídos nas MVs para serem executados.

Na Figura 4.5 pode-se observar o diagrama de sequência que apresenta um erro de autenticação quando o usuário digitado não existe ou no caso da senha ter sido digitada de forma errada pelo usuário.

Na Figura 4.6 é apresentado um diagrama de sequência que demonstra as ações detalhadas de quando um serviço requisitado não existe ou quando não existem recursos suficientes para que o serviço seja executado. O usuário já autenticado faz a requisição do serviço desejado e o Controle de Admissão consulta o MDSM, o qual na sequência consulta os recursos disponíveis no módulo Serviço de Índices e também consulta informações dos serviços disponíveis (Info de Serviços). No caso de não ter recursos suficientes ou o serviço não existir, os módulos responsáveis por essas informações enviam uma mensagem de erro ao MDSM e na sequência envia um sinal de erro identificando o problema ao controle de admissão. Finalmente o módulo de controle de admissão envia uma mensagem de erro ao usuário.

Como já mencionado, o GreenMACC possui 4 estágios de escalonamento: Escolha do Data Center, Criação de Máquina Virtual, Alocação de Máquina Virtual e, finalmente, Alocação do Serviço na Máquina Virtual. Esses estágios são especificados a seguir:

Escolha do Data Center : quando o usuário requisita um serviço a primeira decisão que o metaescalonador deve tomar é escolher qual dos Data Centers disponíveis deverá receber a 


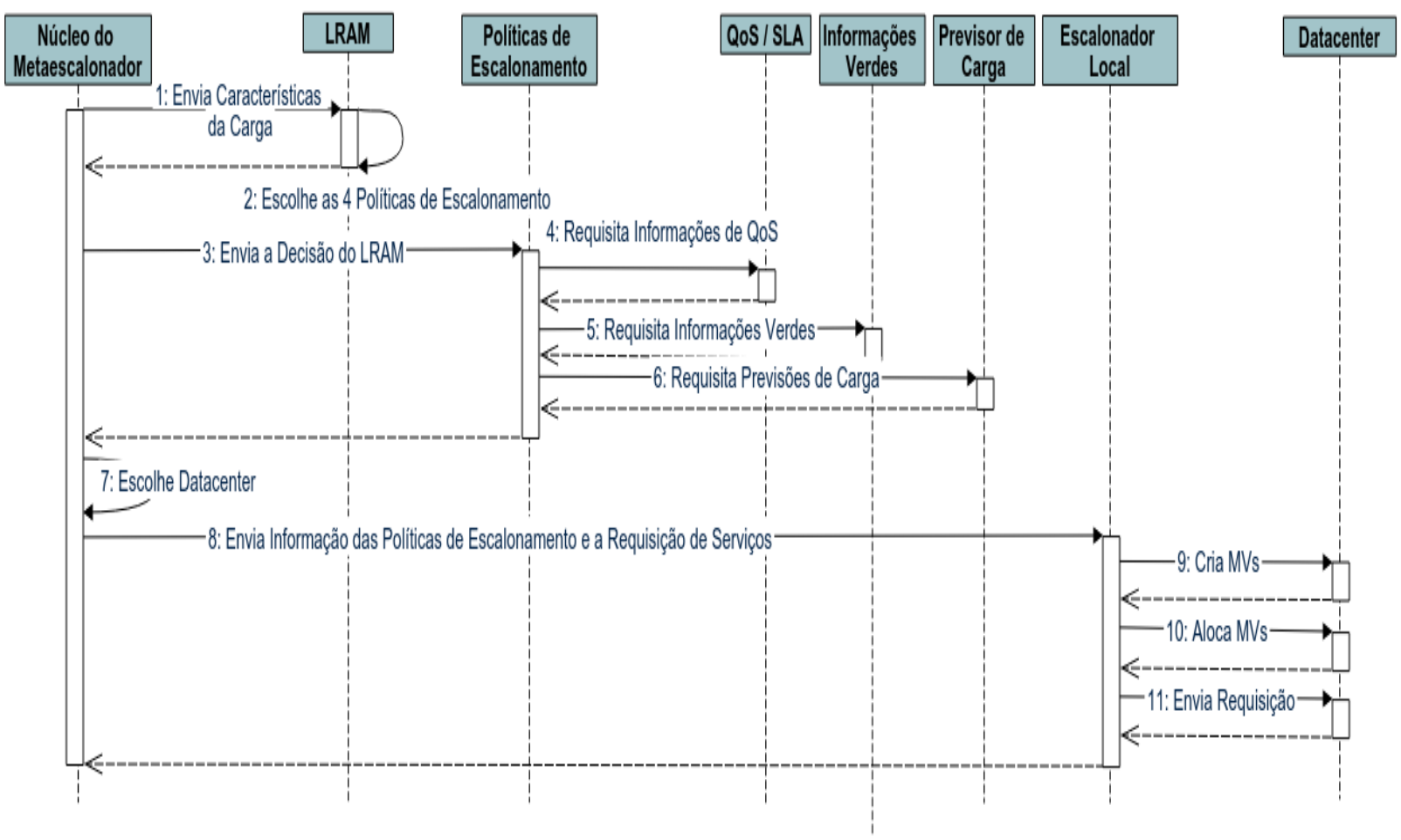

Figura 4.4: Diagrama de Sequência - Núcleo do Metaescalonador

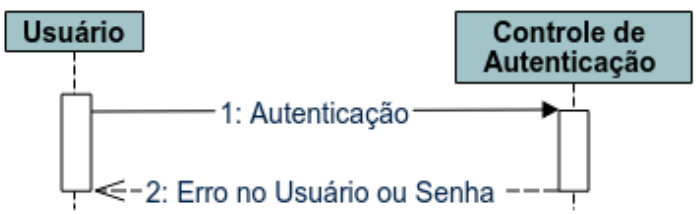

Figura 4.5: Diagrama de Sequência - Erro de Autenticação

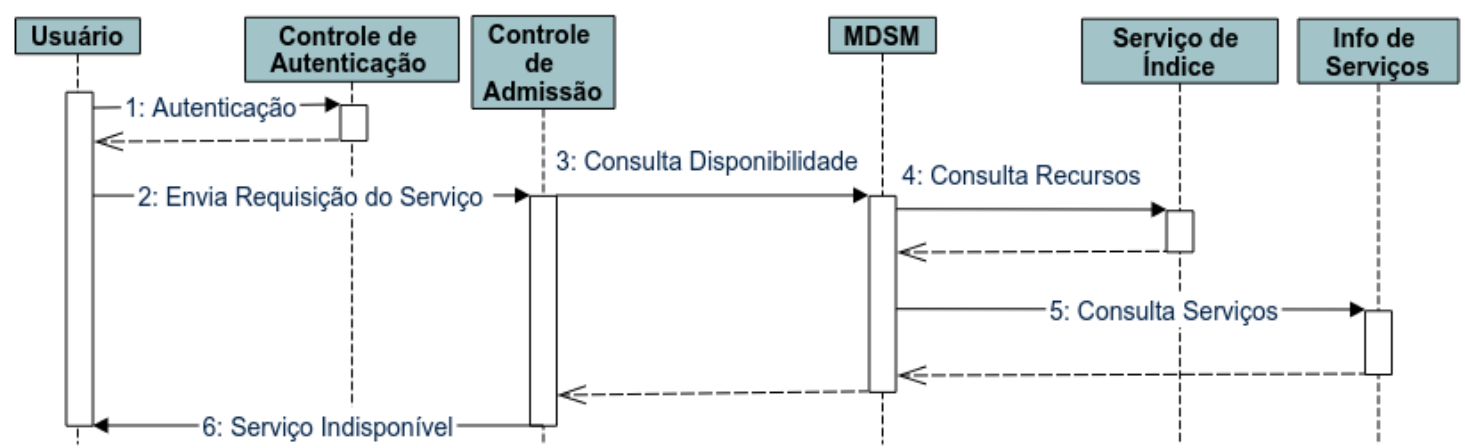

Figura 4.6: Diagrama de Sequência - Serviço Indisponível

requisição e executar o serviço. As decisões tomadas nesse estágio são diversas e o escalonador projetado para esse estágio pode ter pontos de análise muito variados. Por exemplo, pode-se escolher o Data Center com menor latência de rede, ou escolher o que utiliza energia produzida por uma usina menos poluente, etc. 
Criação de Máquina Virtual : após o metaescalonador decidir qual Data Center será o escolhido para executar o serviço, o próximo passo é a criação da(s) Máquina(s) Virtual(is) necessárias para que o serviço seja executado. As políticas desenvolvidas para esse estágio tem como objetivo criar essas MVs de acordo com a demanda. Essas políticas devem observar características do serviço requisitado e criar as MVs com uma configuração que cumpra com o objetivo principal da política desenvolvida para esse estágio. Este objetivo pode ter preocupações verdes ou com a garantia de QoS por exemplo.

Alocação de Máquina Virtual : esse estágio possui 2 momentos sendo que, o primeiro deve decidir quais hosts serão alocados às máquinas virtuais. Quando a política de criação de máquina virtual já especificou a configuração dessas MVs é a política de alocação que escolhe qual local físico (hosts) do Data Center as MV serão criadas para receber os serviços requisitados. O segundo momento de decisão das políticas projetadas para esse estágio é no caso da política fazer ou não a migração de MVs. Existem dois tipos de políticas para esse estágio: as políticas que não fazem migração, ou seja, aloca as MVs nos hosts escolhidos e elas ficam lá até serem eliminadas; e as políticas que fazem migração e decidem em tempo de execução do serviço se as MVs devem ser trocadas entre os hosts por algum motivo. Esse motivo depende diretamente do objetivo principal com que a política em questão foi desenvolvida. Por exemplo, pode-se ter um caso onde um dos hosts está sub-utilizado e as MVs são migradas para outro host e em seguida o host ocioso é desligado para redução do consumo de energia.

Alocação do Serviço : as políticas desenvolvidas para esse estágio determinam como as tarefas (tasks) do serviço serão alocadas nas máquinas virtuais já criadas e alocadas nos hosts do Data Center escolhido. Essas políticas podem ter como pontos de análise para a tomada de decisão as MVs que estão alocadas em hosts que consomem menos energia, ou ainda que possuam o maior processamento pra garantia do QoS por exemplo.

Como já mencionado anteriormente no início dessa seção, o GreenMACC possui 3 camadas distintas: a camada de interface Cliente/Servidor, a camada do núcleo do metaescalonador e a camada do Data Center. Cada uma dessas camadas possuem módulos com características específicas. Alguns desses módulos não foram modificados, ou seja, funcionam exatamente igual como no MACC e definidos na Subseção 3.4.2 do Capítulo 3. Devido a esse fato, nas próximas subseções, onde são definidas as camadas da arquitetura proposta, serão detalhados apenas os módulos que são novos ou que tiveram modificações no seu funcionamento em relação ao MACC.

\subsubsection{Camada de Interface Cliente/Servidor}

Essa camada tem como objetivo principal gerenciar a interação entre o usuário e o servidor do serviço na nuvem. Existem dois tipos de usuários: o administrador do sistema e usuário comum. Se 
o usuário for um usuário comum, essa camada recebe suas requisições, em seguida faz a interface de negociação entre o usuário e a camada do núcleo do metaescalonador. Essa negociação pode ser feita de duas maneiras: manual ou automática. Além disso, é essa camada que retorna ao usuário o resultado do serviço requisitado.

O GreenMACC possui nessa camada três módulos: Controle de Autenticação, Controle de Admissão e o Controle de Negociação. O Controle de Admissão não foi alterado em relação ao MACC. Os outros dois módulos são novos e serão detalhados a seguir.

\section{Controle de Autenticação}

O Controle de Autenticação é o módulo responsável por gerenciar o acesso aos serviços da nuvem através de autenticação do usuário. Como já mencionado, existem dois tipos de usuários: o administrador do sistema e o usuário comum. O administrador é o usuário responsável pela implementação, manutenção e gerenciamento do sistema. E os usuários comuns são os que, de acordo com a configuração do administrador do sistema, têm acesso somente aos serviços oferecidos na nuvem específicos ao grupo que ele pertence (diretoria, gerencia, etc), ou pode ser também especificado de forma individual (Osvaldo, Karin, etc). A técnica de autenticação deve ser escolhida e implementada pelo administrador do sistema.

\section{Controle de Negociação}

O módulo de Controle de Negociação tem a função de verificar com o módulo MDSM da camada do Núcleo do Metaescalonador quais são as informações existentes que permitem uma negociação com o usuário. Essa negociação pode ser feita de forma manual ou automática. A primeira apresenta uma lista de opções ao usuário onde ele escolhe qual sua(s) prioridade(s) para que o serviço seja entregue. Exemplos dessas prioridades são: o tempo de resposta do serviço requisitado, redução no consumo de energia, redução na emissão de gás carbônico, etc. A negociação automática caracteriza-se por já escolher as prioridades previamente configuradas pelo administrador do sistema, automaticamente, de acordo com a identificação do usuário. Após a definição das prioridades, o Controle de Negociação passa essas informações ao núcleo do metaescalonador, mais especificamente ao LRAM que deverá utilizar essas informações para definir a configuração das políticas nos quatro estágios de escalonamento.

\subsubsection{Camada do Núcleo do Metaescalonador}

Essa é a camada intermediária onde é possível garantir, de uma forma transparente ao usuário, a interação entre as camadas de Interface Cliente/Servidor e a camada do Data Center. Devido a isso, ela é responsável por enviar as requisições de serviço da primeira camada para a camada do Data Center e também entregar os resultados desse serviço para a camada de Interface Cliente/Servidor. Na camada do Núcleo do Metaescalonador estão os módulos que têm como objetivo gerenciar todo 
o processo da execução do serviço requisitado e ainda definir quais as políticas que serão utilizadas nos quatro estágios de escalonamento.

Os módulos dessa camada são: Previsor de Carga, LRAM, Políticas de Escalonamento, Gerenciador da Carga de Trabalho (Workload Engine), Info Verde, MDSM, Disparador (Trigger), Serviço de Índice (Service Index) e Info de Serviços (Service Info). Os nomes que estão em parênteses são como são chamados os módulos no MACC. Os novos módulos, ou que foram modificados, nessa camada são o Previsor de Carga, o Info Verde e o LRAM. O módulo MDSM teve um ajuste para conseguir ter acesso ao módulo Info Verde com o objetivo de consultar características verdes e retorná-las ao Controle de Negociação, mas sua essência continua a mesma do MACC.

\section{Previsor de Carga}

Existem algumas políticas de escalonamento que utilizam técnicas de previsão de carga. Essas políticas necessitam de informações prévias do possível comportamento da carga de trabalho em um determinado momento futuro, com o objetivo de fazer a alocação e migração de máquinas virtuais de uma forma otimizada. Essas técnicas que possibilitam prever o comportamento da carga de trabalho devem ser implementadas no módulo Previsor de Carga. Esse módulo tem como objetivo auxiliar o módulo onde as políticas de escalonamento são implementadas. Dessa forma, as políticas de escalonamento que necessitarem utilizar técnicas de previsão de carga acionarão o módulo específico para esse fim.

\section{Info Verde}

As políticas de escalonamento verde necessitam de informações para tomada de decisão. Como já mencionado, neste trabalho essas informações são chamadas de PADEVE. Todos os pontos de análise para decisão dos escalonadores verdes são colocados no módulo Info Verde. Esse módulo também possui todas as informações verdes necessárias para que o MDSM informe ao Controle de Negociação as prioridades possíveis a serem negociadas com o usuário. Dois módulos têm acesso direto ao Info Verde: MDSM e Políticas de Escalonamento. O primeiro acessa para obter quais pontos são negociáveis com o usuário e o segundo para buscar informações necessárias às políticas de escalonamento verdes implementadas. Como exemplo dessas informações verdes temse o coeficiente de emissão de gás carbônico por kWh de cada Data Center da nuvem, qual host utiliza a técnica de DVFS, as latências da rede entre os Data Center, entre outras.

\section{LRAM (Local Resource Allocation Manager)}

O módulo LRAM tem a capacidade de analisar informações sobre o tipo de carga de trabalho imposto pelo usuário e, após essa análise e de forma automática, escolher, dentre as políticas implementadas no módulo Políticas de Escalonamento, quais as que oferecerão um melhor resultado de acordo com a negociação. Essa função importante do LRAM é chamada de automatização do 
GreenMACC, pois permite que as decisões sobre os 4 estágios de escalonamento sejam tomadas de maneira automática. Um detalhamento dessa função será apresentada na Subseção 4.2.4.

Uma informação importante no momento é a diferença de carga leve e carga pesada, isso porque o LRAM observa essa informação para tomada de decisão. A carga leve refere-se a uma carga de trabalho imposta ao sistema que não exige alto poder de processamento, em contraponto a carga pesada é uma carga de trabalho com alta exigência de CPU. Ambas cargas tem características CPU-Bound. Outro ponto importante a esclarecer nesse momento são as possibilidades de fatores negociáveis com o usuário. Esses fatores, ou prioridades, dependem diretamente das políticas implementadas no módulo Políticas de Escalonamento e das informações existentes no módulo Info Verde.

Na subseção 4.2.4 será apresentado como o LRAM decide automaticamente entre as políticas implementadas em cada estágio de escalonamento.

\subsubsection{Camada do Data Center}

A camada do Data Center é onde está a infraestrutura física da nuvem e também onde está localizado o Hypervisor, responsável pela camada de virtualização. Encontra-se também nessa camada o escalonador local. No Capítulo 2 as subseções 2.3.4 e 2.3.5 apresentam um detalhamento sobre virtualização e Data Center respectivamente. Devido a isso, nessa subseção o escalonador local terá uma atenção especial.

O escalonador local é o responsável por executar todas as ações determinadas pelas políticas de escalonamento escolhidas pelo LRAM. Além disso, ele é o ponto de comunicação com a camada do Núcleo do Metaescalonador através do módulo LRAM. Todas as informações necessárias ao processamento do serviço requisitado pelo usuário são passadas ao LRAM que, por sua vez, passa ao escalonador local. Fica livre ao administrador do sistema decidir a melhor forma de como essa comunicação será feita e como o escalonador local será configurado.

\subsubsection{Automatização do GreenMACC}

Como já mencionando, uma importante característica de GreenMACC é sua capacidade de decidir de maneira automática qual a melhor combinação de políticas nos 4 estágios de escalonamento, de acordo com a carga de trabalho imposta e também do que foi negociado com o usuário. O escalonamento é um problema NP completo, dessa forma a automatização no LRAM utiliza da técnica best-effort para chegar no que neste trabalho é chamado de melhor caso. De maneira a exemplificar como essa automatização pode ser implementada, esta subseção irá considerar que os fatores negociados com o usuário foram o Tempo Médio de Resposta (TMR) e o Consumo de Energia (CE).

Como já mencionando, essa negociação é feita pelo módulo chamado Controle de Negociação. O Controle de Negociação apresenta ao usuário opções a serem escolhidas do que é prioridade. 
Somente TMR, ou somente CE, ou ambos. Para o exemplo dado nesta subseção assume-se que o usuário tem o consumo de energia como prioridade. Nesse caso, onde o consumo de energia é prioridade, o TMR pode-se ser relaxado, mas não muito. Assim um deadline para o TMR padrão é estipulado. Para esse exemplo o deadline estipulado é de 40 Unidades de Tempo (UT). Outro ponto importante a ressaltar é que os dados obtidos pelo LRAM são gerados por um benchmark interno que será melhor detalhado na subseção 4.4.

Para se entender melhor como o LRAM toma sua decisão na escolha das políticas, tem-se nas Figuras 4.7 e 4.8 dois gráficos. O primeiro refere-se a resultados obtidos com uma carga de trabalho leve e o segundo apresenta valores obtidos utilizando-se de carga de trabalho pesada. Em ambos os gráficos o eixo x representa valores referentes a consumo de energia em $\mathrm{kWs}$ e o eixo y representa valores referentes ao tempo médio de resposta em unidades de tempo. Os gráficos são divididos em 4 quadrantes. As linhas que separam os quadrantes são definidas seguindo dois critérios diferentes. A linha paralela ao eixo x especifica o limite máximo do deadline estabelecido no contrato com o usuário. A linha paralela ao eixo y é definida pelo valor da média dos valores de consumo de energia obtidos com a carga específica utilizada.

Cada ponto nos gráficos corresponde a uma combinação de políticas de escalonamento nos 4 estágios do metaescalonador. Para esse exemplo são 16 combinação para cada tipo de carga correspondente a combinação total de 2 políticas disponíveis em cada um dos 4 estágios de escalonamento.

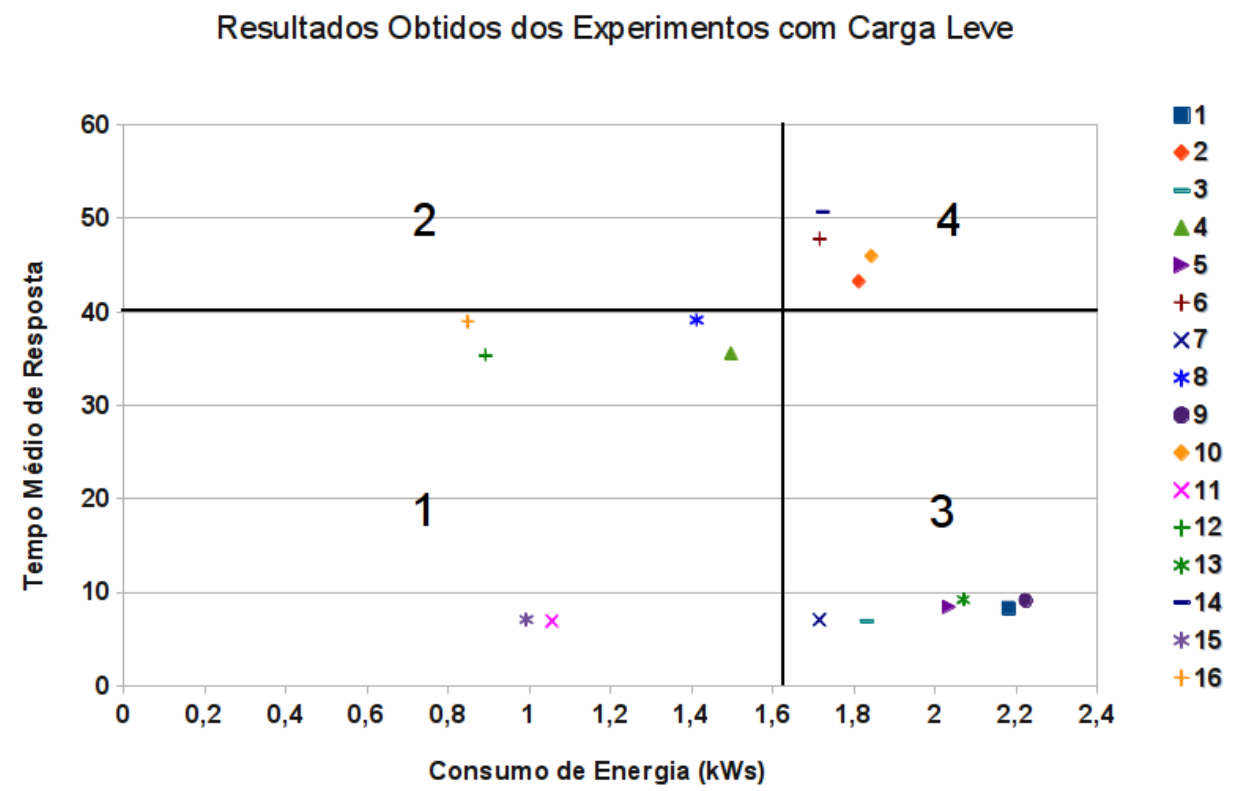

Figura 4.7: Valores Analisados pelo LRAM para Tomada de Decisão (Carvalho Jr et al., 2014)

Com os quadrantes definidos, o LRAM pode tomar a decisão seguindo as seguintes regras na ordem de prioridade:

1. Escolher o caso com o menor consumo de energia no quadrante 1 
2. Escolher o caso com o menor tempo médio de resposta no quadrante 2

3. Escolher o caso com menor consumo de energia no quadrante 3

4. Escolher o caso com menor consumo de energia no quadrante 4

Resultados Obtidos dos Experimentos com Carga Pesada

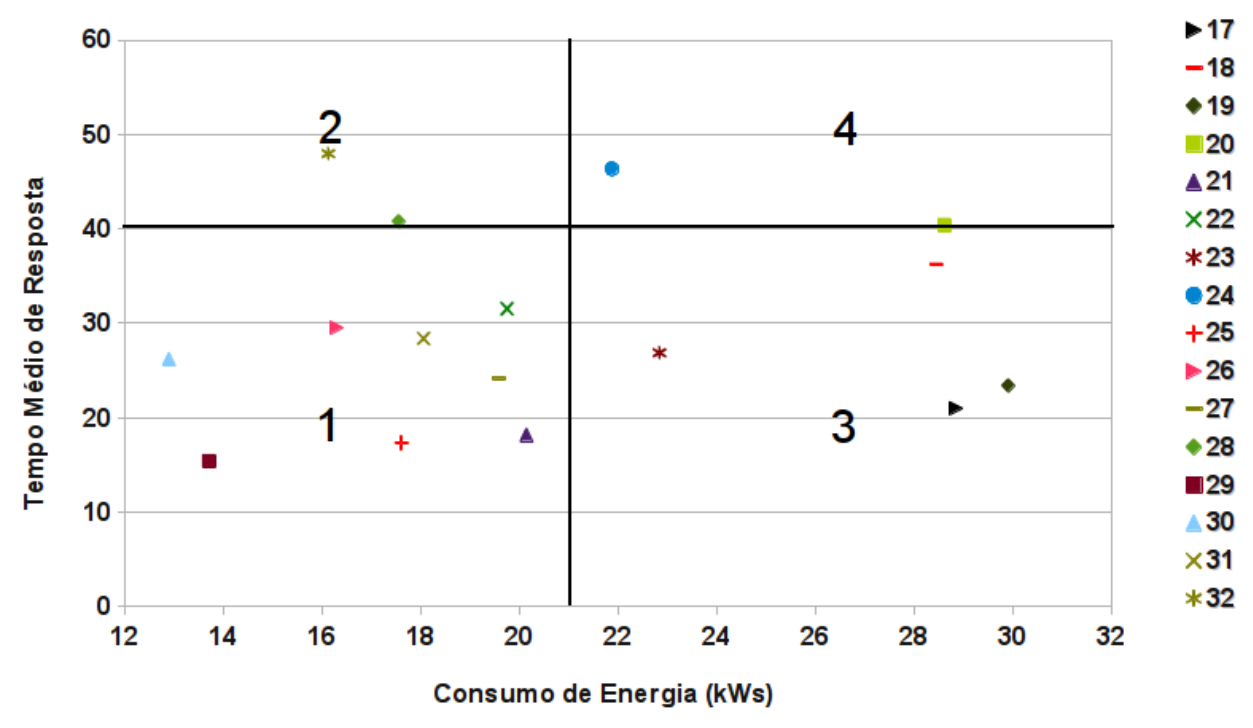

Figura 4.8: Valores Analisados pelo LRAM para Tomada de Decisão (Carvalho Jr et al., 2014)

No Algoritmo 1 pode-se observar como o LRAM está implementado para obter sempre o melhor caso possível. Primeiramente verifica se existem resultados no quadrante 1 e, no caso de existir, retornará a combinação de políticas que fornece o menor consumo de energia uma vez que os casos do quadrante 1 estão abaixo do tempo contratado. Caso não exista nenhum resultado no quadrante 1 o algoritmo procura resultados no quadrante 2, pois supõe-se que a negociação com o usuário dá prioridade à economia de energia. Caso existam valores nesse quadrante a prioridade será os casos de menor TMR. Essa decisão visa obter um valor de consumo de energia abaixo da média e ao mesmo tempo permitir que o deadline seja quebrado com o menor tempo possível. Caso não encontre também no quadrante 2 o próximo quadrante é o 3 . Nesse caso prioriza-se o de menor consumo de energia já que seu tempo está abaixo do deadline estabelecido no contrato. E se nenhum dos casos for encontrado a última opção é o quadrante 4 onde o algoritmo escolhe o que tiver menor consumo de energia.

Com isso pode-se observar que o LRAM, com base nas regras especificadas anteriormente, escolherá o melhor caso buscando sempre o respeito à negociação feita com o usuário. 


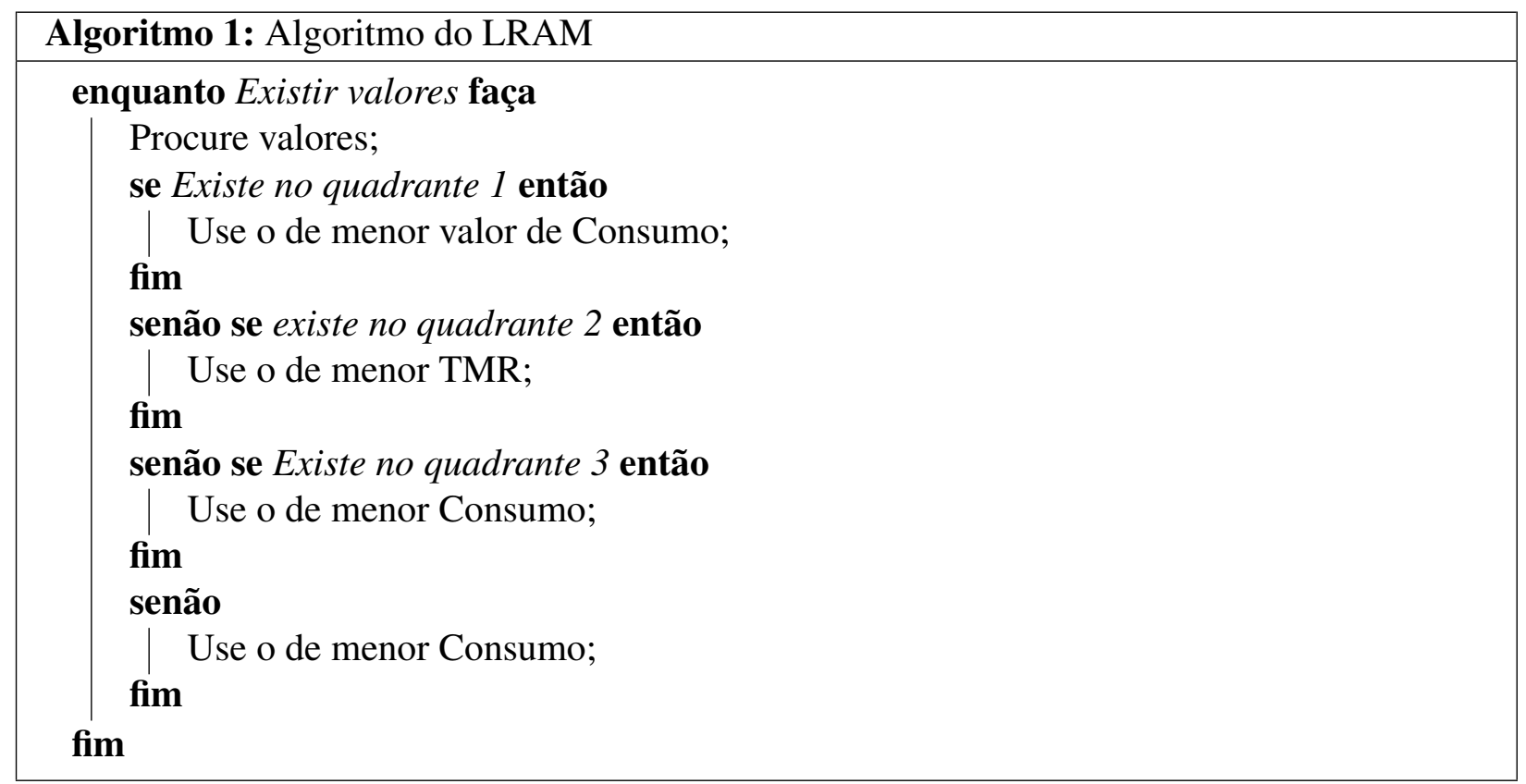

\subsection{Validação}

O objetivo principal desta seção é a validação da arquitetura proposta. Como já relatado anteriormente, o GreenMACC é uma extensão do MACC. O MACC foi implementado no CloudSim 2.1, versão do simulador que tinha poucos recursos para computação verde na nuvem. Quando a versão 3.0 foi lançada com novos modelos de hosts e recursos mais avançados para medição de consumo de energia, migrar o MACC do CloudSim 2.1 para o 3.0 tornou-se uma necessidade uma vez que a ideia era tornar o MACC uma arquitetura que permitisse implementar políticas verdes. Após a migração da arquitetura do MACC para uma versão do CloudSim com mais recursos específicos de computação verde, teve-se início a implementação do GreenMACC. Para implementação da arquitetura proposta nesta tese foi necessária a inclusão de novos módulos, modificações em módulos já existentes e eliminação de módulos não mais necessários.

A implementação do GreenMACC no CloudSim fez-se através da criação de classes, onde cada classe possui todos os atributos e métodos necessários para funcionar exatamente como um módulo específico da arquitetura apresentada neste trabalho. A Figura 4.9 apresenta o diagrama de classes que permite uma melhor visualização, e consequentemente, um melhor entendimento de como o GreenMACC foi implementado no CloudSim.

Na Figura 4.9 é possível observar as classes que são do CloudSim e as classes exclusivas do GreenMACC. As classes CloudSim, Cloudlet, PowerDatacenterBroker, PowerDatacenter, PowerVM, NetworkTopology e PowerHost são classes que já existem no CloudSim e são utilizadas para a construção do modelo da nuvem a ser simulada. As demais classes são exclusivas do GreenMACC, sendo que algumas existem com a finalidade de dar suporte na construção do modelo e gerenciar a execução da simulação, outras são as classes que representam os módulos da arquitetura proposta. 


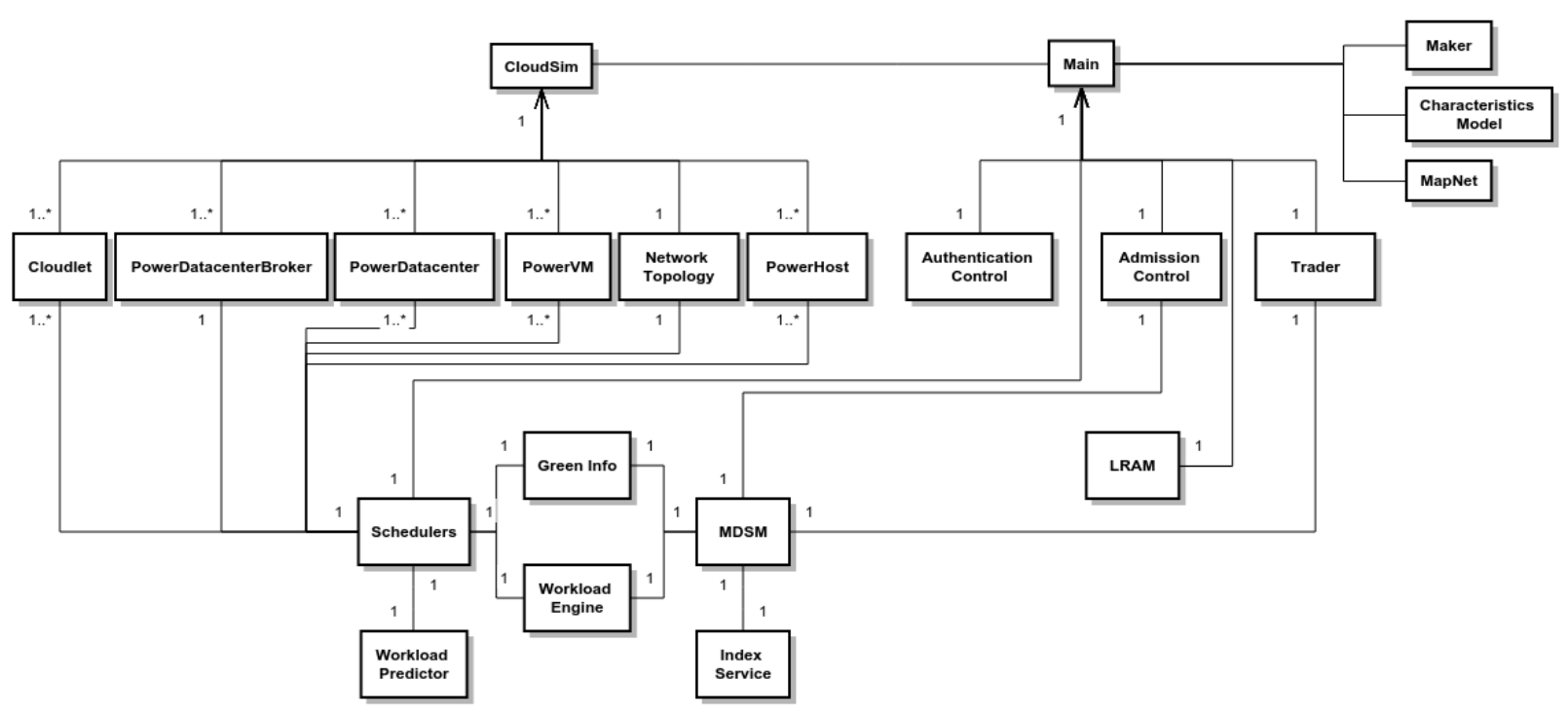

Figura 4.9: Diagrama de Classes do GreenMACC

A classe Main é a classe principal onde se faz o gerenciamento das instanciações dos objetos e também da simulação como um todo. É nessa classe que são gerados os arquivos com os resultados das simulações. Outras três classes fornecem suporte à classe Main: Maker, CharacteristicsModel e MapNet.

A classe Maker é a classe onde são criados de fato os objetos, tais como Data center, Hosts, Broker, etc. A classe CharacteristicsModel é onde são configurados todas as variáveis responsáveis por caracterizar o modelo, como exemplo: número de Data Centers, número de hosts por Data Center, quantidade de núcleos de processamento que cada hosts deve ter, etc. Na classe MapNet estão implementados os métodos responsáveis em criar as conexões da rede da nuvem.

As demais classes são as classes que representam os módulos do GreenMACC. Alguns módulos existentes na arquitetura não estão implementados como classes mas como métodos e atributos. O Disparador e o Info de Serviços são dois módulos do GreenMACC que são métodos e atributos implementados na classe MDSM, os demais módulos são classes que possuem exatamente as mesmas características especificadas na arquitetura.

A primeira necessidade após a implementação do GreenMACC no CloudSim 3.0 foi testar o MACC (2.1) com o GreenMACC (3.0) e analisar se o comportamento dos resultados se mantinham semelhantes. É importante ressaltar que, como os modelos utilizados de hosts, rede, broker, Data Centers haviam sido modificados de uma versão para outra do simulador, os valores dos resultados do MACC no CloudSim 2.1 não seriam idênticos ao do GreenMACC implementado no CloudSim 3.0. Entretanto, esperava-se um comportamento semelhante dos resultados quando comparados os valores de ambas arquiteturas.

Para avaliar o GreenMACC no CloudSim 3.0 optou-se por implementar algumas políticas já existentes na versão 2.1 e executar o mesmo cenário em ambas versões. Como já dito anteriormente, o MACC considera apenas dois estágios de escalonamento: Roteamento e Alocação. O 
Roteamento no MACC equivale ao estágio de Escolha do Data Center no GreenMACC e o estágio de Alocação do MACC, no GreenMACC dividi-se em três estágios distintos: Criação de MV, Alocação de MV e Alocação de Tarefas. A decisão de dividir o estágio de alocação do MACC em três estágios distintos foi tomada devido a modificação feita no LRAM. Como a função do LRAM no GreenMACC é decidir a melhor configuração de políticas de escalonamento, tendo como objetivo cumprir o acordo negociado com o usuário, dividindo-se os estágios as políticas ficam menos genéricas e mais especializadas. Devido a esse fato optou-se pela divisão o que permite ao LRAM uma melhor otimização. Tendo-se como base o estágio de Alocação do MACC, pode-se ter como exemplo uma política que faz a criação de MVs e a alocação de MVs com eficiência, entretanto, não faz a alocação das tarefas do serviço requisitado de uma forma satisfatória. Como no MACC esse estágio é único, a otimização fica prejudicada, uma vez que não é possível trocar a técnica de alocação de tarefas por outra de forma automática.

Nesta seção, para não se ter problemas com a compreensão de conceitos será adotada as nomenclaturas adotadas no MACC (Peixoto, 2012).

Para fazer a avaliação proposta repetiu-se 10 vezes cada cenário, cada uma com uma semente de geração de números aleatórios diferente para que possa ser posteriormente calculada a média e o intervalo de confiança. Isso é necessário pois existe uma aleatoriedade na taxa de chegada das requisições. Foi aplicada a forma de fatorial simples em todos os fatores e níveis para formação dos cenários a serem simulados. No total foram utilizadas 7 políticas de Roteamento e 3 de Alocação. A infraestrutura simulada foi de 15 Data Centers com 1000 hosts cada. Os Data Centers têm característica heterogênea com 3 tipos de hosts distintos em relação ao numero de núcleos. Os hosts podem ter 2, 4 ou 6 núcleos, 16GB de RAM, e rede de 1 Gbit de capacidade de transferência. Essa infraestrutura é igual a utilizada no trabalho onde o MACC é apresentado (Peixoto, 2012). Para essa avaliação foram utilizados 3 fatores (número de usuários, número de serviços e tipo de carga). Para cada fator citado existem 2 níveis. Os fatores e níveis são especificados na Tabela 4.1.

Tabela 4.1: Fatores e Níveis Utilizados

\begin{tabular}{|c|c|}
\hline Fatores & Níveis \\
\hline Número de Usuários & 30 e 60 \\
\hline Número de Serviços & 20 e 100 \\
\hline Tipo de Carga & Leve e Pesada \\
\hline
\end{tabular}

Analisando o número de políticas de Roteamento e de alocação de MVs e a quantidade de fatores e níveis apresentados, torna-se inviável fazer uma avaliação utilizando o fatorial completo visando testar todos os cenários possíveis, uma vez que o objetivo dessa validação é verificar se o comportamento do GreenMACC no CloudSim 3.0 está semelhante ao MACC do 2.1. Dessa forma, utilizando-se de fatorial simples nos fatores e níveis já especificados na Tabela 4.1 tem-se os cenários especificados na Tabela 4.2.

Para cada política de Roteamento testada fixou-se a política de Alocação SD2c e para cada politica de Alocação testada foi também fixada uma única política de Roteamento, a Round Robin. 
Ou seja, aplica-se fatorial simples no cruzamento das políticas nos dois estágios de escalonamento do MACC. Esse cruzamento de políticas pode ser chamado de forma de escalonamento, e pode ser observado na Tabela 4.3. A obtenção dos cenários partiu de um cenário padrão com 30 usuários, 20 tarefas e com tipo de serviço leve. Para cada cenário diferente do padrão variou-se apenas um fator, totalizando assim 4 cenários para cada forma de escalonamento.

Tabela 4.2: Cenários Utilizados

\begin{tabular}{|c|c|c|}
\hline Número de Usuários & Número de Tarefas & Tipo de Serviço \\
\hline 30 & 20 & Leve \\
\hline 30 & 100 & Leve \\
\hline 30 & 20 & Pesado \\
\hline 60 & 20 & Leve \\
\hline
\end{tabular}

As políticas chamadas de Alocação no MACC, especificamente no GreenMACC são de criação das MVs. No MACC, todas as políticas citadas como de Alocação na verdade apenas criam as MVs. As políticas de alocação de MV e de tarefas estão ocultas dentro das políticas de criação de MV e são iguais para todas as políticas citadas no trabalho do Peixoto (2012). A política de alocação de MVs utiliza-se de uma distribuição homogênea das máquinas virtuais para os hosts do Data Center escolhido. E para a distribuição das tarefas é utilizada a política Space-share. A política Space-share caracteriza-se por alocar apenas um serviço para cada MV. Nesse caso, cria-se uma fila de tarefas aguardando sua alocação.

Com o cruzamento das políticas nos estágios de Roteamento e de Alocação tem-se na Tabela 4.3 as seguintes formas de escalonamento.

Tabela 4.3: Formas de Escalonamento

\begin{tabular}{|c|c|c|}
\hline Forma & Roteamento & Alocação \\
\hline 1 & Round Robin & SD2c \\
\hline 2 & BCR (Latência) & SD2c \\
\hline 3 & BCR (Saltos) & SD2c \\
\hline 4 & Chord (Latência) & SD2c \\
\hline 5 & Chord (Saltos) & SD2c \\
\hline 6 & Pastry (Latência) & SD2c \\
\hline 7 & Pastry (Saltos) & SD2c \\
\hline 8 & Round Robin & SD4c \\
\hline 9 & Round Robin & RG \\
\hline
\end{tabular}

Com as simulações de todos os modelos e cenários citados obtêm-se quatro gráficos, um para cada cenário, onde pode-se observar os resultados obtidos nas simulações. Os gráficos estão na Figura 4.10.

No eixo x de todos os quatro gráficos pode-se observar as formas de escalonamento cujos números são expressos na Tabela 4.3. No eixo y pode-se observar o tempo médio de resposta (TMR), em Unidades de Tempo, obtido para cada forma de escalonamento. O primeiro gráfico da Figura 

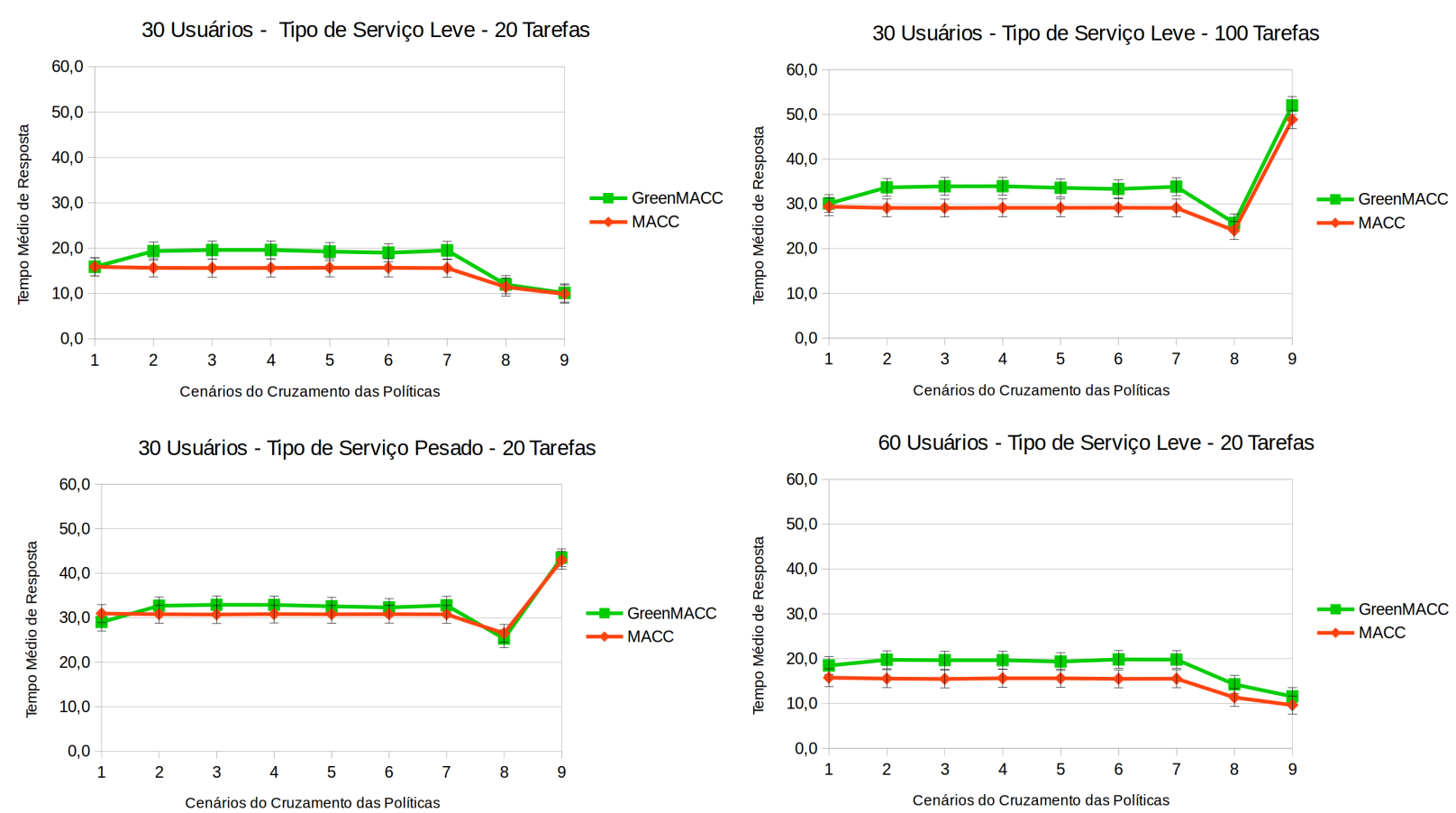

Figura 4.10: Gráficos Comparativos das Arquiteturas MACC e GreenMACC

4.10 representa os resultados das simulações com o cenário de 30 usuários requisitando 20 tarefas para cada com carga de trabalho leve. No segundo gráfico, os resultados representam o comportamento das arquiteturas em um cenário com 30 usuários requisitando 100 tarefas de carga leve. O terceiro gráfico apresenta resultados de um cenário com 30 usuários onde cada usuário faz requisições de 20 tarefas com carga de trabalho pesada. Finalmente, no último gráfico, o cenário com 60 usuários requisitando 20 tarefas com carga de trabalho leve, os resultados comparativos entre o MACC e o GreenMACC são apresentados. Observando-se os 4 gráficos é possível verificar que, como já esperado, os valores apresentados pelas duas arquiteturas não são idênticos. Isso se deve ao fato das classes utilizadas serem diferentes, como exemplo, o MACC utiliza uma classe chamada DatacenterBroker do CloudSim 2.1 para representar o Broker. Já no 3.0, com a possibilidade de implementar modelos que permitam a medição do consumo de energia a classe utilizada é o PowerDatacenterBroker. O mesmo ocorre para as classes de hosts, Data Centers, MVs, etc. Entretanto, pelos resultados apresentados nos quatro gráficos, pode-se observar que o comportamento dos resultados são semelhantes, o que permite afirmar que a implementação do GreenMACC está gerando resultados compatíveis com os resultados gerados pelo MACC na versão 2.1 do CloudSim. Como no trabalho do Peixoto (2012) a Arquitetura do MACC foi validada com esse modelo implementado no CloudSim 2.1, pode-se afirmar que com base nos resultados apresentados na Figura 4.10 o modelo utilizado nesta tese do GreenMACC no CloudSim 3.0 está validado. 


\subsection{Flexibilidade do GreenMACC}

Uma característica importante do GreenMACC é a possibilidade que o usuário tem de inserir novas políticas de escalonamento ou novos pontos de análise (PADEVE) e negociação com o usuário. Para que o LRAM possa tomar a decisão que atenda o que foi negociado com o usuário, as informações que ele consulta precisam ser atualizadas. Todo esse processo só é possível pelo fato do GreenMACC ser uma arquitetura flexível e nesta seção será detalhado como isso pode ser implementado.

O GreenMACC, como já demonstrado na Figura 4.1, possui uma interface com o usuário. Essa interface permite a interação com dois tipos de usuários. O usuário comum que utiliza o sistema apenas para requisitar um serviço, e o usuário avançado, o qual é o administrador do sistema. A interface com o administrador permite a ele inserir políticas de escalonamento em qualquer um dos quatro estágios de escalonamento do GreenMACC. Além da inserção de novas políticas, o administrador também pode inserir novas variáveis com o intuito de obter mais informações sobre o sistema ou para utilizar como variáveis de entrada nas novas políticas implementadas.

Na Figura 4.11 pode-se visualizar uma possível interface do GreenMACC com o administrador do sistema. Essa interface permite ao administrador inserir novas políticas no GreenMACC além de novas variáveis. No combobox à esquerda, o administrador escolhe em qual dos 4 estágios de escalonamento que a nova política será inserida. Logo abaixo do combobox está o campo referente a data que as alterações deverão começar a valer. No centro da janela está a caixa de texto onde o administrador deve implementar a nova política. Na caixa de texto menor à direita, as novas variáveis podem ser inseridas. No canto direito abaixo da caixa de texto menor fica o campo onde pode-se selecionar a forma que o LRAM deve analisar as novas variáveis de saída. O intuito dessa informação é deixar claro para o LRAM se os valores menores da nova variável são melhores resultados do que os de valores maiores ou vice-versa. No caso onde várias variáveis possuem a mesma configuração para o campo Melhor Valor, a inserção dessas variáveis pode ser de uma vez. Caso contrário, a inserção dessas variáveis deve ser feita separadamente. No caso do administrador desejar inserir somente uma nova variável sem uma nova política ou somente uma nova política sem uma nova variável, basta deixar a caixa de texto referente ao dado não inserido em branco.

Para demonstrar melhor a flexibilidade do GreenMACC, pode-se utilizar como exemplo a inserção de uma nova política que também precisa de novas variáveis. A política baseada na emissão de $\mathrm{CO}_{2}$ (CEB - $\mathrm{CO}_{2}$ Emission Based), que é baseada nos trabalhos de (Garg et al., 2010) (Garg et al., 2011), enquadra-se nesse caso por ser uma nova política que utiliza de uma nova variável de análise, o coeficiente de consumo de $\mathrm{CO}_{2}$. A política CEB escalona de forma que as requisições são distribuídas para os Data Centers que possuírem o menor coeficiente de consumo de $\mathrm{CO}_{2}$, ou seja, a menor emissão de $\mathrm{CO}_{2}$ por Kilowatt/hora consumido. Sua vantagem é que sempre haverá prioridade na escolha de Data Centers que poluem menos. Entretanto, a escolha do Data Center pode não ser a ideal para redução do consumo de energia ou qualidade do serviço. 


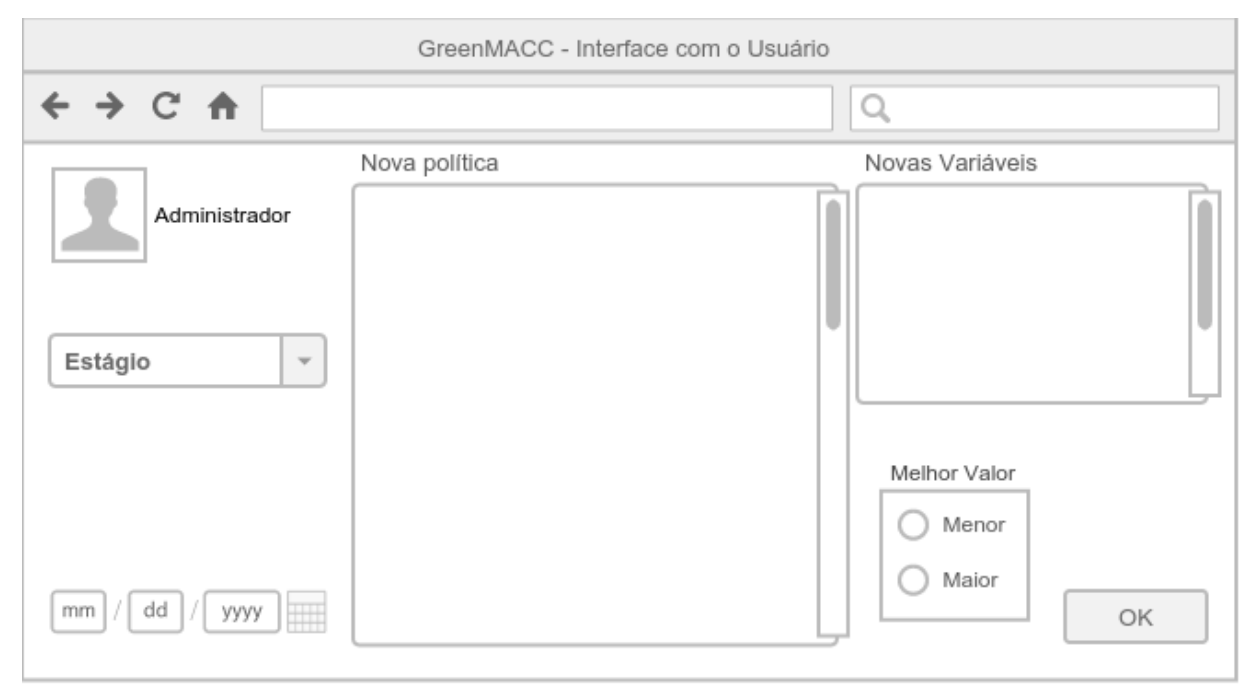

Figura 4.11: Interface do GreenMACC com o Administrador do Sistema

Para inserção dessa nova política, o administrador do sistema deve inicialmente indicar no combobox à esquerda que a nova política deve ser inserida no estágio de escolha do Data Center. O sistema coloca no campo específico a data atual automaticamente, ou seja, deve ser alterada somente se o administrador decidir por alguma questão técnica que a data de atualização do sistema deva ser diferente da data do dia que a nova política está sendo inserida. Na caixa de texto central, o administrador deve implementar o código da nova política CEB. Na caixa de texto menor a direita deve-se inserir a variável responsável por guardar a emissão de gás carbônico por kW/h de cada Data Center. No campo abaixo o campo "Menor" deve ser selecionado, pois nesse caso os valores menores de emissão de gás carbônico são melhores do que os com maior emissão de $\mathrm{CO}_{2}$ na atmosfera.

Quando o administrador clicar no botão OK uma série de ações serão executadas no sistema de forma automática. A primeira ação será inserir a nova política no módulo Políticas de Escalonamento do GreenMACC no primeiro estágio de escalonamento, ou seja, o de escolha do Data Center. Em seguida a nova variável, responsável por armazenar o coeficiente de emissão de $\mathrm{CO}_{2}$ de cada Data Center, será inserida em uma tabela já existente no módulo Info Verde. Com a inserção da variável no Info Verde, seu conteúdo passará a ser considerado pelo módulo Controle de Negociação nas futuras negociações com o usuário. A última ação é passar ao módulo LRAM a informação de que os valores menores de emissão de gás carbônico são os melhores resultados. Esses dados são importantes no momento da execução do benchmark para atualização do LRAM. Essa atualização possibilita ao módulo LRAM inserir no seu leque de opções a nova política implementada.

É importante frisar que a flexibilidade do GreenMACC se restringe à sua arquitetura. A cada nova variável inserida no GreenMACC, a infraestrutura deve também ser atualizada. Ou seja, no caso da variável de emissão de $\mathrm{CO}_{2}$, o administrador de cada Data Center da nuvem deve configurar o sistema para que os DCs informem os dados necessários ao GreenMACC para que a 
nova política possa utilizá-la. Essas informações enviadas de cada DC serão inseridas pelo sistema de forma automática na tabela do módulo Info Verde.

Um outro fato importante a ser discutido é como o LRAM se autoconfigura. O LRAM executa um benchmark no momento em que são inseridas uma nova política e/ou uma nova variável. Esse benchmark pode ser melhor visualizado na Figura 4.12.

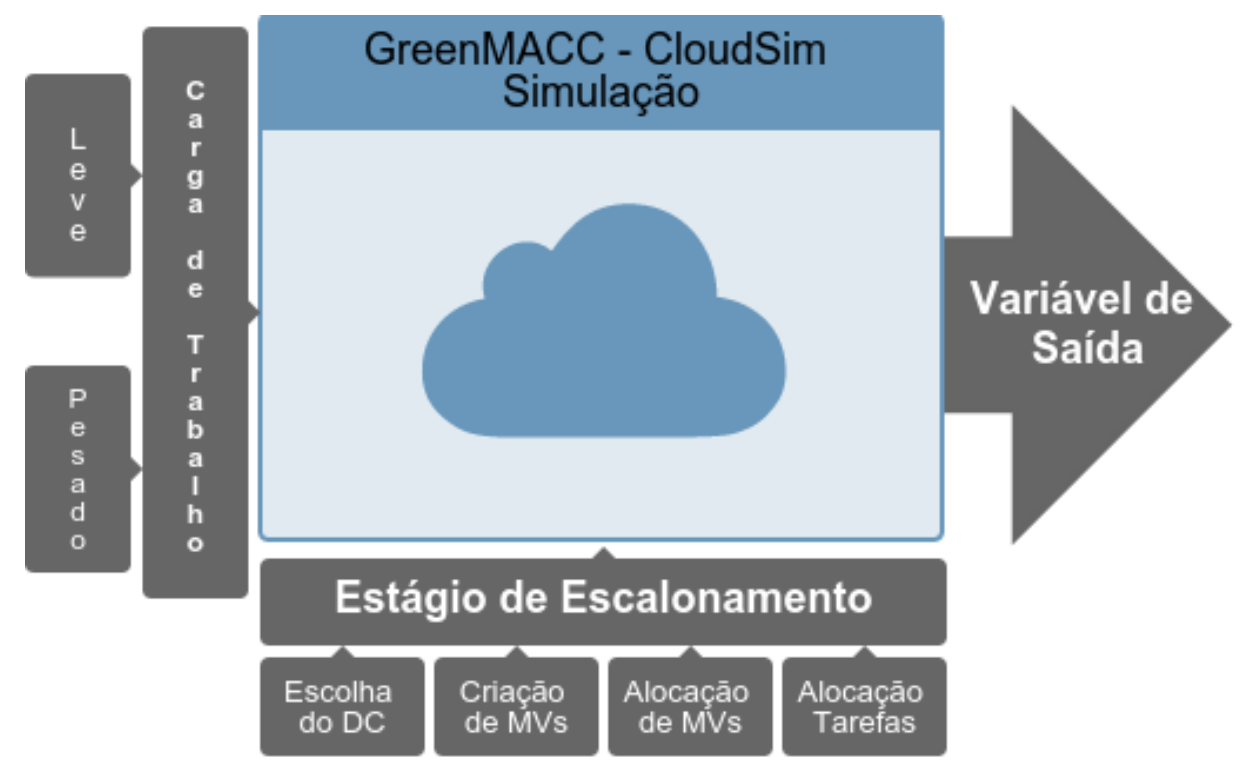

Figura 4.12: Benchmark utilizado pelo LRAM

O benchmark é na verdade a simulação do próprio GreenMACC utilizando-se o CloudSim (Calheiros et al., 2009) (Calheiros et al., 2011) na versão 3.0, como descrito na seção 4.3. No caso da configuração do benchmark, o modelo utilizado para as simulações para esse exemplo específico possui as seguintes características: 15 Data centers com 1000 hosts cada. Os hosts podem ter dois, quatro ou seis núcleos divididos igualmente em cada Data Center. As características fixas dos hosts são a memória RAM de 16GB e Bandwich de $1 \mathrm{Gbit} / \mathrm{s}$. As simulações são feitas considerando a execução de uma nuvem privada por 24 horas, com Data Centers espalhados pelo mundo nos cinco continentes. Todos os Data centers oferecem o mesmo serviço. Os dados armazenados e as aplicações e serviços não estão distantes geograficamente, ou seja, os dados são replicados em todos os Data Centers. Todos os serviços oferecidos são de aplicações com características CPU-Bound. Esse modelo de replicação de dados em todos os Data Centers pode ser utilizado por empresas que oferecem os mesmos serviços em todos os seus Data Centers. Cita-se como exemplo uma empresa bancária onde os serviços oferecidos na nuvem são os mesmos independente de sua localização geográfica.

Inicialmente o benchmark foi implementado considerando 2 políticas em cada nível de estágio de escalonamento totalizando 8 políticas. As políticas escolhidas para o benchmark serão detalhadas na seção 5.2. Além desses 4 fatores tem-se a carga como um fator, a qual pode ser leve ou pesada. A carga leve foi modelada em 30 usuários, com requisições de 500 tarefas por usuário 
com pouco processamento. A carga pesada tem 60 usuários, com requisições de 1000 tarefas por usuário e com alta demanda de processamento. Os fatores e níveis são apresentados na Tabela 4.4. O total de cenários considerando as variações dos níveis quando se usa o planejamento fatorial completo é $32\left(2^{5}\right)$.

Tabela 4.4: Fatores e Níveis Utilizados no Benchmark

\begin{tabular}{|c|c|}
\hline Fatores & Níveis \\
\hline Escolha do Data center & RR e BCR \\
\hline Criação de Máquina Virtual & SD2c e SD4c \\
\hline Alocação de Máquina Virtual & Sem Migração e Com Migração \\
\hline Alocação de Serviços & Space-share e Time-share \\
\hline Carga de Trabalho & Leve e Pesado \\
\hline
\end{tabular}

As variáveis de saída consideradas inicialmente para benchmark são o Tempo Médio de Resposta (TMR) que considera o tempo de rede, tempo de fila e o tempo de serviço, e o consumo de energia em kiloWatts/segundo (kW/s). No entanto, essas variáveis podem ser alteradas conforme o usuário escolhe incluir uma nova variável de análise.

A forma de execução do benchmark depende da informação atualizada pelo administrador. $\mathrm{Ou}$ seja, o administrador pode inserir somente uma nova política, ou somente variáveis, ou inserir uma nova política em conjunto de novas variáveis. Em qualquer um dos três casos o benchmark executa 10 vezes cada cenário, cada um com uma semente de geração de números aleatórios diferente para que possam ser posteriormente calculados a média e o intervalo de confiança. Isso é necessário pois existe uma aleatoriedade na taxa de chegada das requisições. Cada uma das três possibilidades é tratada de uma maneira:

- Inserção de uma nova política: nesse caso, aumenta-se o número de cenários, pois agora um dos fatores tem um nível a mais. Para que as informações do LRAM sejam atualizadas, o benchmark deve ser executado novamente, considerando agora essa política como um fator fixo do estágio onde está sendo inserida, e deve-se variar todos os outros 4 fatores (outros 3 estágios de escalonamento e a carga).

- Inserção de uma nova variável: nesse caso, deve-se executar o benchmark inicial com 32 cenários, só que agora tendo como variável de resposta a variável que se deseja incluir.

- Inserção de uma nova política e de uma nova variável: nesse caso, o benchmark deve ser executado para todos os cenários, incluindo a nova política no fator que ela se refere e depois todos os cenários devem ser executados novamente para que os resultados com a nova variável possam ser obtidos.

Na seção 5.5 do capítulo 5 é feito um estudo de caso mais detalhado da flexibilidade do GreenMACC onde é inserida uma nova política com uma nova variável. Nessa mesma seção citada é feita uma avaliação de desempenho que demonstra a consistência e a flexibilidade da arquitetura proposta. 
A vantagem da utilização de uma ferramenta de simulação, nesse caso o CloudSim, é que o modelo da nuvem pode ser calibrado pelo administrador do sistema de acordo com as necessidades do proprietário da nuvem. Ou seja, o número de Data Centers, a quantidade de hosts por Data Center, as características dos hosts, as características das MVs, etc, são dados flexíveis para configurar da forma que o Administrador achar mais adequado.

\subsection{Comparação Qualitativa}

$\mathrm{Na}$ literatura existem diversos trabalhos relacionados ao tema desta tese. A função dessa seção é fazer uma comparação qualitativa onde pode-se fazer uma distinção entre a proposta desta tese com os demais trabalhos relacionados. Na Tabela 4.5 podem ser observadas as arquiteturas avaliadas em relação a seis características: mecanismos de controle de múltiplos Data Centers, controle de usuários, consumo de energia (kWs), emissão de Gás Carbônico $\left(\mathrm{CO}_{2}\right)$, Qualidade de Serviços (QoS) e finalmente escolha automatizada das políticas nos quatro estágios de escalonamento (Auto).

A Tabela 4.5 permite observar as diferenças entre as propostas de arquiteturas para escalonamento em nuvem. O MACC (Peixoto, 2012), arquitetura que serviu de base para o desenvolvimento do GreenMACC, consegue trabalhar com múltiplos Data Centers visando a qualidade de serviços. Entretanto, não tem módulos específicos que permitam a implementação de políticas verdes. O MACC também não tem autenticação e controle de usuários, já o GreenMACC possui, o que permite fazer escolhas automáticas de quais políticas podem ser executadas conforme o perfil do usuário. Essa escolha automatizada pode ser feita também conforme a carga de serviços imposta ao GreenMACC.

Tabela 4.5: Comparação de trabalhos relacionados

\begin{tabular}{|c|c|c|c|c|c|c|}
\hline Arquitetura & Múltiplos DCs & Usuários & $\mathbf{k W s}$ & $\mathbf{C O}_{2}$ & QoS & Auto \\
\hline GreenMACC & $\mathrm{X}$ & $\mathrm{X}$ & $\mathrm{X}$ & $\mathrm{X}$ & $\mathrm{X}$ & $\mathrm{X}$ \\
\hline MACC(Peixoto, 2012) & $\mathrm{X}$ & & & & $\mathrm{X}$ & \\
\hline CAGCA(Garg et al., 2011) & $\mathrm{X}$ & & $\mathrm{X}$ & $\mathrm{X}$ & $\mathrm{X}$ & \\
\hline GreenCloud(Liu et al., 2009) & & & $\mathrm{X}$ & & $\mathrm{X}$ & \\
\hline GCA(Beloglazov et al., 2011) & & $\mathrm{X}$ & $\mathrm{X}$ & & $\mathrm{X}$ & \\
\hline 2níveis(Jayarani et al., 2009) & $\mathrm{X}$ & & & & $\mathrm{X}$ & \\
\hline HICCAM(Bossche et al., 2010) & $\mathrm{X}$ & $\mathrm{X}$ & & & $\mathrm{X}$ & \\
\hline UMATGC2(Zhang et al., 2013) & $\mathrm{X}$ & $\mathrm{X}$ & & & $\mathrm{X}$ & \\
\hline
\end{tabular}

Além do MACC e do GreenMACC o CAGCA (Carbon Aware Green Cloud Architecture) (Garg et al., 2011) também possui a capacidade de gerenciar múltiplos Data Centers. O CAGCA apresenta uma arquitetura verde que permite o escalonamento verde visando tanto o consumo de energia quanto o de emissão de Dióxido de carbono além de se preocupar com o QoS. Entretanto não possui autenticação e controle de usuários nem a capacidade de escolha de múltiplas políticas nos quatro estágios de escalonamento da nuvem. 
O GreenCloud (Liu et al., 2009) não foi projetado para múltiplos Data Centers, não possui controle de usuários e, sua arquitetura prioriza o escalonamento visando a economia de energia e o QoS sem preocupar-se com a emissão de $\mathrm{CO}_{2}$. O GCA (Green Cloud Architecture) (Beloglazov et al., 2011) oferece controle de usuários e técnicas para economia de energia e respeito ao QoS, entretanto não gerencia múltiplos Data Centers e consequentemente não oferece automatização na escolha de políticas nos quatro estágios de escalonamento, além de não ter em suas políticas preocupações com emissão de gás carbônico.

Em 2009, foi proposto um metaescalonador que oferece 2 níveis de escalonamento (Jayarani et al., 2009). Assim como o MACC, o primeiro escolhe o Data Center e o segundo a aloca os recursos do Data Center escolhido. O metaescalonador em dois níveis proposto no trabalho citado consegue trabalhar com múltiplos Data Centers e permite implementar políticas nesse nível de escalonamento. E, assim como o MACC, tem também preocupações com a Qualidade do Serviço oferecido ao Usuário. Entretanto, no trabalho apresentado não é citado nenhum módulo de controle de usuários ou que permita ter controle sobre dados de consumo de energia e emissão de gás carbônico. O metaescalonador de 2 níveis também não oferece a possibilidade de automatizar a escolha de várias políticas de escalonamento para ambos os níveis.

A arquitetura HICCAM (Hybrid Cloud Construction and Management) (Bossche et al., 2010) possui um módulo responsável pelo gerenciamento dos usuários que permite sua autenticação e oferece um controle rigoroso do uso dos serviços oferecidos na nuvem. Suas prioridades são sempre QoS e suas técnicas de escalonamento permitem gerenciar o uso de vários Data Centers. Entretanto, não existe nenhuma preocupação com computação verde nem um sistema automatizado que permita escolher um cardápio de opções de técnicas de escalonamento.

O trabalho mais recente presente nessa comparação com o GreenMACC é a arquitetura de metaescalonamento UMATGC2 (Zhang et al., 2013). Este Metaescalonador possui características muito parecidas com o HICCAM, pois oferece controle de usuários da nuvem, possibilita o escalonamento em um nível acima dos Data Centers e prioriza políticas que visam exclusivamente a Qualidade do serviço oferecida ao seu usuário. O gerenciamento de várias técnicas de escalonamento não existe e não existe na arquitetura nenhuma estrutura que ofereça a possibilidade de gerenciamento do consumo de energia nem de emissão de gás carbônico.

De acordo com o que é exposto nesta seção, pode-se concluir que o GreenMACC é uma arquitetura de Metaescalonamento que abrange várias características e que permite o gerenciamento de todos os usuários através do módulo de Autenticação. A arquitetura proposta nesta tese permite que seja implementada políticas nos 4 estágios. Permite também que sejam implementadas várias políticas em cada um desses estágios, e ainda escolhe automaticamente as melhores políticas para cada um desses estágios visando cumprir de forma otimizada a negociação com o usuário. O GreenMACC permite ainda a implementação de políticas que provisam QoS e de forma conjunta com políticas verdes. 


\subsection{Considerações Finais}

Neste capítulo foi apresentado o GreenMACC, uma arquitetura de metaescalonamento que foi estendida da arquitetura MACC (Peixoto, 2012). Para o GreenMACC foram propostas modificações que permitiram que, além de oferecer QoS na nuvem, também fosse possível a implementação e gerenciamento de políticas de escalonamento verdes.

Sua arquitetura possui módulos específicos para o oferecimento de serviços requisitados por usuários de uma nuvem privada. Além disso, possibilita a negociação com o usuário permitindo que o mesmo opte por prioridades na oferta dos serviços, como tempo médio de resposta, consumo de energia, etc.

Devido às modificações feitas na arquitetura é possível gerenciar diversas políticas para os 4 estágios de escalonamento de forma automática, visando otimizar a oferta dos serviços respeitando a negociação com o usuário.

O GreenMACC é uma arquitetura flexível e que permite a implementação e atualização de novas políticas sem precisar de modificações na estrutura da arquitetura.

As características do metaescalonador proposto permitem afirmar que é uma arquitetura que abrange várias características e que permite, de forma transparente ao usuário, a oferta de serviços de uma nuvem privada de forma ambientalmente sustentável e provendo Qualidade de Serviços.

No capítulo seguinte são apresentadas avaliações de desempenho que visam comprovar as qualidades do GreenMACC. 



\section{Avaliação de Desempenho do GreenMACC}

\subsection{Considerações Iniciais}

$\mathrm{O}$ GreenMACC é uma arquitetura de um metaescalonador que busca oferecer diversas vantagens para quem optar por utilizá-lo. Permite implementar políticas com diversos objetivos nos 4 estágios de escalonamento em uma nuvem. Oferece a possibilidade de negociar com o usuário as prioridades para a oferta do serviço tais como tempo médio de resposta, emissão de gás carbônico, consumo de energia, etc. O Metaescalonador demonstra flexibilidade ao permitir que novas variáveis e políticas com outros propósitos e objetivos sejam implementadas sem a necessidade de mudanças na arquitetura. A possibilidade de escolher automaticamente as políticas nos 4 estágios de escalonamento com o objetivo de otimizar a negociação com o usuário também é uma das principais contribuições deste trabalho.

Neste capítulo são apresentadas diversas avaliações de desempenho da arquitetura proposta. A seção 5.2 tem como objetivo apresentar a metodologia utilizada para obtenção dos resultados apresentados neste capítulo. Na seção 5.3 é apresentada a avaliação de desempenho de uma das funções principais do GreenMACC, a eficiência na escolha das políticas dos 4 estágios de escalonamento. Na seção 5.4 é feita uma avaliação das influências que as políticas dos 4 estágios têm entre elas. Finalmente a seção 5.5 apresenta uma avaliação da flexibilidade do GreenMACC em receber novas variáveis e políticas sem a necessidade de alteração na arquitetura. 


\subsection{Metodologia}

Para avaliar a arquitetura proposta neste trabalho foi utilizada a técnica de simulação. A ferramenta utilizada foi o CloudSim (Calheiros et al., 2009) (Calheiros et al., 2011) na versão 3.0 que já vem sendo utilizado desde suas primeiras versões em diversos outros trabalhos na área de computação em nuvem (Duy et al., 2010) (Jayarani et al., 2009) (Beloglazov e Buyya, 2010b) (Farahnakian et al., 2013) (Cao e Dong, 2013) (Zhu et al., 2013) (Hongyou et al., 2013) (Royaee e Mohammadi, 2013) (Cao e Zhu, 2013) (Chen et al., 2013) (Karthick et al., 2013) (Kaur et al., 2014) (Alahmadi et al., 2014) (Ouyang et al., 2014) (Hosseinimotlagh e Khunjush, 2014).

O modelo utilizado para as simulações é o mesmo apresentado na Subseção 4.3 do Capítulo 4. A implementação do GreenMACC fez-se através da criação de classes e está melhor detalhada na Subseção 4.2.4 do Capítulo 4. Após a implementação do GreenMACC no CloudSim, oito políticas, duas para cada estágio de escalonamento, são implementadas. Os níveis e fatores utilizados para a avaliação de desempenho são as mesmas utilizadas pelo benchmark. As oito políticas de escalonamento e o benchmark são descritos na Subseção 4.3 do Capítulo 4. O ambiente escolhido para execução das simulações é homogêneo, essa decisão se deve ao fato de se utilizar políticas de migração, o que no ambiente homogêneo se torna mais eficiente.

Como já mencionado, o GreenMACC possui 4 estágios de escalonamento: Escolha do Data Center, Criação de Máquina Virtual, Alocação de Máquinas Virtuais e, finalmente, de alocação de tarefas nas Máquinas Virtuais.

As políticas do estágio de escolha do DC são responsáveis pela tomada de decisão da escolha do Data Center que receberá a requisição do usuário e executará o serviço. Neste trabalho foram utilizadas duas políticas de escolha do Data Center: Round Robin (RR), a Baseada na Capacidade da Rede (BCR). Essas duas política já existem no GreenMACC e a escolha dessas duas políticas foi feita com o objetivo de demonstrar a capacidade do GreenMACC de trabalhar com políticas onde o foco não é de GreenIT. Essas duas políticas foram detalhadas na Subseção 3.4.2 do Capítulo 3.

Feita a escolha do Data Center, segue-se para o segundo estágio de escalonamento do Metaescalonador, a criação de Máquinas Virtuais. Nesse trabalho são avaliadas duas políticas de criação, ambas do MACC.

As duas políticas escolhidas são a SD2c (Slotted Dynamic 2 vCores) e a SD4c (Slotted Dynamic 4 vCores). Ambas as políticas são apresentadas na Subseção 3.4.2 do Capítulo 3. A escolha dessas duas tem o propósito de mostrar como o GreenMACC pode trabalhar com diversos tipos de políticas onde seus propósitos podem ser os mais variados possíveis. Além de oferecer ao LRAM políticas que tenham preocupação com a qualidade de serviço, uma vez que o metaescalonador deve também respeitar o contrato com o usuário. Após a criação das MVs, torna-se necessária a alocação das mesmas nos hosts do Data Center escolhido, caminhando dessa forma para o próximo estágio. 
O terceiro estágio do metaescalonador é encarregado de alocar as Máquinas Virtuais criadas no estágio anterior nos hosts físicos do Data Center. Outra tarefa dessa fase é gerenciar as migrações dessas MVs quando a política de escalonamento implementada nesse estágio tem essa característica. Neste artigo, duas políticas foram utilizadas. Uma com características de alocação estática, ou seja, sem migração de máquinas virtuais, e a outra política com características dinâmicas, essa última utilizando a técnica de migração. Ambas políticas foram apresentadas em trabalhos que visam avaliar políticas com preocupações na redução do consumo de energia (Beloglazov e Buyya, 2010b) (Beloglazov e Buyya, 2012). Essa escolha fez-se com o intuito de permitir ao LRAM ter a sua escolha políticas com e sem migração além de permitir entender melhor o comportamento de políticas com e sem migração de máquinas virtuais no GreenMACC. Outro objetivo dessa escolha foi comprovar que a arquitetura proposta permite mesclar políticas de características bem distintas em todos os estágios de escalonamento da arquitetura proposta sem perder o foco na computação verde e na qualidade de serviço.

A política sem migração aloca as Máquinas Virtuais de forma estática nos hosts seguindo uma lista simples. Já a política com migração, Static Threshold tem um limite fixo de SLA (Service Level Agreements). Esse limite do contrato é o fator determinante na tomada de decisão da migração de uma máquina virtual. Após a alocação das máquinas virtuais nos hosts, finalmente pode-se decidir como será a distribuição das tarefas.

O último estágio de escalonamento tem como objetivo escolher a forma da alocação das tarefas nas máquinas virtuais já alocadas no estágio anterior. Para essa tarefa foram utilizadas 2 técnicas de escalonamento já existentes no módulo Políticas de Escalonamento: Time-share e Space-share. As duas políticas já foram utilizadas em trabalhos que se preocupam com economia de energia (Beloglazov e Buyya, 2010a)(Beloglazov e Buyya, 2010b) (Beloglazov e Buyya, 2012), apesar de não terem sido desenvolvidas para esse fim exclusivamente. Foi por esse motivo que ambas foram escolhidas para esse nível de escalonamento.

A política Time-share pode alocar mais de um serviço em uma Máquina Virtual, não sendo criada fila de tarefas aguardando alocação. Já a política Space-share caracteriza-se por alocar apenas um serviço para cada MV. Nesse último caso, cria-se uma fila de tarefas para serem alocados nas MVs criadas no terceiro estágio de escalonamento do GreenMACC.

As métricas consideradas no GreenMACC são o Tempo Médio de Resposta (TMR) que considera o tempo de rede, tempo de fila e o tempo de serviço, e o consumo de energia em kiloWatts/segundo (kW/s). Para fazer a avaliação cada cenário foi executado 10 vezes, cada um com uma semente de geração de números aleatórios diferente para o cálculo da média e do intervalo de confiança, com nível de confiabilidade de $95 \%$. Isso é necessário pois existe uma aleatoriedade na taxa de chegada das requisições. Foi aplicada a forma de fatorial completo com todos os fatores e níveis, ou seja, todos os cenários possíveis foram testados. Na próxima seção, são apresentados os resultados obtidos das simulações dos cenários apresentados anteriormente. 


\subsection{Eficiência na escolha das políticas dos 4 estágios de escalonamento}

Nessa seção são apresentados e discutidos os resultados das simulações descritas na seção anterior. Primeiramente são apresentados os principais efeitos ocasionados no tempo médio de resposta e no consumo de energia quando alterado algum dos 5 fatores avaliados neste trabalho. Em seguida é feita uma avaliação dos resultados obtidos com uma comparação entre cenários diferentes, analisando-se a importância da escolha correta da política de cada um dos estágios de escalonamento em relação a carga utilizada.

As primeiras quatro figuras dessa seção $(5.1,5.2,5.3,5.4)$ apresentam gráficos que permitem que se observe os principais efeitos nas variáveis de resposta gerados pelas políticas de um estágio de escalonamento em relação à outra política do mesmo estágio. Essas variáveis de resposta são o Tempo Médio de Resposta (TMR), medido em unidades de tempo, e o Consumo de Energia, medido em KiloWatts por segundo (kWs). O eixo y dos gráficos representam os valores obtidos pelas políticas apresentadas no eixo x. Cada figura possui quatro gráficos e cada gráfico representa um estágio de escalonamento.

Na Figura 5.1 pode-se observar que as políticas avaliadas dos estágios de Escolha do Data Center (Escolhe DC) e de criação de Máquinas Virtuais (Cria MV) não influenciaram significantemente no Tempo Médio de Resposta (TMR) com uma carga de trabalho leve. Isso se deve ao fato da infraestrutura oferecida (15 DCs com 1000 hosts cada) ser muito superior ao necessário para execução da carga de trabalho exigida. No estágio de Alocação de Máquina Virtual (Aloca MV) a política sem migração se mostra com um TMR menor que a política com migração quando utilizada a carga leve graças ao custo alto que a migração de MVs exige ao sistema como um todo. Dos quatro estágios avaliados, a mudança da política de Alocação de Serviços (Aloca Serviços) são as que mais influenciaram no TMR. A política Space-share mostrou-se bem mais eficiente que a Time-share. Esse fato ocorre devido a política Time-share alocar todas as Máquinas virtuais de uma vez nos núcleos de processamento sem ocorrência de filas. Esse fato gera uma alta ocorrência de troca de contexto no processador tornando o sistema mais lento. Por outro lado a política Space-share isso não ocorre pois aloca-se uma MV por vez não sobrecarregando as unidades de processamento.

A Figura 5.2 apresenta os resultados de TMR com carga de trabalho pesada. Com o aumento da carga, os tempos aumentaram consideravelmente como esperado e a eficiência das políticas ficaram mais evidentes. No estágio de criação de MVs, a política SD4c mostrou-se um pouco mais eficiente do que a $\mathrm{SD} 2 \mathrm{c}$ e a RR apresentou tempos levemente menores em relação à $\mathrm{BCR}$. $\mathrm{O}$ fato da SD4c ter mais vCPUs do que a SD2c influenciou no TMR como esperado. Como a política RR não possui nenhum pré-processamento para a tomada de decisão no escalonamento, ela obteve menores tempos do que a BCR. No estágio de alocação de MV percebe-se uma inversão em relação à carga leve. Com a carga pesada, a política que usou a técnica de migração se mostrou com tempos 


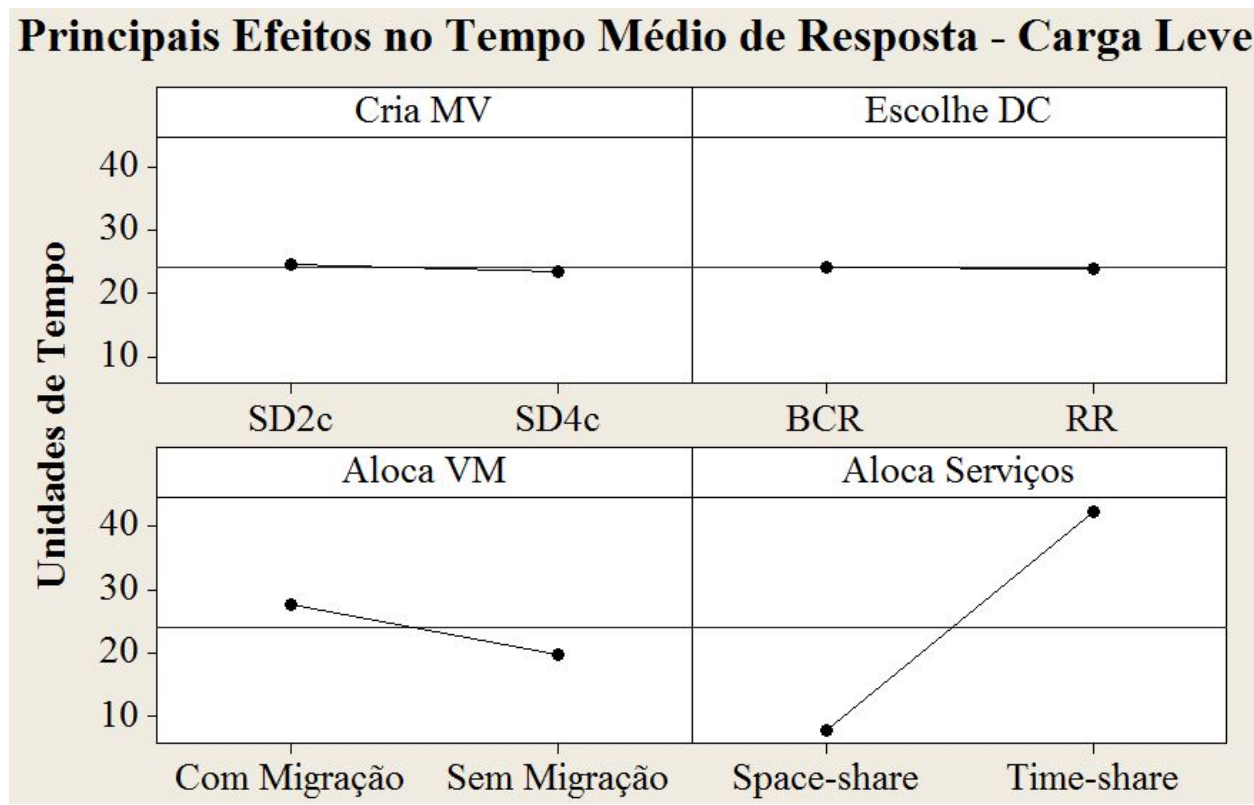

Figura 5.1: Efeitos no Tempo Médio de Resposta com Carga de Trabalho Leve

menores do que a política com características de alocação estática de MV. A explicação para esse fato é o custo da migração de uma MV de um host à outro do Data Center. Com a carga leve a migração de MV não compensa devido ao tempo gasto pelo processo de migração em relação ao TMR. No último estágio de escalonamento a política Space-share se manteve como a mais eficiente pelo mesmo motivo já especificado anteriormente.

\section{Principais Efeitos no Tempo Médio de Resposta - Carga Pesada}

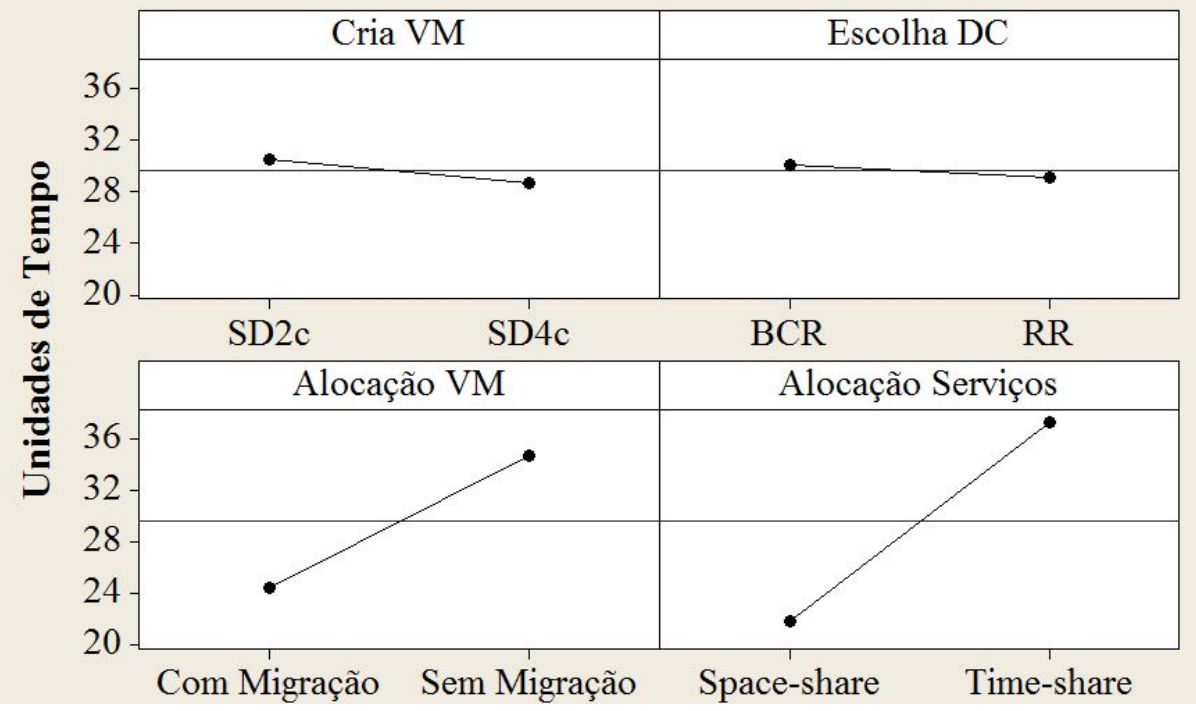

Figura 5.2: Efeitos no Tempo Médio de Resposta com Carga de Trabalho Pesada

O Consumo de Energia (CE) com a carga de trabalho leve pode ser observado na Figura 5.3. A política SD2c consumiu um pouco mais de energia em comparação à política SD4c quando utilizase serviços que demandam pouca carga de trabalho. Supõe-se que isso ocorreu devido a política SD2c ter menos vCPUs do que a SD4c, fato que sobrecarregou mais o sistema aumentando o 


\subsection{EFICIÊNCIA NA ESCOLHA DAS POLÍTICAS DOS 4 ESTÁGIOS DE}

clock dos processadores e com isso aumentando o consumo de energia. A mudança de políticas de escolha de Data Center não influenciou no consumo de energia com a carga leve. Esse fato se deve ao grande número de Data Centers existentes na infraestrutura oferecida para uma carga que não exige grande esforço. A política de alocação sem migração com a carga leve além de ter um TMR menor que a com migração, o consumo também mostrou-se menor. Isso ocorreu pelo mesmo motivo citado anteriormente, ou seja, o custo da migração de MVs para uma carga leve de serviços é muito alta demandando muito trabalho de rede e processamento o que demanda mais consumo de energia. Quando observado o TMR a política do quarto estágio de escalonamento Space-share se mostrou bem superior à Time-Share, entretanto, no tocante ao consumo de energia mostrou-se menos econômica. Isso se deve ao fato da política Time-share não utilizar filas de processos, ou seja, aloca todos os serviços ao mesmo tempo nas máquinas virtuais criadas e já alocadas. Esse fato apesar de demandar mais tempo de resposta mantém o consumo de energia mais linear. Com a política Space-share ocorrem picos de alto processamento o que causa maior consumo de energia.

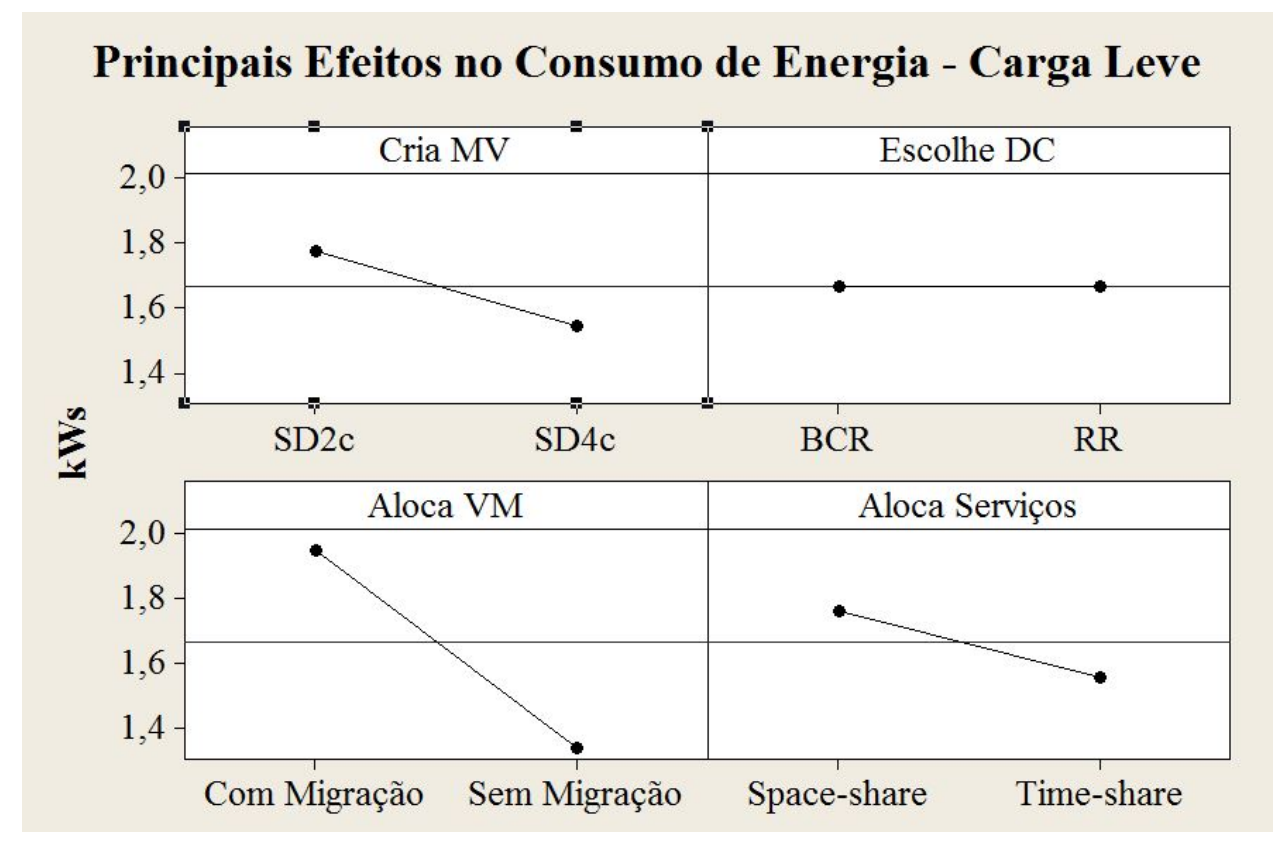

Figura 5.3: Efeitos no Consumo de Energia com Carga de Trabalho Leve

Quando observada a Figura 5.4 pode-se ter algumas conclusões em relação à influência das políticas de escalonamento no consumo de energia com serviços de carga de trabalho pesada. A primeira observação pode ser feita em relação ao aumento do consumo de energia em todos os casos devido ao aumento da carga de trabalho. A política SD2c com a carga leve já tinha um consumo menor que a SD4c e, com o aumento da carga, a melhor eficiência da primeira ficou mais evidente do que a segunda política avaliada. No estágio de escolha do Data Center a política BCR consumiu significativamente menos energia do que a Round Robin. A política RR utiliza todos os Data Centers da nuvem o que permite obter um TMR menor, por outro lado, o consumo de energia tende a ser maior do que a BCR pois a segunda reduz significativamente o número de Data Centers ativos com hosts ligados. No terceiro estágio pode-se observar que a política com 
migração além de ter seu TMR menor que a sem migração, mostrou-se também mais eficiente em relação ao consumo de energia. A partir do momento que a carga aumentou, a migração de MVs passou a compensar, ao contrário de quando se impõe uma carga leve ao sistema. Com o aumento da carga de trabalho, a política Time-share manteve-se como a política mais econômica do quarto estágio pelo mesmo motivo de quando utilizada a carga leve.

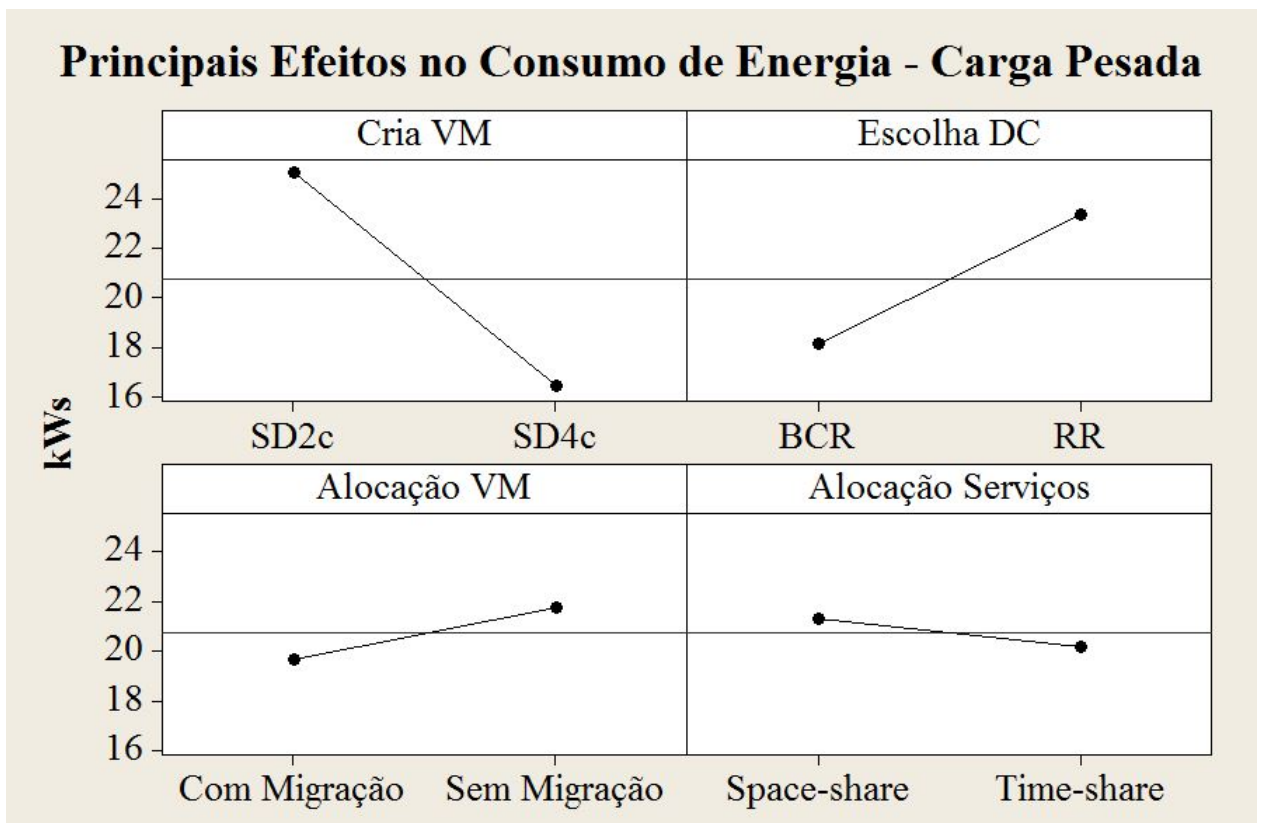

Figura 5.4: Efeitos no Consumo de Energia com Carga de Trabalho Pesada

Com os resultados apresentados neste trabalho torna-se possível fazer uma comparação de cenários onde se pode demonstrar a importância do módulo LRAM fazer uma boa escolha das políticas para cada um dos estágios de escalonamento. O LRAM e a forma como esse módulo faz a escolha das políticas foram apresentados na Seção 4.2 do Capítulo 4.

Para essa avaliação, supõe-se que a negociação com o usuário resultou que seria importante economizar energia. Portanto, o LRAM irá escolher a melhor combinação de políticas de escalonamento que atenda o que foi negociado, que na Tabela 5.1 está definido como melhor caso. O pior caso é definido utilizando-se das regras do LRAM de forma invertida. O processo foi feito tanto para carga leve quanto para carga pesada.

Tabela 5.1: Cenários Escolhidos

\begin{tabular}{|c|c|c|c|c|}
\hline Estágios & \multicolumn{2}{|c|}{ Melhor Caso } & \multicolumn{2}{c|}{ Pior Caso } \\
\hline & Leve & Pesado & Leve & Pesado \\
\hline Escolha do Data Center & BCR & BCR & BCR & RR \\
\hline Criação de MV & SD4c & SD4c & SD4c & SD2c \\
\hline Alocação de MV & S/Migração & C/Migração & C/Migração & S/Migração \\
\hline Alocação de Serviços & Space-share & Time-share & Time-share & Time-share \\
\hline
\end{tabular}

No gráfico à esquerda da Figura 5.5 pode-se observar que quando se faz a melhor escolha das políticas no caso de uma carga de trabalho leve, pode-se obter na média um tempo de resposta seis 
vezes menor em relação ao pior caso. Com a carga pesada, caso a escolha das políticas não seja bem feita, pode-se piorar o tempo médio de resposta em aproximadamente $60 \%$.

Influência da Escolha do LRAM Tempo Médio de Resposta

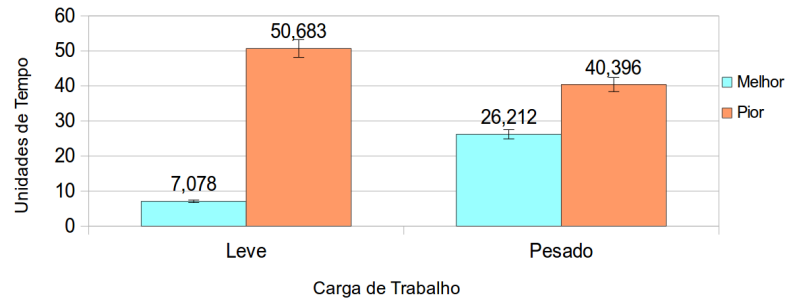

Influência da Escolha do LRAM Consumo de Energia

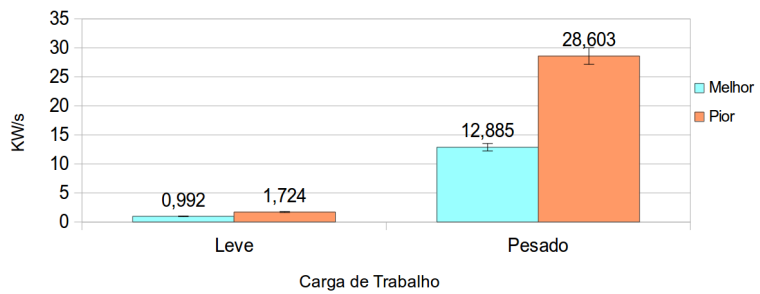

Figura 5.5: Comparação entre o Melhor e o Pior Caso para Tempo Médio de Resposta e Consumo de Energia

Observando-se o gráfico à direita da Figura 5.5 verifica-se que com uma escolha equivocada pode-se ter o consumo de energia do Data Center praticamente dobrado para serviços com carga de trabalho leve. Analisando-se a composição das políticas para cada estágio de escalonamento com serviços de carga pesada, pode-se piorar o consumo de energia do Data Center em mais que o dobro caso seja feita de forma não otimizada.

Nesta seção foram apresentados os resultados obtidos dos experimentos executados para avaliação da eficiência na escolha das políticas nos 4 estágios de escalonamento do GreenMACC e que permitem reforçar alguns pontos relevantes.

A escolha adequada das políticas de escalonamento através da análise do TMR e do Consumo de energia feitas no módulo LRAM do GreenMACC, mostrou-se um forte aliado para se obter menores tempos de resposta, fator crucial para se conseguir respeitar o contrato (SLA) com o usuário, e também para se obter economia de energia em uma nuvem privada. Esse fatos permitem à empresa que utilizar a arquitetura proposta uma considerável redução de custos com energia além de manter a qualidade do serviço prestado aos seus usuários.

Na seção seguinte será avaliada a influência que cada política exerce nas demais políticas de outros estágios de escalonamento.

\subsection{Influência entre as políticas dos 4 estágios de esca- Ionamento}

Continuando a análise da seção anterior, essa seção mostra a influência das políticas de escalonamento de cada um dos quatro estágios de escalonamento. O tipo de carga de trabalho (leve ou 
pesada) e a variável de resposta (TMR ou o consumo de energia) podem ser observados no título de cada figura.

A primeira coluna de cada figura refere-se aos resultados do estágio de Criação de MV e a segunda coluna apresenta os resultados do estágio de Escolha do Data Center (DC). Na terceira coluna, o resultado da Alocação de Máquinas Virtuais podem ser observados e, finalmente, a última coluna mostra os resultados de Alocação de Tarefas em máquinas virtuais. Cada linha também fornece um estágio de escalonamento do GreenMACC na mesma ordem que as colunas. Nas figuras dessa seção, as interações das políticas em cada estágio com as políticas de outros estágios podem ser observadas através da mesma linha, de modo que essa análise pode ser feita observandose as linhas dos gráficos. Para analisar se há interação entre as políticas, é necessário observar se as linhas no gráfico são paralelas. Se forem, mostra que não há interação, caso contrário, há uma interação entre as políticas.

Afirmar que uma política de escalonamento, que para este caso é representada pela letra $a$, interage com outra política aqui representada pela letra $b$, é o mesmo que afirmar que quando as políticas $a$ e $b$ são utilizadas simultaneamente, uma em cada estágio, a política $a$ influencia os resultados obtidos pela política $b$, e vice versa.

Na Figura 5.6, os resultados da simulação, com carga de trabalho leve e o tempo médio de resposta (TMR) como variável de resposta podem ser analisados. Na primeira linha da Figura 5.6 pode ser observado que todos os gráficos têm linhas em paralelo. Neste caso, pode-se afirmar que não há nenhuma influência no tempo médio de resposta dos serviços solicitados, mesmo que haja mudanças na escolha de políticas durante outras fases de escalonamento. Na segunda linha da Figura 5.6, observando-se o terceiro gráfico, pode-se afirmar-se que há uma ligeira influência entre a fase de Alocação de Tarefas e a escolha de Data Center. No terceiro gráfico da terceira linha observa-se que as linhas não são paralelas, o que caracteriza a influência entre as políticas de alocação de tarefas e as políticas de alocação de MV. A última linha comprova as influências descritas na segunda e terceira linhas.

Considerando as políticas avaliadas, a conclusão sobre a Figura 5.6 é que a decisão do LRAM sobre as políticas de Escolha de Data Center e políticas de Alocação de MVs podem ser influenciadas de acordo com a política de Alocação de Tarefas escolhida.

Os gráficos da Figura 5.7 mostram a interação entre as políticas dos quatro estágios de escalonamento com carga de trabalho leve e considerando-se o consumo de energia (em $\mathrm{kW} / \mathrm{s}$ ). $\mathrm{Na}$ primeira linha, tanto o primeiro quanto o terceiro gráficos apresentam linhas paralelas, mostrandose que não há influência entre as políticas dos estágios de Escolha de Data Center e de Alocação de Tarefas sobre os resultados de consumo de energia nas políticas de Criação de MV. No entanto, no segundo gráfico pode-se observar a influência entre as políticas de Alocação de MV e as políticas de Criação de MV. Na segunda linha, os resultados mostram que a escolha do Data Center não é influenciada pelas demais, uma vez que todos os gráficos apresentam linhas paralelas. O primeiro gráfico na terceira linha reforça a influência da mudança de política de Alocação de MV sobre os 


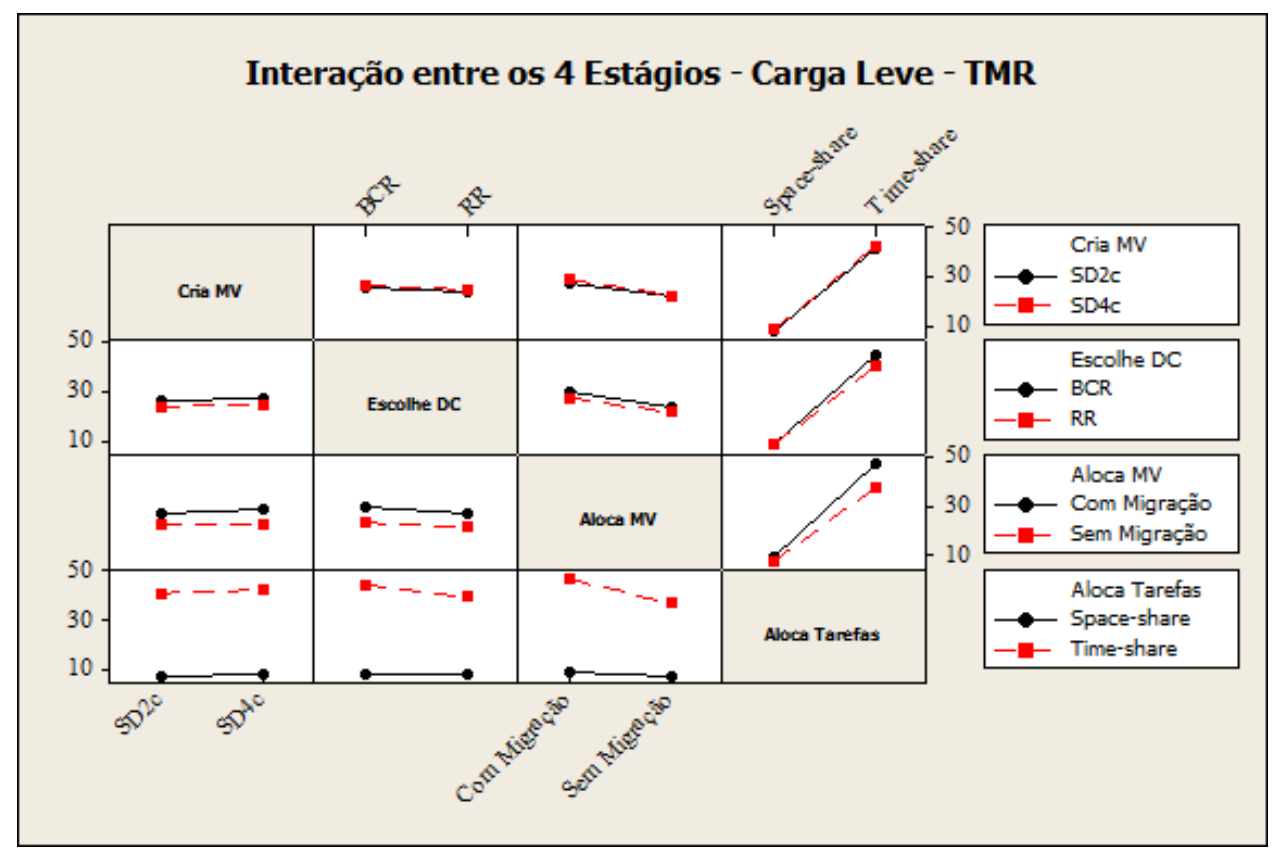

Figura 5.6: Influência no Tempo Médio de Resposta com carga de trabalho Leve

resultados das políticas de criação de MV. Finalmente, o último gráfico da terceira fila também tem linhas paralelas, não mostrando nenhuma influência entre as políticas.

Considerando as políticas avaliadas, a conclusão sobre a Figura 5.7 é que a decisão do LRAM sobre políticas de criação de MV pode ser influenciada de acordo com a política de Alocação de MV que é escolhida.

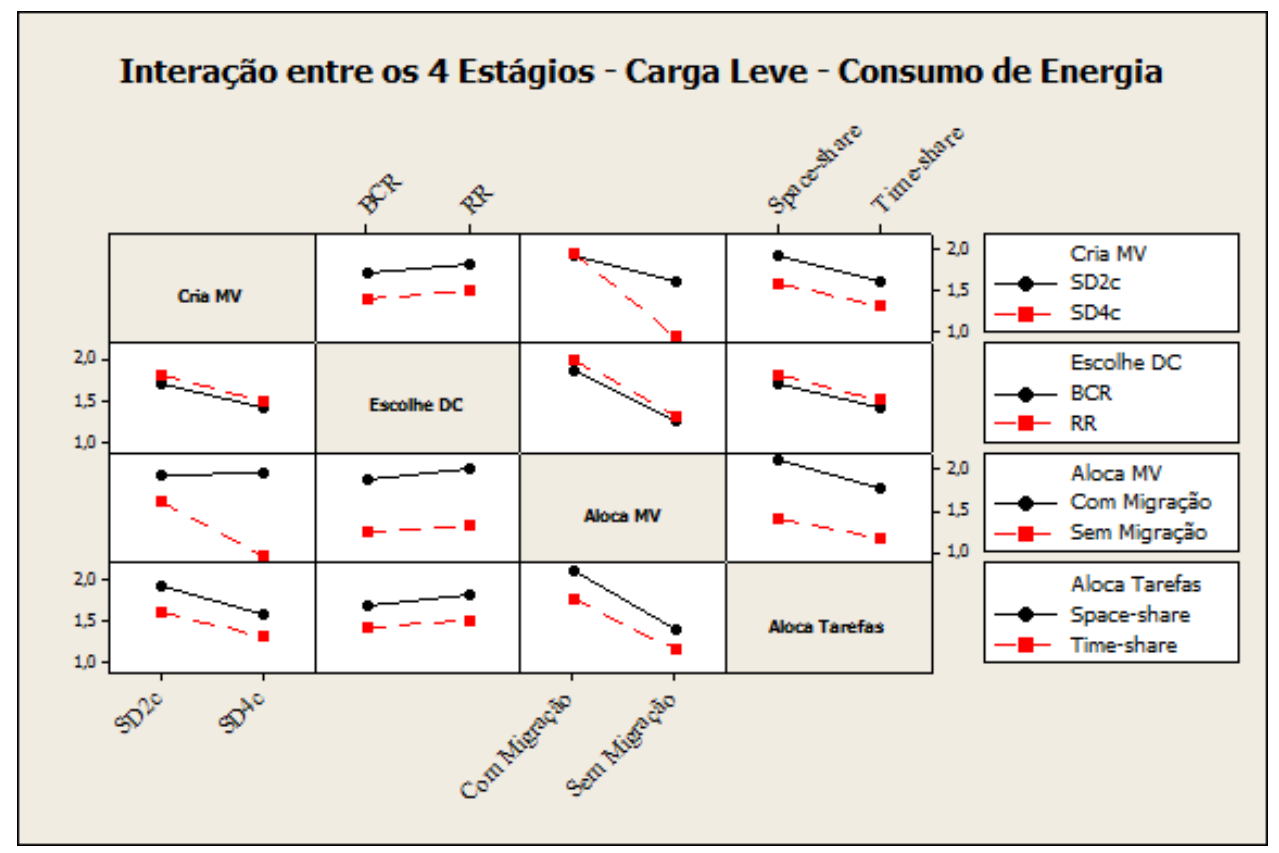

Figura 5.7: Influência no Consumo de Energia com carga de Trabalho Leve

O TMR usando uma carga de trabalho pesada pode ser observado nos gráficos da Figura 5.8. Nos estágios de Criação de MV (primeira linha) e Escolha do DC (segunda linha) as linhas dos 
gráficos estão quase sobrepostos. Isso demonstra que as políticas desses estágios não influencia significativamente os resultados de outras políticas nas demais fases. Ainda analisando as primeiras e segundas linhas pode ser observado nos gráficos na terceira coluna, um cruzamento das linhas. Isto significa que a política que utiliza de migração de MV é mais eficiente, devido à influência das políticas SD4c e BCR, e a política que não utiliza da técnica de migração de MV é influenciada pelas políticas SD2c e RR. Em outras palavras, é possível afirmar que existe influência entre as políticas de Alocação de MV com as políticas de Criação de MV e de Escolha do DC. Os primeiro e segundo gráficos na terceira linha confirmam a influência das políticas de Alocação de MV nos resultados dos estágios de Criação de MV e de Escolha do DC. O restante dos gráficos apresentam linhas paralelas, o que reforça a ideia de que não há nenhuma influência nos resultados entre outras políticas.

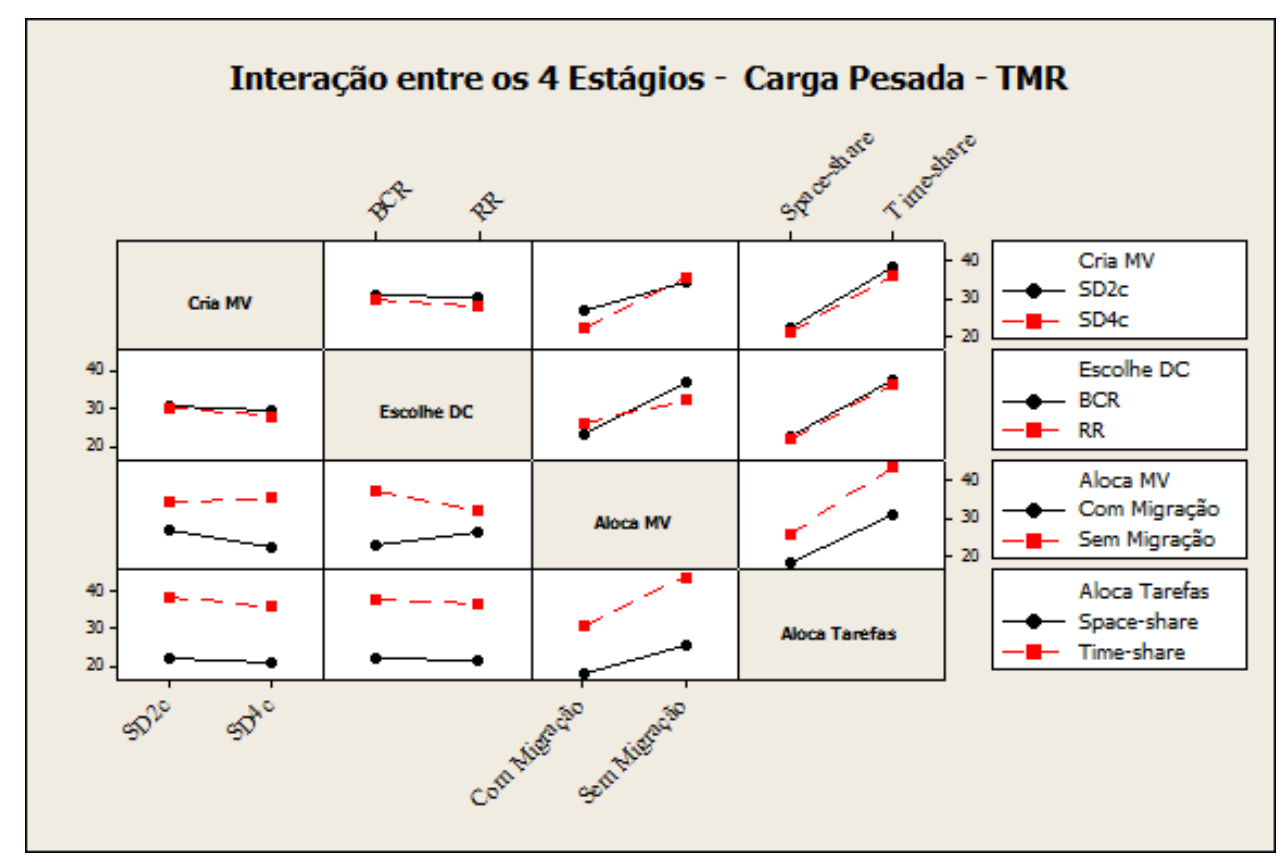

Figura 5.8: Influência no Tempo Médio de Resposta com carga de trabalho Pesada

Ao observar os gráficos da Figura 5.9 é possível concluir sobre a influência das políticas de escalonamento no consumo de energia em $\mathrm{kW} / \mathrm{s}$ com uma carga de trabalho pesada. O primeiro gráfico na primeira linha da Figura 5.9 mostra que as duas linhas que representam os resultados obtidos não são paralelas. Este fato leva à conclusão de que há influência entre as políticas dos estágios de Criação de MV com os de Escolha do DC. O segundo gráfico, na primeira linha mostra uma ligeira influência entre as políticas de Criação de MV com as políticas de Alocação de MV. No terceiro gráfico, é evidente que não há nenhuma influência entre as etapas de alocação de tarefas, com a de Criação de MV. Na segunda linha, o primeiro e segundo gráficos são tomados como prova da influência das políticas de Escolha do DC com a de Criação de MV e políticas de Alocação de MV. Os gráficos nas terceira e quarta linhas mostram que não há nenhuma influência entre as políticas dos respectivos estágios. 


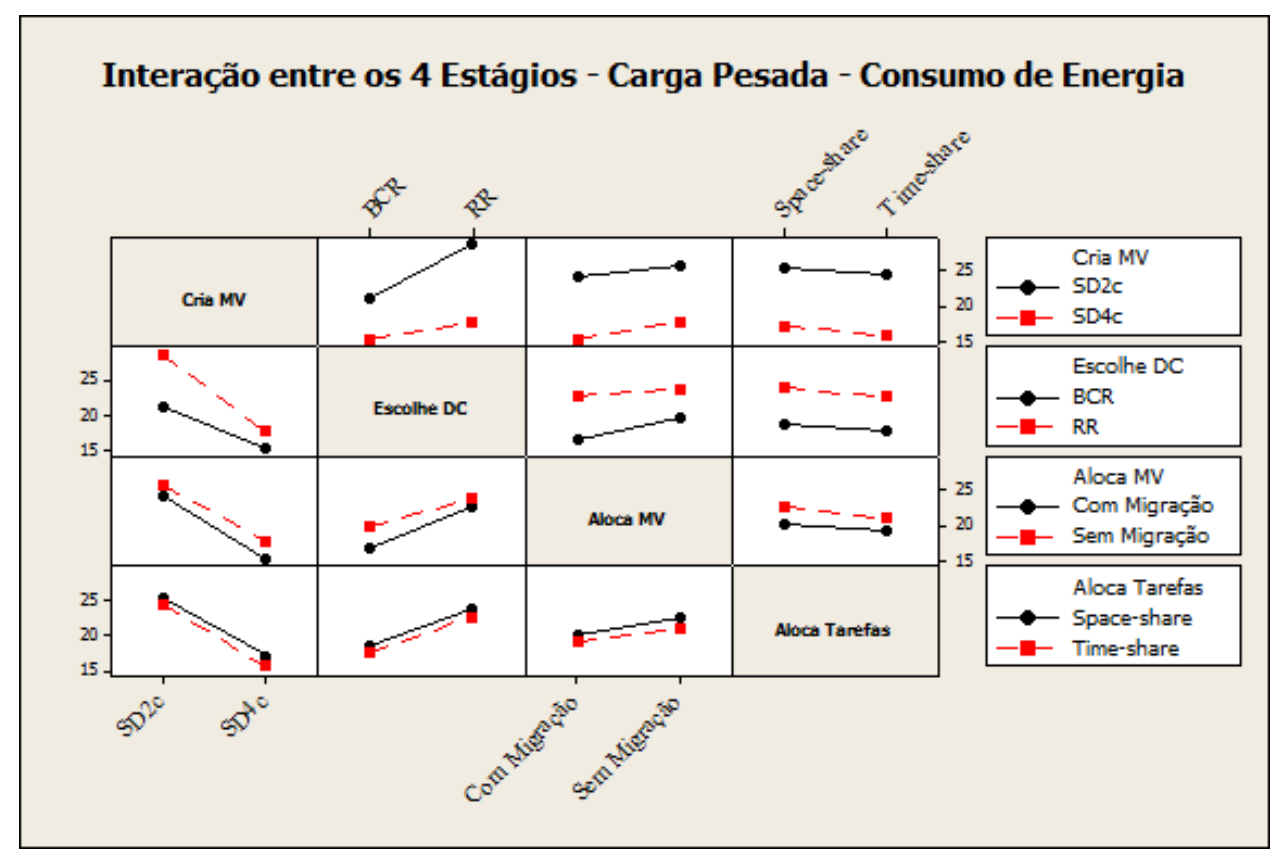

Figura 5.9: Influência no Consumo de Energia com carga de Trabalho Pesada

Esta seção teve como objetivo avaliar a interação de políticas de escalonamento em todas as fases de uma arquitetura para metaescalonamento verde com provisão de QoS. Com os resultados obtidos neste trabalho pode-se afirmar que a política de escalonamento, independentemente do estágio que se encontra, pode influenciar positiva ou negativamente outras políticas de outros estágios de escalonamento do GreenMACC.

Devido à análise da interação entre as políticas em todos os estágios de escalonamento, pode-se afirmar que a escolha certa dessas políticas em todos os quatro estágios, através da análise de TMR e consumo de energia feito no módulo LRAM, é relevante no que diz respeito a redução do tempo médio de resposta, e a redução do consumo de energia.

Na próxima seção, é apresentado um estudo de caso onde é inserida uma nova política com uma nova variável podendo-se comprovar a flexibilidade da arquitetura GreenMACC.

\subsection{Flexibilidade}

Esta seção tem como objetivo avaliar a flexibilidade da arquitetura GreenMACC. O GreenMACC possui um módulo chamado LRAM, já apresentado no Capítulo 4, que permite automatizar a execução de todas as políticas de escalonamento implementadas na arquitetura. Esse módulo possibilita que, para cada tipo de serviço requisitado pelo usuário de uma nuvem privada, o metaescalonador se ajuste automaticamente. Devido a essa função, é possível garantir o comportamento mais adequado aos princípios de GreenIT sem deixar de se preocupar com a qualidade do serviço prestado. No decorrer desta seção é mostrada a importância do LRAM no GreenMACC e seu fun- 
cionamento e também é mostrado como incluir uma nova política no GreenMACC de uma forma que o LRAM a identifique e a utilize automaticamente.

Inicialmente precisa-se definir qual a política que será inserida. Neste trabalho a política baseada no coeficiente de emissão de $\mathrm{CO}_{2}(\mathrm{CEB})$ foi escolhida. Essa política é baseada nos trabalhos de (Garg et al., 2010) (Garg et al., 2011). A política CEB escalona de forma que as requisições são distribuídas para os Data Centers que possuírem o menor coeficiente de consumo de $\mathrm{CO}_{2}$, ou seja, a menor emissão de $\mathrm{CO}_{2}$ por Killowatt/hora consumido. Sua vantagem é que sempre haverá prioridade na escolha de Data Centers que poluem menos. Entretanto, a escolha do Data Center pode não ser a ideal para redução do consumo de energia ou qualidade do serviço. Na política CEB não se observa sobrecarga no processo de busca do Data Center pois a informação sobre a emissão de $\mathrm{CO}_{2}$ não é tão dinâmica quanto a latência da rede, utilizada na Política BCR, e fica por um longo período fixo no módulo Info Verde.

Após a escolha da política, precisa-se analisar quais são as variáveis de entrada e saída da política inserida. A CEB tem como variável de entrada o coeficiente de emissão de $\mathrm{CO}_{2}$ por $\mathrm{kW} / \mathrm{h}$ $\left(\mathrm{CO}_{2} / \mathrm{kWh}\right)$ consumidos no Data Center. Nesta tese é utilizada para avaliação uma nuvem privada com 15 Data Centers espalhados pelo mundo, mais exatamente em 7 países. O critério para a escolha dos países teve como base a importância econômica do país para o continente ou região. Os países escolhidos foram: USA (América do Norte), Brasil (América Latina), Alemanha (Europa), Austrália (Oceania), Africa do Sul (Africa), Emirados Árabes (Oriente Médio) e Japão (Ásia). Com base no Appendix F do documento oficial do US Department of Energy (USDE, 2007) foi estipulado para cada Data Center a quantidade de $\mathrm{CO}_{2} / \mathrm{kWh}$ que é emitido na atmosfera por cada um dos países escolhidos. Esse valor refere-se a posição geográfica de cada Data Center, ou seja, cada país possui um valor para o coeficiente de emissão de gás carbônico e é esse valor que deve ser atribuído ao Data Center. Essa informação deve ser inserida no módulo Info Verde da arquitetura. Após inseridas no Info Verde as informações verdes que serão utilizadas no escalonamento, a nova política deve ser implementada no módulo Políticas de Escalonamento. Outro módulo que deve ser atualizado é o Trader. Esse módulo é responsável pela negociação com o usuário. Antes da inserção da nova política os pontos negociados com o usuário eram tempo de resposta e consumo de energia. Após a inserção das novas informações no Info Verde, o Trader também terá o coeficiente de emissão de gás carbônico $\left(\mathrm{CO}_{2}\right)$ como ponto de negociação com o usuário. Essa atualização do Trader ocorrerá automaticamente assim que o usuário requisitar um novo serviço e o Trader requisitar ao MDSM informações verdes do Info Verde.

O próximo passo é executar o benchmark para obter os resultados necessários para que o LRAM seja atualizado. Assim como especificado na na seção 4.4 onde a flexibilidade do LRAM é discutida, pode-se ter 3 formas de atualizar as informações pelo administrador. Neste caso foram inseridos uma nova política e um novo ponto de análise (PADEVE). Devido a esse fato, o benchmark deverá ser executado para todos os cenários. A partir do momento que o LRAM está atualizado, esse módulo já pode tomar decisões, ou seja, já pode escolher entre as políticas já implementadas e a nova política. 
Com a inserção da nova política, o Trader poderá negociar com o usuário a emissão de gás carbônico além de Tempo Médio de Resposta (TMR) e consumo de energia. Como exemplo para esse trabalho será considerado que o usuário negociou como fatores mais importantes para a oferta do serviço a emissão de gás carbônico e o consumo de energia. Ou seja, o usuário deseja ter o serviço mais verde possível.

Feita a negociação, o LRAM irá utilizar o mesmo algoritmo que o apresentado na Subseção 4.2.4 do Capítulo 4 para a escolha das políticas nos 4 níveis de escalonamento. A diferença está no fator utilizado, ou seja, ao invés do TMR irá utilizar Emissão de $\mathrm{CO}_{2}$. Essa característica torna o GreenMACC uma arquitetura flexível (Algoritmo 2).

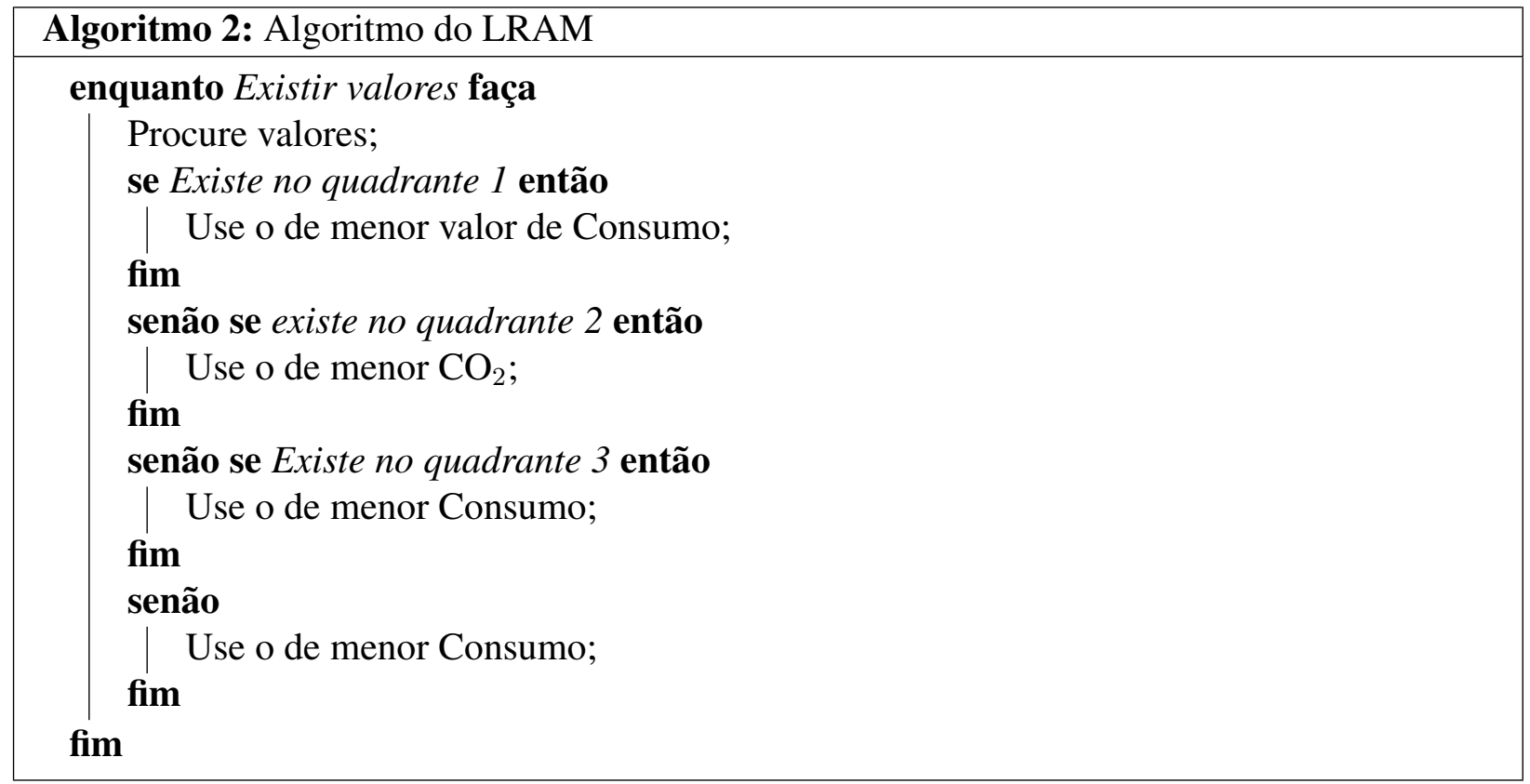

O LRAM, através da execução dos passos descritos na Subseção 4.2.4 do Capítulo 4, irá utilizar os dados dos gráficos representados nas Figuras 5.10 e 5.11 para a decisão na escolha das 4 políticas utilizadas. A decisão final do LRAM será tomada conforme o tipo de carga imposta ao sistema.

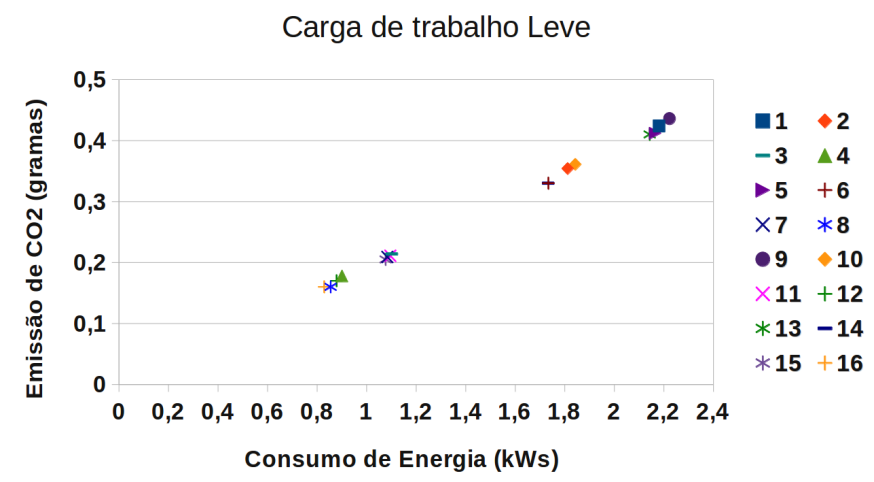

Figura 5.10: Valores Analisados pelo LRAM para Tomada de Decisão 
Caso a carga seja leve, ou seja, não demanda alto poder de processamento, o LRAM utilizará os dados do gráfico da Figura 5.10. Por outro lado, caso a carga seja pesada o LRAM irá utilizar os dados do gráfico da Figura 5.11.

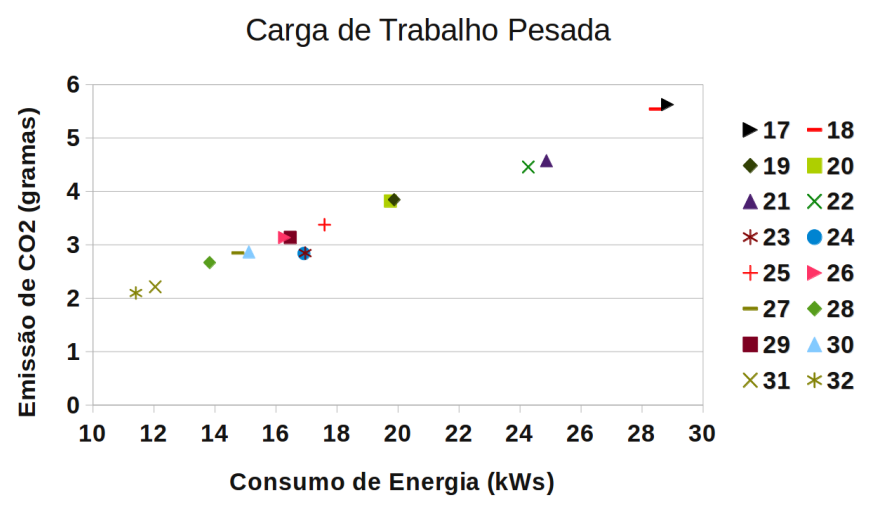

Figura 5.11: Valores Analisados pelo LRAM para Tomada de Decisão

\subsubsection{Avaliação dos resultados obtidos com a Nova Política Inserida}

Nesta subseção é apresentada uma avaliação de desempenho dos resultados obtidos com a nova política inserida no GreenMACC. Com os resultados apresentados nesta subseção fica mais claro o entendimento da flexibilidade e da capacidade de tomar decisões do LRAM e consequentemente do GreenMACC. Para essa avaliação utilizou-se o mesmo modelo utilizado nos resultados das duas subseções anteriores. A diferença é a nova política implementada no GreenMACC que tem como PADEVE a emissão de $\mathrm{CO}_{2}$.

Na Figura 5.12 pode-se observar os Tempos Médios de Resposta (TMR) no melhor e no pior caso de escolha das políticas de escalonamento nos quatro estágios do GreenMACC. Observandose os resultados obtidos, pode-se verificar que com uma carga leve, o melhor caso entrega o serviço ao usuário em um tempo menor que o do pior caso. Entretanto, com serviços que exigem um poder computacional maior, o tempo de entrega do serviço do pior caso é menor do que no melhor caso. Isso se deve ao fato de que no momento da negociação com o usuário a opção foi priorizar a redução do consumo de energia e da redução da emissão do gás carbônico. Essa opção faz com que o LRAM escolha políticas para os quatro estágios com foco na negociação com o usuário. Ou seja, como o Tempo Médio de Resposta não foi um dos fatores considerados para a escolha do LRAM, pode ocorrer casos onde não se obtenha um resultado ótimo para este fator. Em contrapartida, mesmo não sendo o caso ótimo, os tempos obtidos no melhor caso não ultrapassaram o deadline estipulado.

A Figura 5.13 apresenta o gráfico com os resultados de Emissão de $\mathrm{CO}_{2}$ na atmosfera considerando-se os dois tipos de carga testados. Quando o usuário exige menos trabalho computacional, ou seja, demanda uma carga leve de serviços, o melhor caso emite uma quantidade de $\mathrm{CO}_{2}$ um pouco menor do que o pior caso. Entretanto, quando a carga de trabalho aumenta, com o usuário 


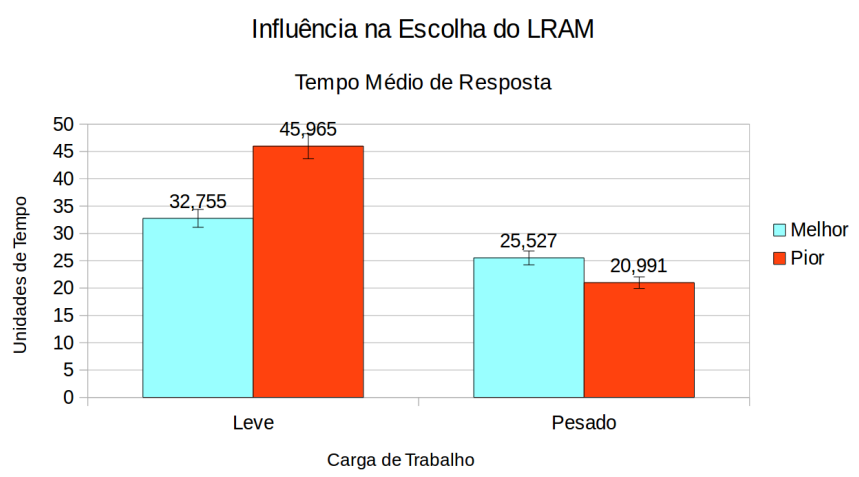

Figura 5.12: Comparação entre o Melhor e o Pior Caso para Tempo Médio de Resposta

exigindo um poder computacional maior com uma carga pesada de serviços a diferença aumenta consideravelmente. Diferente do TMR, a emissão de gás carbônico era um dos fatores relevantes para a escolha do LRAM. Com a escolha adequada das políticas de escalonamento feita pelo LRAM (melhor caso) pode-se observar uma redução de mais de 50\% na emissão de gás carbônico em relação a um possível caso onde o LRAM não exista (pior caso).

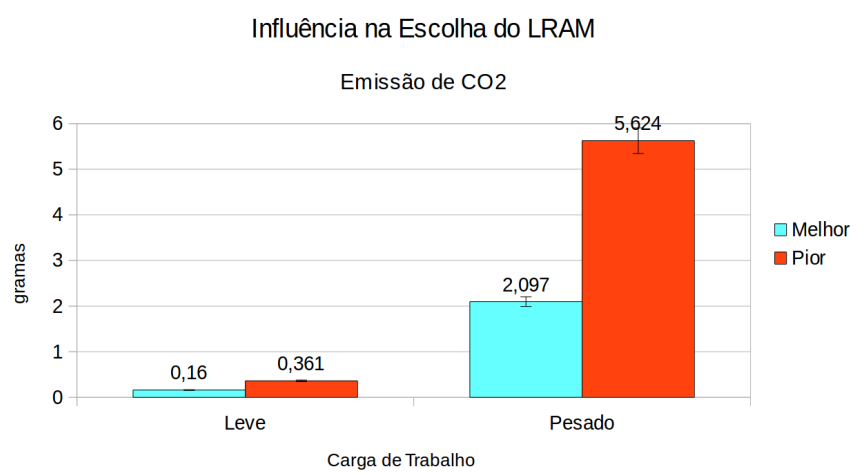

Figura 5.13: Comparação entre o Melhor e o Pior Caso para Emissão de $\mathrm{CO}_{2}$

Outro fator considerado pelo LRAM na escolha das políticas de escalonamento devido a negociação com o usuário foi o consumo de energia. Na Figura 5.14 é possível observar os valores referentes ao consumo de energia em relação à carga utilizada. Quando a carga é leve, o melhor caso se apresenta mais econômico do que o pior caso. Exigindo-se uma carga pesada de serviços, devido a uma escolha adequada do LRAM, pode-se reduzir o consumo de energia do Data Center a menos da metade. Esses resultados confirmam a eficiência do LRAM em relação a negociação feita com o usuário.

Através da avaliação de desempenho da nova política inserida pôde-se concluir que o GreenMACC é uma arquitetura flexível, confiável e que o módulo LRAM possibilita a automatização da escolha do melhor mecanismo de escalonamento em uma nuvem privada.

Esta seção teve como objetivo apresentar e avaliar a flexibilidade de uma arquitetura de um metaescalonador verde com provisão de QoS. A negociação inicial com o usuário feita pelo módulo Trader é relevante. Os resultados apresentados mostram que os fatores negociados com o 


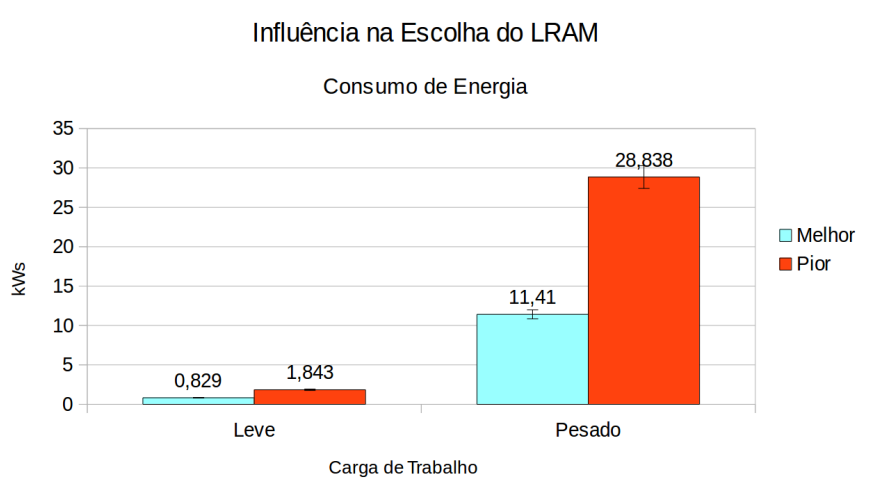

Figura 5.14: Comparação entre o Melhor e o Pior Caso para Consumo de Energia

usuário e escolhidos como prioritários obtiveram valores positivos quando o LRAM fez a escolha das políticas. Mesmo quando o fator não é considerado como prioridade pelo usuário (TMR) o melhor caso não ultrapassou o deadline.

A escolha adequada das políticas de escalonamento feitas pelo módulo LRAM baseada na negociação com o usuário mostrou-se uma boa forma de se obter redução na emissão de Gás Carbônico na atmosfera e também no consumo de energia em uma nuvem privada.

\subsection{Considerações Finais}

Nesta seção o GreenMACC foi avaliado em diversos aspectos, tais como: eficiência na sua capacidade de escolha automática das políticas nos quatro estágios de escalonamento, influência entre as políticas de todos os estágios de escalonamento e sua flexibilidade para se adaptar a novas políticas e variáveis sem necessidade de adaptação da arquitetura.

Com as avaliações de desempenho apresentadas nessa seção pode-se concluir que a arquitetura GreenMACC, fruto desta tese, possui diversas vantagens no tocante aos pontos avaliados. O GreenMACC mostrou-se consistente, permitindo a execução dos serviços requisitados com diversas técnicas de escalonamento em todos os seus estágios. Além disso, demonstrou flexibilidade permitindo a inserção de uma nova política de escalonamento onde as variáveis de entrada e de saída são diferentes das políticas já implementadas anteriormente no GreenMACC.

A automatização proposta e executada pelo módulo LRAM demonstra resultados positivos onde a negociação com o usuário é respeitada e os casos avaliados demonstraram que as políticas implementadas no GreenMACC conseguem cumprir seus objetivos.

As políticas podem influenciar positivamente ou negativamente os resultados de outras políticas implementadas em outros estágios de escalonamento, depende de cada caso.

No próximo capítulo são apresentadas as conclusões, contribuições e trabalhos futuros desta tese. 

Computação Verde na Nuvem é um tema recente, e ainda existem diversas lacunas na 1 literatura que podem ser estudadas. O MACC, arquitetura proposta por Peixoto (2012), 1 é eficiente na garantia de QoS, entretanto, não oferece recursos para o uso de políticas de escalonamento verde. A escolha automática de políticas nos 4 estágios de escalonamento também não é tratada pela arquitetura citada.

Este trabalho teve como objetivo apresentar, discutir e avaliar uma nova arquitetura de um metaescalonador verde com provisão de QoS. Nessa seção são apresentadas as conclusões da proposta e dos resultados apresentados nesta tese.

O GreenMACC é uma extensão da arquitetura MACC (Peixoto, 2012) para automatização na escolha de políticas nos quatro estágios de escalonamento e também permitir o uso de computação verde em nuvens privadas. Para que fosse permitido o uso de políticas que tenham preocupações pertinentes à computação verde, a arquitetura do MACC foi remodelada, criando-se novos módulos e excluindo-se ou modificando-se outros. Para a avaliação de desempenho do GreenMACC e das políticas de escalonamento implementadas para este trabalho usou-se a técnica de simulação. A ferramenta utilizada foi o CloudSim 3.0 (Calheiros et al., 2009) (Calheiros et al., 2011).

A arquitetura proposta mostrou-se consistente, permitindo a execução dos serviços requisitados com diversas técnicas de escalonamento em todos os seus quatro estágios.

O metaescalonador proposto demonstrou a capacidade de obter e controlar o consumo de energia e o tempo médio de resposta, métrica importante para controlar o QoS. Além disso, demonstrou flexibilidade permitindo a inserção de uma nova política de escalonamento onde as variáveis de entrada e de saída são diferentes das políticas já implementadas anteriormente. 
O LRAM se destaca como um dos principais módulos do GreenMACC. Apesar de já existir anteriormente na arquitetura anterior (MACC), no GreenMACC ganhou mais funções. No MACC o LRAM era um intermediador entre o metaescalonador com o Data Center. No GreenMACC, além dessa função, o LRAM tem a capacidade de analisar a negociação feita com o usuário e escolher a melhor configuração de políticas nos quatro estágios de escalonamento.

Foram executadas diversas simulações com o objetivo de validar e avaliar o GreenMACC. Com os resultados obtidos pode-se afirmar que a arquitetura proposta torna-se uma importante ferramenta na busca de um equilíbrio entre sustentabilidade e respeito ao contrato de serviço feito com o usuário.

Através dos resultados pode-se afirmar que uma política de escalonamento, independentemente do estágio que ela se encontra, pode oferecer um serviço com um TMR menor, entretanto pode apresentar consumo maior de energia, como nos casos das políticas SD4c, Round Robin e Spaceshare. Existem casos onde tem-se um TMR menor e ainda um consumo de energia menor, esse é o caso da política de alocação de Máquina Virtual utilizada neste trabalho.

A carga de trabalho influencia diretamente no tempo médio de resposta e no consumo de energia, além de ser um fator importante para a escolha da política de escalonamento em todos os estágios, especialmente na alocação de Máquina Virtual. No caso de se ter uma carga de trabalho leve a política sem migração se mostrou mais adequada, entretanto quando a carga aumenta consideravelmente a política com a técnica de migração mostra-se mais vantajosa.

Analisando-se a interação entre as políticas implementadas nos quatro estágios de escalonamento pode-se afirmar que a política de escalonamento, independentemente do estágio que se encontra, pode influenciar positiva ou negativamente outras políticas de outros estágios de escalonamento do GreenMACC.

A negociação inicial com o usuário feita pelo módulo Trader é relevante. Os resultados apresentados mostram que os fatores negociados com o usuário e escolhidos como prioritários obtiveram valores positivos quando o LRAM fez a escolha das políticas. Mesmo quando o fator não é considerado como prioridade pelo usuário (TMR) o melhor caso não ultrapassou o deadline.

Em todos os tipos de carga testados os resultados são positivos no tocante a negociação com o usuário. Ou seja, os fatores escolhidos pelo usuário como relevantes para a oferta do serviço requisitado, independente da carga, apresentam valores onde a escolha das políticas feita pelo LRAM respeita o acordo com o usuário.

A escolha adequada das políticas de escalonamento através da análise do TMR e do Consumo de Energia feitas no módulo LRAM do GreenMACC, mostrou-se um forte aliado para se obter menores tempos de resposta, fator crucial para se conseguir respeitar o contrato (SLA) com o usuário e também para se obter reduções na emissão de Gás Carbônico na atmosfera e também no consumo de energia em uma nuvem privada. Esses fatos permitem à empresa que utilizar a arquitetura proposta uma considerável redução de custos com energia além de manter a qualidade do serviço prestado aos seus usuários. 


\subsection{Contribuições}

Esta tese de doutorado apresenta como contribuição principal uma nova arquitetura para metaescalonamento verde com provisão de Qualidade de Serviços para nuvens privadas. Outras contribuições podem ser referenciadas a este trabalho. São elas:

Atualização do MACC Antes de estender o MACC para se tornar o GreenMACC foi necessária sua migração do CloudSim 2.1 para o 3.0. Isso foi necessário devido as limitações dos pacotes e modelos de computação verde na versão 2.1. A versão 3.0 possui pacotes e modelos mais atualizados e para execução de simulações de nuvens com objetivos de computação verde na nuvem.

Estender o MACC para o GreenMACC Foi retirado alguns módulos do MACC que são desnecessários para uma nuvem privada e que eram específicos para metaescalonamento em uma intercloud. Foram adaptados e modificados alguns módulos do MACC visando a automatização da escolha das políticas de escalonamento em quatro estágios. E também foram acrescentados novos módulos para que a nova arquitetura permita o uso de políticas verdes.

Negociação Verde com o Usuário O GreenMACC possibilita negociar com o cliente fatores verde como Emissão de Gás Carbônico, Consumo de energia, dentre outros.

Automatização no Escalonamento A nova arquitetura proposta permite a implementação de vários tipos de políticas para todos os quatro estágios de escalonamento. Dependendo das políticas implementadas e da negociação feita com o usuário o GreenMACC seleciona automaticamente as quatro políticas de escalonamento, uma para cada estágio, que deverão ser executadas para que a negociação feita seja respeitada.

Flexibilidade da Arquitetura A possibilidade de implementar políticas com diversos objetivos como redução do consumo de energia, respeito ao tempo de resposta do serviço contratado e redução da emissão de gás carbônico e ainda o metaescalonador se adequar ao cenário de cada requisição de forma automática torna a arquitetura proposta bastante flexível.

Avaliação de Desempenho da Automatização na Escolha das Políticas de Escalonamento Este trabalho apresenta uma avaliação de desempenho que permite avaliar como a escolha adequada de políticas nos quatro estágios de escalonamento pode afetar a qualidade da oferta de serviços em uma nuvem computacional.

Avaliação de Desempenho da Influência entre as Políticas de Escalonamento Esta tese apresenta uma avaliação da interação entre as políticas que executam nos diferentes estágios de escalonamento. Essa avaliação permite também analisar a influência que uma política de um estágio tem nos resultados de outra política executando em estágio diferente. 
Estudo de Caso - Inclusão de Novas Políticas No mesmo capítulo onde são feitas as avaliações de desempenho do GreenMACC é descrito um estudo de caso explicando detalhadamente como incluir uma nova política na nova arquitetura proposta e a mesma se adaptar para que a nova política implementada possa ser reconhecida para ser uma das possíveis políticas escolhidas pelo metaescalonador.

Avaliação de Desempenho da Flexibilidade da Arquitetura em Permitir Novas Políticas É apresentada neste trabalho uma avaliação de desempenho da nova política implementada no estudo de caso com o objetivo de demonstrar a flexibilidade da arquitetura e como a mesma se mostrou eficiente na escolha das políticas mesmo depois da nova política ser inserida.

\subsection{Trabalhos Futuros}

Os trabalhos futuros vislumbrados para continuação das pesquisas utilizando-se do conteúdo desta tese são:

- Desenvolver e avaliar novas políticas de escalonamento verde para Escolha de Data Center;

- Desenvolver e avaliar novas políticas de escalonamento verde para Criação de Máquinas Virtuais;

- Desenvolver e avaliar novas políticas de escalonamento verde para Alocação de Máquinas Virtuais;

- Desenvolver e avaliar novas políticas de escalonamento verde para Alocação de Tarefas;

- Desenvolver e avaliar políticas de escalonamento otimizadas para o GreenMACC;

- Desenvolver e avaliar políticas com outros propósitos além dos que tenham metas de Gree$n I T$;

- Desenvolver e avaliar políticas de escalonamento que utilizem técnicas de previsão de carga;

- Implementar o GreenMACC em outras ferramentas de simulação que possuam carga dinâmica;

- Implementar e avaliar o GreenMACC em um protótipo (versão reduzida e controlada de uma nuvem privada);

\subsection{Artigos Produzidos}

Esta tese possibilitou a produção de quatro artigos científicos: 


\subsubsection{Artigos Publicados}

CLEI'14 (Qualis B4) : "GreenMACC: An Architecture to Green Metascheduling with Quality of Service in Private Clouds" foi apresentado em setembro de 2014 na 40a Conferência Latinoamericana em Informática (CLEI'14) na cidade de Montevideo, Uruguai.

ESM'14 (Qualis B2) : "Evaluation of Energy Consumption and QoS in The Four Stage Scheduling in a Private Green Cloud Using Simulation" foi apresentado em Outubro de 2014 na $28^{\mathrm{a}}$ Conferência Europeia de Simulação e Modelagem (ESM'14) na cidade do Porto, Portugal.

\subsubsection{Artigos Submetidos}

CLEI Electronic Journal (Qualis B5) : “Green Metascheduler Architecture to Provide QoS in Cloud Computing" Devido ao primeiro artigo citado apresentado na CLEI'14, os autores foram convidados a enviar um artigo estendido ao CLEI Eletronic Journal. Esse fato gerou o terceiro artigo fruto desta tese, com mais de $30 \%$ de conteúdo inédito em relação ao da conferência. Foi submetido no dia 31 de Outubro de 2014 e até a impressão desta tese os autores não foram notificados da resposta do Journal em questão.

Journal of Grid Computing (Qualis B1) : "Green Cloud Meta-Scheduling: a flexible and automatic approach " o quarto artigo produzido com o título "Green Cloud Meta-Scheduling: a flexible and automatic approach."foi submetido no final do mês de Outubro ao Journal of Grid Computing da Springer. Os autores não foram notificados da resposta até a impressão desta tese. 

Addis, B.; Ardagna, D.; Capone, A.; Carello, G. Energy-aware joint management of networks and cloud infrastructures. Computer Networks, v. 70, n. 0, p. 75-95, 2014.

Akgun, O.; Down, D.; RighteR, R. Energy-aware scheduling on heterogeneous processors. Automatic Control, IEEE Transactions on, v. 59, n. 3, p. 599-613, 2014.

Al-Sulami, A. A.; Al-Hazmi, A.; KatiB, I. Energy-awareness at data centers: An overview of management and architecture framework techniques. International Journal of Computer Technology and Electronics Engineering (IJCTEE), p. 5-10, 2014.

Alahmadi, A.; Alnowiser, A.; Zhu, M.; Che, D.; Ghodous, P. Enhanced first-fit decreasing algorithm for energy-aware job scheduling in cloud. In: Computational Science and Computational Intelligence (CSCI), 2014 International Conference on, 2014, p. 69-74.

Arjona Aroca, J.; Chatzipapas, A.; Fernández Anta, A.; Mancuso, V. A measurement-based analysis of the energy consumption of data center servers. In: Proceedings of the 5th International Conference on Future Energy Systems, e-Energy '14, New York, NY, USA: ACM, 2014, p. 63-74 (e-Energy'14, ).

Assunção, M. D.; Costanzo, A.; Buyya, R. A cost-benefit analysis of using cloud computing to extend the capacity of clusters. Cluster Computing, v. 13, n. 3, p. 335-347, cited By (since 1996): 1, 2010.

Atrey, A.; JAIn, N.; IYEngAR, N. A study on green cloud computing. International Journal of Grid and Distributed Computing, v. 6, n. 6, p. 93-102, 2013.

Baliga, J.; Ayre, R.; Hinton, K.; Tucker, R. Green Cloud Computing: Balancing Energy in Processing, Storage, and Transport. Proceedings of the IEEE, v. 99, n. 1, p. 149-167, 2011.

Beloglazov, A.; Abawajy, J.; BuyYA, R. Energy-aware resource allocation heuristics for efficient management of data centers for Cloud computing. Future Generation Computer Systems, v. In Press, Corrected Proof, p. -, 2011. 
Beloglazov, A.; BuyYa, R. Energy Efficient Allocation of Virtual Machines in Cloud Data Centers. In: Cluster, Cloud and Grid Computing (CCGrid), 2010 10th IEEE/ACM International Conference on, 2010a, p. 577-578.

Beloglazov, A.; BuYya, R. Energy efficient resource management in virtualized cloud data centers. In: CCGrid 2010 - 10th IEEE/ACM International Conference on Cluster, Cloud, and Grid Computing, 2010b, p. 826-831.

Beloglazov, A.; Buyya, R. Optimal Online Deterministic Algorithms and Adaptive Heuristics for Energy and Performance Efficient Dynamic Consolidation of Virtual Machines in Cloud Data Centers. Concurr. Comput. : Pract. Exper., v. 24, n. 13, p. 1397-1420, 2012.

Berners-lee, T.; Cailliau, R.; Luotonen, A.; Nielsen, H. F.; Secret, A. The World Wide Web. In: Communications of the ACM, 1994, p. 76-82.

Bird, S.; Achuthan, A.; Maatallah, O. A.; Hu, W.; Janoyan, K.; Kwasinski, A.; Matthews, J.; Mayhew, D.; OWen, J.; MarzocCA, P. Distributed (green) data centers: A new concept for energy, computing, and telecommunications. Energy for Sustainable Development, v. 19, n. 0, p. $83-91,2014$.

Bossche, R. V. D.; VAnmechelen, K.; Broeckhove, J. Cost-optimal scheduling in hybrid IaaS clouds for deadline constrained workloads. In: Proceedings - 2010 IEEE 3rd International Conference on Cloud Computing, CLOUD 2010, 2010, p. 228-235.

Bruneo, D.; Lhoas, A.; Longo, F.; Puliafito, A. Analytical evaluation of resource allocation policies in green iaas clouds. In: Cloud and Green Computing (CGC), 2013 Third International Conference on, 2013, p. 84-91.

Buyya, R.; Broberg, J.; Goscinski, A. Cloud Computing - Principles and Paradigms. John Wiley \& Sons, Inc, 2011.

Buyya, R.; PAndey, S.; VeCChiOla Cloudbus Toolkit for Market-oriented Cloud Computing. In: International Conference on Cloud Computing (CloudCom), 2009 First International Conference Springer, 2009.

Calheiros, R. N.; Ranjan, R.; Beloglazov, A.; De Rose, C. A. F.; Buyya, R. CloudSim: A toolkit for modeling and simulation of cloud computing environments and evaluation of resource provisioning algorithms. Software - Practice and Experience, v. 41, n. 1, p. 23-50, 2011.

Calheiros, R. N.; Ranjan, R.; Rose, C. A. F. D.; Buyya, R. CloudSim: A Novel Framework for Modeling and Simulation of Cloud Computing Infrastructures and Services. CoRR, v. abs/0903.2525, 2009. 
CAO, F.; ZHU, M. Energy-aware workflow job scheduling for green clouds. In: Green Computing and Communications (GreenCom), 2013 IEEE and Internet of Things (iThings/CPSCom), IEEE International Conference on and IEEE Cyber, Physical and Social Computing, 2013, p. 232-239.

CAO, Z.; Dong, S. Energy-aware framework for virtual machine consolidation in cloud computing. In: IEEE International Conference on Embedded and Ubiquitous Computing, 2013 IEEE 10th International Conference on, HPCC EUC'13, 2013, p. 1890-1895 (HPCC EUC'13, ).

Cappiello, C.; Plebani, P.; Vitali, M. Energy-aware process design optimization. In: Cloud and Green Computing (CGC), 2013 Third International Conference on, 2013, p. 451458.

Carvalho JR, O. A. D.; Bruschi, S. M.; Santana, R. H. C.; Santana, M. J. GreenMACC: An Architecture to Green Metascheduling with Quality of Service in Private Clouds. In: Conferencia Latinoamericana en Informática, CLEI'14, 2014, p. 195-203 (CLEI'14, ).

CHACHAR, V. D.; KUlKaRni, N. P. Energy efficient request pool for a green private cloud architecture with global collaboration. International Journal of Science and Research (IJSR), v. 3 , p. $65-68,2014$.

CHen, H.; ZHU, X.; ZHU, J.; WANG, J. Eres: An energy-aware real-time elastic scheduling algorithm in clouds. In: IEEE International Conference on Embedded and Ubiquitous Computing, 2013 IEEE 10th International Conference on, HPCC EUC'13, 2013, p. 777-784 (HPCC EUC'13, ).

CHou, D. C. Risk identification in green $\{$ IT $\}$ practice. Computer Standards \& Interfaces, v. 35 , n. 2, p. $231-237,2013$.

DuY, T. V. T.; SATo, Y.; Inoguchi, Y. Performance evaluation of a green scheduling algorithm for energy savings in cloud computing. In: Proceedings of the 2010 IEEE International Symposium on Parallel and Distributed Processing, Workshops and Phd Forum, IPDPSW 2010, 2010.

FARAgardi, H.; Rajabi, A.; Shojaee, R.; Nolte, T. Towards energy-aware resource scheduling to maximize reliability in cloud computing systems. In: IEEE International Conference on Embedded and Ubiquitous Computing, 2013 IEEE 10th International Conference on, HPCC EUC'13, 2013, p. 1469-1479 (HPCC EUC'13, ).

Farahnakian, F.; Pahikkala, T.; Liljeberg, P.; Plosila, J. Energy aware consolidation algorithm based on k-nearest neighbor regression for cloud data centers. In: Utility and Cloud Computing (UCC), 2013 IEEE/ACM 6th International Conference on, 2013, p. 256-259. 
FAUCHEUX, S.; NiCOLAÏ, I. \{IT \} for green and green it: A proposed typology of eco-innovation. Ecological Economics, v. 70, n. 11, p. 2020 - 2027, special Section - Earth System Governance: Accountability and Legitimacy, 2011.

Foster, I.; Zhao, Y.; RAiCU, I.; LU, S. Cloud Computing and Grid Computing 360-Degree Compared. In: Grid Computing Environments Workshop, 2008. GCE '08, 2008, p. 1-10.

Furht, B.; Escalante, A. Handbook of Cloud Computing. Springer Science + Business Media, 2010.

Garg, S. K.; Yeo, C. S.; AnAndasivam, A.; Buyya, R. Environment-conscious scheduling of HPC applications on distributed Cloud-oriented data centers. Journal of Parallel and Distributed Computing, v. 71, n. 6, p. 732-749, 2010.

GARG, S. K.; YEO, C. S.; BUYYA, R. Green cloud framework for improving carbon efficiency of clouds. In: Proceedings of the 17th international conference on Parallel processing - Volume Part I, Euro-Par'11, Berlin, Heidelberg: Springer-Verlag, 2011, p. 491-502 (Euro-Par'11, ).

Gong, C.; LiU, J.; Zhang, Q.; Chen, H.; Gong, Z. The Characteristics of Cloud Computing. In: Parallel Processing Workshops (ICPPW), 2010 39th International Conference on, 2010, p. 275-279.

Gong, W.; Chen, Z.; YAn, J.; Qianjun, S. An optimal vm resource allocation for nearclient-datacenter for multimedia cloud. In: Ubiquitous and Future Networks (ICUFN), 2014 Sixth International Conf on, 2014, p. 249-254.

GREENITBRASIL Greenitbrasil. http://www.greenitbrasil.com.br/?p=2774, acessado em 21/08/2014, 2014.

Grossman, W. M. The Dirty Secrets of Green IT. Infosecurity, v. 8, n. 1, p. 28-30, 2011.

Heydarikiya, F.; Toroghy Haghighat, A.; Heydarikiya, M. e-stab: Energy-efficient scheduling for cloud computing applications with traffic load balancing. In: e-Commerce in Developing Countries: With Focus on e-Trust (ECDC), 2014 8th International Conference on, 2014, p. 1-12.

Hongyou, L.; JiAngyong, W.; JiAn, P.; JunfEng, W.; TANG, L. Energy-aware scheduling scheme using workload-aware consolidation technique in cloud data centres. Communications, China, v. 10, n. 12, p. 114-124, 2013.

Hosseinimotlagh, S.; Khunjush, F. Migration-less energy-aware task scheduling policies in cloud environments. In: Advanced Information Networking and Applications Workshops (WAINA), 2014 28th International Conference on, 2014, p. 391-397.

IBGE Receita de serviços cresce 5,7\% em julho. Acessado em 02/09/2014, 2014. 
J. Wetherall, D.; Tanenbaum, A. S. Redes de Computadores - $5^{a}$ edição. Pearson Education, 2011.

Jayarani, R.; Ram, R. V.; SAdhasivam, S.; NAGAVEni, N. Design and Implementation of an Efficient Two-level Scheduler for Cloud Computing Environment. Advances in Recent Technologies in Communication and Computing, International Conference on, v. 0, p. 884-886, 2009.

KARThICK, A.; RAmARAJ, E.; KANNAN, R. An efficient tri queue job scheduling using dynamic quantum time for cloud environment. In: Green Computing, Communication and Conservation of Energy (ICGCE), 2013 International Conference on, 2013, p. 871-876.

KAUR, G.; KAUR, R.; Sharma, S. Energy aware cloud computing. a review. International Journal of Enhanced Research in Management \& Computer Applications, p. 51-56, 2014.

Kennedy, M.; Muntean, G.-M. A study on the effect of transmission power adaptation and multi-hop path usage on power consumption and qos in adaptive mobile video delivery. In: Broadband Multimedia Systems and Broadcasting (BMSB), 2014 IEEE International Symposium on, 2014, p. 1-7.

Khalid, O.; Maljevic, I.; Anthony, R.; Petridis, M.; Parrott, K.; Schulz, M. Deadline aware virtual machine scheduler for grid and cloud computing. In: 24th IEEE International Conference on Advanced Information Networking and Applications Workshops, WAINA 2010, 2010, p. 85-90.

Lago, D.; Madeira, E.; Bittencourt, L. Power-Aware Virtual Machine Scheduling on Clouds Using Active Cooling Control and DVFS. In: 9th International Workshop on Middleware for Grids, Clouds and e-Science - MGC 2011, 2011.

Laszewski, G.; Wang, L.; Younge, A.; He, X. Power-Aware Scheduling of Virtual Machines in DVFS-enabled Clusters. In: IEEE Cluster 2009, 2009.

LEE, Y. C.; ZOMAYA, A. Y. Energy efficient utilization of resources in cloud computing systems. Journal of Supercomputing, p. 1-13, article in Press, 2010.

LI, D.; SHANG, Y.; CHEN, C. Software defined green data center network with exclusive routing. In: INFOCOM, 2014 Proceedings IEEE, 2014, p. 1743-1751.

LiU, L.; WAnG, H.; LiU, X.; Jin, X.; He, W. B.; Wang, Q. B.; Chen, Y. GreenCloud: a new architecture for green data center. In: Proceedings of the 6th international conference industry session on Autonomic computing and communications industry session, ICAC-INDST '09, New York, NY, USA: ACM, 2009, p. 29-38 (ICAC-INDST '09, ).

Mell, P. M.; GRANCE, T. Sp 800-145. the nist definition of cloud computing. Relatório Técnico, Gaithersburg, MD, United States, 2011. 
MoschaKis, I. A.; KARATZA, H. D. Evaluation of gang scheduling performance and cost in a cloud computing system. Journal of Supercomputing, p. 1-18, article in Press, 2010.

Murugesan, S. Harnessing green it: Principles and practices. IT Professional, v. 10, n. 1, p. 24-33, 2008.

ONU A onu e o meio ambiente. http://www.onu.org.br/a-onu-em-acao/ a-onu-e-o-meio-ambiente/, acessado em 04/09/2014, 2014.

OUYANG, Z.; WANG, K.; XU, L. Green cloud task scheduling algorithm based on improved bpso. Journal of Information \& Computational Science, p. 4301-4308, 2014.

PAndey, S.; Wu, L.; Guru, S. M.; BuyYA, R. A particle swarm optimization-based heuristic for scheduling workflow applications in cloud computing environments. In: Proceedings International Conference on Advanced Information Networking and Applications, AINA, cited By (since 1996): 2, 2010, p. 400-407.

Peixoto, M.; Santana, M.; Estrella, J.; Tavares, T.; Kuehne, B.; Santana, R. H. C. A metascheduler architecture to provide qos on the cloud computing. In: Telecommunications (ICT), 2010 IEEE 17th International Conference on, 2010, p. 650-657.

Peixoto, M. L. M. Oferecimento de QoS para computação em nuvens por meio de metaescalonamento. Doutorado em ciências matemáticas e de computação, Instituto de Ciências Matemáticas e de Computação, Universidade de São Paulo (USP), São Carlos - SP - Brazil, 2012.

Perelló, J.; Morea, A.; SPadaro, S.; PAgès, A.; Ricciardi, S.; Gunkel, M.; Junyent, G. Power consumption reduction through elastic data rate adaptation in survivable multi-layer optical networks. Photonic Network Communications, p. 1-11, 2014.

Rowstron, A. I. T.; Druschel, P. Pastry: Scalable, decentralized object location and routing for large-scale peer-to-peer system. In: Proceedings of the IFIP/ACM International Conference on Distributed Systems Platforms Heidelberg, Middleware'01, Springer-Verlag, 2001, p. 329350 (Middleware'01, ).

Royaee, Z.; Mohammadi, M. Energy aware virtual machine allocation algorithm in cloud network. In: Smart Grid Conference (SGC), 2013, 2013, p. 259-263.

Ruth, S. Green IT More Than a Three Percent Solution? Internet Computing, IEEE, v. 13, n. 4, p. 74-78, 2009.

SAntos, J. B.; JABBOUR, C. J. C. Critical factors to be considered when planning the implementation of environmental improvements and energy saving. Journal of Energy in Southern Africa, v. 24, n. 4, p. 22-29, 2013. 
Shon, T.; ChO, J.; HAN, K.; CHOI, H. Toward advanced mobile cloud computing for the internet of things: Current issues and future direction. Mobile Networks and Applications, v. 19, n. 3, p. 404-413, 2014.

Stoica, I.; Morris, R.; Karger, D.; KaAshoek, M. F.; Balavrishnan, H. Chord: A scalable peer-to-peer lookup for internet applications. In: Proceedings of the 2001 conference on applications, technologies, architectures and protocols for computer communications, SIGCOMM'01, 2001, p. 149-160 (SIGCOMM'01, ).

Suresh, A.; ViJAYAKARTHICK, P. Improving scheduling of backfill algorithms using balanced spiral method for cloud metascheduler. In: Recent Trends in Information Technology (ICRTIT), 2011 International Conference on, 2011, p. 624-627.

Sustainable-DC Sustainable development commision. http://www.sd-commission. org.uk/pages/what-is-sustainable-development.html, acessado em 21/08/2014, 2014.

TAO, F.; FEnG, Y.; Zhang, L.; LiAO, T. Clps-ga: A case library and pareto solution-based hybrid genetic algorithm for energy-aware cloud service scheduling. Applied Soft Computing, v. 19 , n. 0 , p. $264-279,2014$.

ThanAVANich, T.; Uthayopas, P. Efficient energy aware task scheduling for parallel workflow tasks on hybrids cloud environment. In: Computer Science and Engineering Conference (ICSEC), 2013 International, 2013, p. 37-42.

Thiam, C.; Da Costa, G.; Pierson, J.-M. Cooperative scheduling anti-load balancing algorithm for cloud: Csaac. In: Cloud Computing Technology and Science (CloudCom), 2013 IEEE 5th International Conference on, 2013, p. 433-438.

TIEsPeCIALISTAS.COM Ti especialistas. http://www.tiespecialistas.com. br/2010/08/governanca-de-ti-x-compliance-auditoria/, acessado em 02/09/2014, 2014.

USDE Voluntary reporting of greenhouse gases: Appendix F. Eletricity emission factors. Relatório Técnico, 2007.

Veras, M. Datacenter - Componente Central da Infraestrutura de TI. Brasport, 2009.

Veras, M. Virtualização - Componente Central do Datacenter. Brasport, 2011.

Veras, M. Cloud Computing - Nova Arquitetura da TI. Brasport, 2012.

WAnG, J.; HuAng, C.; He, K.; WAnG, X.; Chen, X.; QIN, K. In: IEEE International Conference on Embedded and Ubiquitous Computing, 2013 IEEE 10th International Conference on, HPCC EUC'13, 2013a, p. 587-594 (HPCC EUC'13, ). 
WAng, S.; LiU, Z.; Zheng, Z.; Sun, Q.; YAng, F. Particle swarm optimization for energyaware virtual machine placement optimization in virtualized data centers. In: Parallel and Distributed Systems (ICPADS), 2013 International Conference on, 2013b, p. 102-109.

WANG, X.; WANG, Y.; CUI, Y. A new multi-objective bi-level programming model for energy and locality aware multi-job scheduling in cloud computing. Future Generation Computer Systems, v. 36, n. 0, p. 91 - 101, special Section: Intelligent Big Data Processing Special Section: Behavior Data Security Issues in Network Information Propagation Special Section: Energyefficiency in Large Distributed Computing Architectures Special Section: eScience Infrastructure and Applications, 2014.

XU, Z. Measuring green it in society. Computer, v. 45, n. 5, p. 83-85, 2012.

Younge, A.; LAszewski, G.; Wang, L.; Lopez-Alarcon, S.; CARithers, W. Efficient resource management for Cloud computing environments. In: Green Computing Conference, 2010 International, 2010, p. 357-364.

Zhang, J.; Gu, C.; WAng, X.; HuAng, H. A unified metascheduler architecture for telecom grade cloud computing. In: Information Science and Technology (ICIST), 2013 International Conference on, 2013, p. 354-360.

ZhANG, Z.; ChANG, J. A cool scheduler for multi-core systems exploiting program phases. Computers, IEEE Transactions on, v. 63, n. 5, p. 1061-1073, 2014.

ZhaO, C.; Zhang, S.; LiU, Q.; XIE, J.; Hu, J. Independent Tasks Scheduling Based on Genetic Algorithm in Cloud Computing. In: Wireless Communications, Networking and Mobile Computing, 2009. WiCom '09. 5th International Conference on, 2009, p. 1-4.

ZhU, X.; Chen, H.; YAnG, L.; Yin, S. Energy-aware rolling-horizon scheduling for real-time tasks in virtualized cloud data centers. In: IEEE International Conference on Embedded and Ubiquitous Computing, 2013 IEEE 10th International Conference on, HPCC EUC'13, 2013, p. 1119-1126 (HPCC EUC'13, ). 